\title{
Contributions à la connaissance des faunes de Mammifères pléistocènes de la Dépression de Brasov (Roumanie)
}

\author{
par C. Radulesco, P. S Amson, N. MihăILĂ et Al. Kovács, Bucarest
}

Avec 17 figures, 4 planches et 9 tableaux

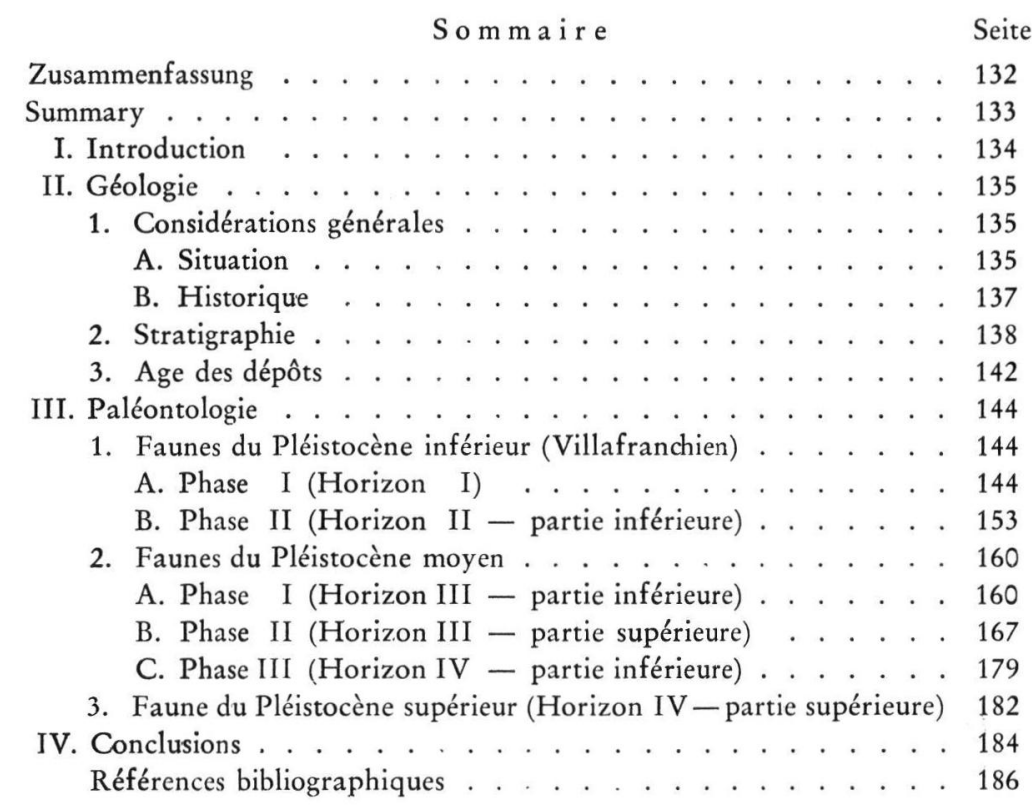

$\mathrm{Zusammenfassung.} \mathrm{Die} \mathrm{Autoren} \mathrm{befassen} \mathrm{sich} \mathrm{in} \mathrm{dieser} \mathrm{Arbeit} \mathrm{mit} \mathrm{der} \mathrm{Geologie} \mathrm{und}$ der Paläontologie der Becken von Baraolt und Sfîntu-Gheorghe, welche zu der im Südosten von Transylvanien (Siebenbürgen) gelegenen Senke von Braşov (Kronstadt) gehören. Diese Senkung tektonischen Ursprungs bildete fast während des ganzen Pleistozäns ein großes Seebecken. Die auf mesozoischem Grund abgelagerten Sedimente wurden in vier Horizonte eingeteilt, welche gleichzeitig ebenso vielen Phasen in der Entwicklung der Becken entsprechen. Die Säugetierfauna dieser Horizonte wurde in drei Hauptkomplexe gruppiert, welche dem Unter-, Mittel- und Oberpleistozän entsprechen. Der erste faunistische Komplex umfaßt zwei Phasen, der zweite drei und der letzte eine einzige Phase. Die vier Horizonte sind von unten nach oben betrachtet (vgl. die Tabelle 1) die folgenden:

Horizon t I, mergelig-sandig mit drei Lignitflözen, von denen das oberste (Schicht III) am bedeutendsten ist. Dieser Horizont entspricht der ersten Phase der Bildung des Seebeckens, als, besonders im Nordteil des Beckens von Baraolt (Căpeni) und im Becken von Vîrghiş, die Moorfazies vorherrschend war. Es scheint, daß diese erste Phase mit einer Fazies von tieferem Wasser abschließt, welcher die sandigen Ablagerungen mit Küstencharakter entsprechen würden, welche sich ziemlich hoch auf dem kretazischen Uferrand im Süden des Baraolter Beckens (Araci - Fîntîna Fagului) befinden und vielleicht auch im Becken von Sf. Gheorghe (die Ablagerungen mit Mastodonten von Ghidfalău). Im allgemeinen ist die Fauna dieses Horizontes durch das Erscheinen des Pferdes und des Rindes gekennzeichnet, welches Phänomen eine wesentliche Wiedererneuerung im Vergleich zur Fauna des Oberen Pliozäns aufweist und gleichzeitig den Beginn des Pleistozäns anzeigt. Genauer gesagt, kann dieser Horizont wegen der Anwesenheit einiger archaischer Arten (Zygolophodon borsoni, Anancus arvernensis, Tapirus arvernensis, Dicerorbinus cf. megarbinus, Propotamochoerus cf. provincialis, Ursus ruscinensis) und des Fehlens der Elefanten dem Unteren Villafranchium (Phase I) zugeschrieben werden. Diese auch im Süden der Moldau (Măluşteni und Berești) und im Südwesten der Sowjet-Union bekannte faunistische Assoziation ist ein wenig älter als die Fauna von Perrier-Etouaires, aber bestimmt jüngeren Datums im Vergleich zu der von 
Roussillon. Folglich muß die Grenze Plio-Pleistozän in diesem Teil Europas an der Basis der Sedimente gezogen werden, welche diese faunistische Gesellschaft geliefert haben.

Horizon t I I, mergelig in der Achsenzone und mit verschiedenen Fazies in der Küstenzone (Sand, Schotter, Seekreide, Lignit usw.). Infolge der fortschreitenden Senkung des Seegrundes wurde das Seebecken sehr tief und breitete sich stark gegen die Kreideumrahmung aus. Während dieser Phase haben sich auch die kleinen anliegenden Becken (Ilieni u. a.) gebildet. Während der Ablagerung dieses Horizontes haben auch die vulkanischen Phänomene im Harghita-Gebirge begonnen und sich weiter entwickelt, welche in den mächtigen Strömen von Basalt und der Bildung von Andesit-Agglomeraten im Norden des Beckens von Baraolt den Höhepunkt erreichen. Die Fauna, welche im unteren Teil dieses Horizontes in dessen litoralen Fazies entdeckt wurde, ist noch durch die Persistenz der zwei Mastodonten (Z.borsoni, A. arvernensis) und des Tapirs gekennzeichnet und durch das Erscheinen von neuen Formen, wie Ursus etruscus und einem Nashorn (Dicerorbinus sp.), welches sich von D. megarhinus durch eine weniger robuste Gestalt und durch einige entwickelte morphologischen Merkmale unterscheidet. Diese Fauna entspricht dem Unteren Villafranchium, II. Phase. Dieser Horizont scheint mit dem klassischen von Perrier-Etouaires übereinzustimmen. Das heftige Auftreten von vulkanischen Phänomenen ist sehr wahrscheinlich in das Obere Villafranchium zu stellen.

Horizont III. Dieser aus Sanden, Tonen und Schotter gebildete Horizont ist auf die südliche Zone der Becken von Baraolt und Sf. Gheorghe beschränkt. Die Fauna umfaßt zwei aufeinanderfolgende Phasen, von denen die erste in dem unteren Teil des Horizontes III (Rotbav Silvestru), die zweite sich in dessen oberen Teil befindet (Araci - Sandgrube, Rotbav - Dealul Tiganilor, Feldioara). In der ersten Phase, welche an den Beginn des Mittleren Pleistozäns (Günz?) zu stellen ist, enthält die faunistische Gesellschaft neben einem primitiven Megacerinen (gen. et spec. nov.) und einem kleinen caballinen Pferd noch die Überlebenden des Unteren Pleistozäns (Archidiskodon meridionalis, Hippotigris ef. stenonis, einen "rusoiden“ Hirsch). Dieser Komplex entspricht ungefähr der Fauna von St. Prest, Aalen, Jockgrim, Taman u. a. und kennzeichnet den Beginn des Mittleren Pleistozäns in unseren Gegenden. Die zweite Phase ist durch das Erscheinen des Parelephas trogontherii (archaische Form), Dicerorhinus kirchbergensis, die Fortentwicklung der Megaceriden (Dolichodoryceros savini), die Anwesenheit eines sehr mächtigen Elches (Praealces latifrons), der ersten Elaphinen usw. bestimmt. Diese Phase entspricht wahrscheinlich dem Ende des Cromer-Interglazials und dem Mindel-Glazial. Die Fauna scheint sich in jener Welle einzureihen, die vom Forest-Bed durch die gut bekannten mitteleuropäischen Fundstellen wie Mosbach, Süßenborn usw. bis Tiraspol verbreitet war. Während dieser Phase hat sich der See nur im Süden behauptet, wo der Senkungsvorgang weiter anhielt.

Der Horizont IV ist durch sehr verschiedene Ablagerungen vertreten: Torrent-, Fluß-, Hangablagerungen usw. In diesem letzten Stadium, welches der Aufteilung und der endgültigen Auffüllung des Sees entspricht, hat der Olt den magmatischen Damm von Tuşnad durchbrochen und einen mächtigen Schwemmkegel abgelagert, welcher im Becken von Sf. Gheorghe den unteren Teil dieses Horizontes bildet. Die Fauna, welche Parelephas trogontherii (entwickelte Form), ein dem Equus steinheimensis nahestehendes Pferd und Coelodonta antiquitatis umfaßt, gehört zu der III. Phase des faunistischen Komplexes des Mittel-Pleistozäns und kennzeichnet die Riß-Eiszeit; sie ist der Fauna aus dem „trogontherii-primigenius-Schotter" von Steinheim und der des älteren Lösses von Achenheim ähnlich. Der obere Teil des IV. Horizontes umfaßt die Flußschotter, die auf den Schwemmkegel des Oltes abgesetzt wurden, sowie verschiedene Hang- und Torrentablagerungen, die eine Fauna mit Mammuthus primigenius, Equus germanicus, Megaceros giganteus u. a. geliefert haben. Sie gehört in das Ober-Pleistozän (Würm).

$\mathrm{Sum}$ a ry. The present paper deals with the geology and the paleontology of the Baraolt and Sf. Gheorghe Basins, that are part of the Braşov Depression lying in the south-eastern part of Transylvania. This structural depression represented a big lacustrine basin almost during the whole Pleistocene. The deposits were laid down on a Mesozoic floor and are to be divided into four horizons in accordance with a same number of phases of the basin developement. Mammalian faunas of these horizons were grouped into three main complexes corresponding to the Lower, Middle and Upper Pleistocene. The first faunal complex comprises two phases, the second three and the last only one. The four horizons from bottom to top are as follows:

Horizon I is a marly-sandy one and includes three lignite layers, out of which the top one (layer III) is the most developed. This horizon corresponds to the first phase in the development of the lacustrine basin. In the northern part of the Baraolt Basin (Căpeni) and in the Vîrghiş Basin the marshy facies was then mainly prevalent. It seems that this first phase ended by a deeper water facies. The sandy, littoral deposits, lying somewhat up on the Cretaceous rim of the southern part of the Baraolt Basin (Araci-Fîntîna Fagului) would correspond to this facies as well as the Mastodon-bearing sediments from Ghidfalău of the Sf. Gheorghe Basin. As a rule the fauna of this horizon is distinguished by the occurrence of horse and ox. The phenomenon points out an essential renewal in comparison with the Upper Pliocene fauna and indicates at the 
same time the advent of the Pleistocene. More precisely this horizon can possibly be assigned to the Lower Villafranchian (first phase) on account of the presence of some archaic species, e. g., Zygolophodon borsoni, Anancus arvernensis, Tapirus arvernensis, Dicerorbinus cf. megarbinus, Propotamochoerus cf. provincialis, Ursus ruscinensis. This faunal assemblage known likewise from the southern Moldova (Măluşteni and Bereşti) and the south-western Soviet Union is somewhat older than the Perrier-Etouaires fauna, but obviously younger than the Roussillon fauna. The Pliocene-Pleistocene boundary is consequently to be traced in eastern Europe at the base of the deposits which yielded the above-mentioned faunal assemblage.

$\mathrm{Horizon}$ II is a marly one in the axial region and includes various facies in the littoral zone (sands, pebbles, lacustrine chalk, lignite, etc.). Following the successive subsidence of the bottom, the lake became very deep and at the same time extended far over the Cretaceous rim. During this phase small adjoining basins (Ilieni, a.s.o.) were also formed. During the deposition of this horizon volcanic activity started and developed in the Harghita range, culminating with strong basaltic flows and the genesis of andesitic agglomerates in the north-eastern Baraolt Basin. The fauna discovered in the lower part of this horizon within its littoral facies is characterized by the persistence of two mastodons (Zygolophodon borsoni and Anancus arvernensis) and of the tapir, but also by the occurrence of new forms, e.g., Ursus etruscus and of a rhinoceros (Dicerorhinus sp.). This latter differs from D.megarbinus in having a less robust size and some more advanced morphological features. This fauna corresponds to the second phase of the Lower Villafranchian. This horizon seems to correspond to the classical one of Perrier-Etouaires. The paroxysm of volcanic phenomena occurring in this region can very likely be assigned to the Upper Villafranchian.

Horizon III is composed of sands, clays and pebbles, and is to be found in the southern part of the Baraolt and Sf. Gheorghe Basins. The fauna comprises two successive phases out of which the first corresponds to the lower part of Horizon III (Rotbav-Silvestru) and the second one to its upper part (Araci-sand quarry, Rotbav-Dealul Tiganilor, Feldioara). In the first phase, i. e., advent of the Middle Pleistocene (Günz ?), the faunal assemblage comprises besides a primitive megacerine deer (gen. et sp. nov.) and a small caballine horse, also some survivors from the Lower Pleistocene (Archidiskodon meridionalis, Hippotigris cf. stenonis, a "rusoid" deer). This complex corresponds approximately to the St. Prest, Aalen, Jockgrim, Taman, a.s.o., faunas and is indicative of the beginning of the Middle Pleistocene in our parts. The second phase is distinguished by the occurrence of Parelephas trogontherii (archaic form) and Dicerorbinus kirchbergensis, the further evolution of megacerid deers (Dolichodoryceros savini), the presence of a very robust elk (Praealces latifrons), belonging already to the first Elaphus-deers, etc. This phase likely corresponds to the close of the Cromer Interglacial and to the Mindel Glacial, with its fauna belonging to the wave extending from England (Forest Bed), through Central Europe (Mosbach, Süssenborn, etc.) as far as the Soviet Union (Tiraspol). During this phase the lake was only restricted to the southern part of the Braşov Depression where gradual subsidence continued.

Horizon IV ist represented by highly different deposits. During this last stage corresponding to both the splitting up and definitive filling of the lake, the Olt river broke through the magmatic dam of Tuşnad and laid down a strong alluvial fan. This forms the basal part of this horizon in the Sf. Gheorghe Basin. The fauna comprising Parelephas trogontherii (advanced form), a horse close to Equus steinheimensis, and Coelodonta antiquitatis is to be assigned to the third phase of the faunal complex of the Middle Pleistocene and is indicative of Riss Glacial. It is similar to the fauna from "trogontherii-primigenius Schotter" of Steinheim and from the older loess of Achenheim. The top part of Horizon IV is composed of sands, sandy clays, pebbles, etc., the origin of which is very different (slope deposits, fluviatile sediments, etc.). The fauna which comprises Mammuthus primigenius, Equus germanicus, Megaceros giganteus, etc. is indicative of the age assignment of these deposits to the Upper Pleistocene (Würm).

\section{Introduction}

Le but de ce travail est de mieux faire connaître les faunes successives de Mammifères, témoins, durant un long laps de temps, de la naissance et de la disparition de ce grand bassin lacustre qui occupait la Dépression de Braşov et à la fois, spectateurs effrayés, désertant la région devant les grands phénomènes volcaniques qui participèrent au comblement de l'ancien lac et à la formation des puissants agglomérats andésitiques et des énormes coulées de basalte.

Objet de recherches qui s'étalent pendant plus d'un siècle, les depôts charbonneux de cette région ont livré une faune de Mammifères dont l'importance exerça toujours une grande attraction. Malgré cela, aucune étude d'ensemble n'est venue satisfaire la curiosité 
par une description plus ample. Malheureusement, de nos jours, le matériel fossile, irrémédiablement perdu ou éparpillé dans différentes collections européennes, reste presque inconnu.

Les investigations récentes ont non seulement conduit à de nouvelles récoltes de pièces fossiles dans les couches ligniteuses, mais encore révélé, dans les autres dépôts, l'existence d'une faune assez riche qui vient combler une importante lacune de nos connaissances sur l'histoire des Mammifères de la Dépression de Braşov et même de notre pays.

Les recherches furent commencées et effectuées entre 1960 et 1961 par l'un de nous (N. M.) qui, à l'occasion des études stratigraphiques entreprises dans la région, a signalé la présence de plusieurs horizons fossilifères. Les restes de Mammifères recueillis alors ont fourni les bases d'un premier travail sur la stratigraphie générale du Bassin de Baraolt (E. Litteanu, N. Mihăılă, T. Bandrabur 1962).

Les recherches ultérieures (AL. K ., C. R. et P. S.), poursuivies entre 1962 et 1964, ont contribué à l'enrichissement des associations faunistiques et ont apporté de nouvelles précisions sur leur stratigraphie. Une grande partie de ces découvertes a été utilisée par deux d'entre nous (P. S. et C. R.) à des fins chronologiques dans une note générale sur les faunes du Pléistocène inférieur et moyen de Roumanie, présentée à l'Académie des Sciences de Paris (1963), ensuite dans une communication plus détaillée au Symposium International de Paléontologie à Weimar (1965).

Le matériel que nous avons recueilli fut substantiellement complété par les pièces fossiles provenant de diverses collections.

Nous désirons exprimer nos vifs remerciements au Directeur du Musée Régional de Sfîntu-Gheorghe, Mr. Z. SzéKely, qui nous a toujours aidé dans nos recherches. Nous demeurons également reconnaissants à la Direction de l'Exploitation Minière de Căpeni et surtout à Mr. Z. KISGYöRGY, géologue à cette entreprise, qui a obligeamment mis à notre disposition sa collection de Mammifères découverts à Căpeni et Vîrghiş, ainsi que certains profils concernant les zones fossilifères.

Nous avons aussi bénéficié, grâce à Mr. I. Croitoru, Directeur de l'école de Rotbav, de l'importante collection, provenant des points fossilifères de Silvestru et Dealul Tiganilor, qu'il a soigneusement gardée depuis 1936, pour la faire don récemment au Musée de Sf. Gheorghe. Qu'il veuille trouver ici le témoignage de toute notre reconnaissance. Nous remercions encore MM. G. KÁszoni de Baraolt et J. Török, instituteur à Hăghig, pour certaines pièces fossiles, trouvées à Căpeni, Feldioara et Iarăş qu'ils nous ont aimablement confiées pour étude.

Dans notre travail nous avons été constamment soutenus par Mr. le Docteur $\mathrm{T}_{\mathrm{R}}$. Orghidan, Directeur de l'Institut de Spéologie "E. Racoviţă" de Bucarest, qui a bien voulu aussi accepter l'ingrate tâche de faire les belles photographies qui accompagnent ce mémoire. Nous sommes heureux de lui exprimer ici notre profonde gratitude.

\section{Géologie}

1. Considérations générales

\section{A. Situation}

La grande zone dépressionnaire, d'origine tectonique, du Sud-Est de la Transylvanie, connue sous le nom de la $\mathrm{D}$ épression de $\mathrm{Br}$ aşov (fig. 1), représente un ancien bassin lacustre rempli de sédiments, de divers faciès, qui reposent sur un socle crétacé.

Orientées vers le Nord, les ramifications centrale et occidentale, qui correspondent aux Bassins de Sf. Gheorghe et de Baraolt, constituent la région où nous avons effectué nos 


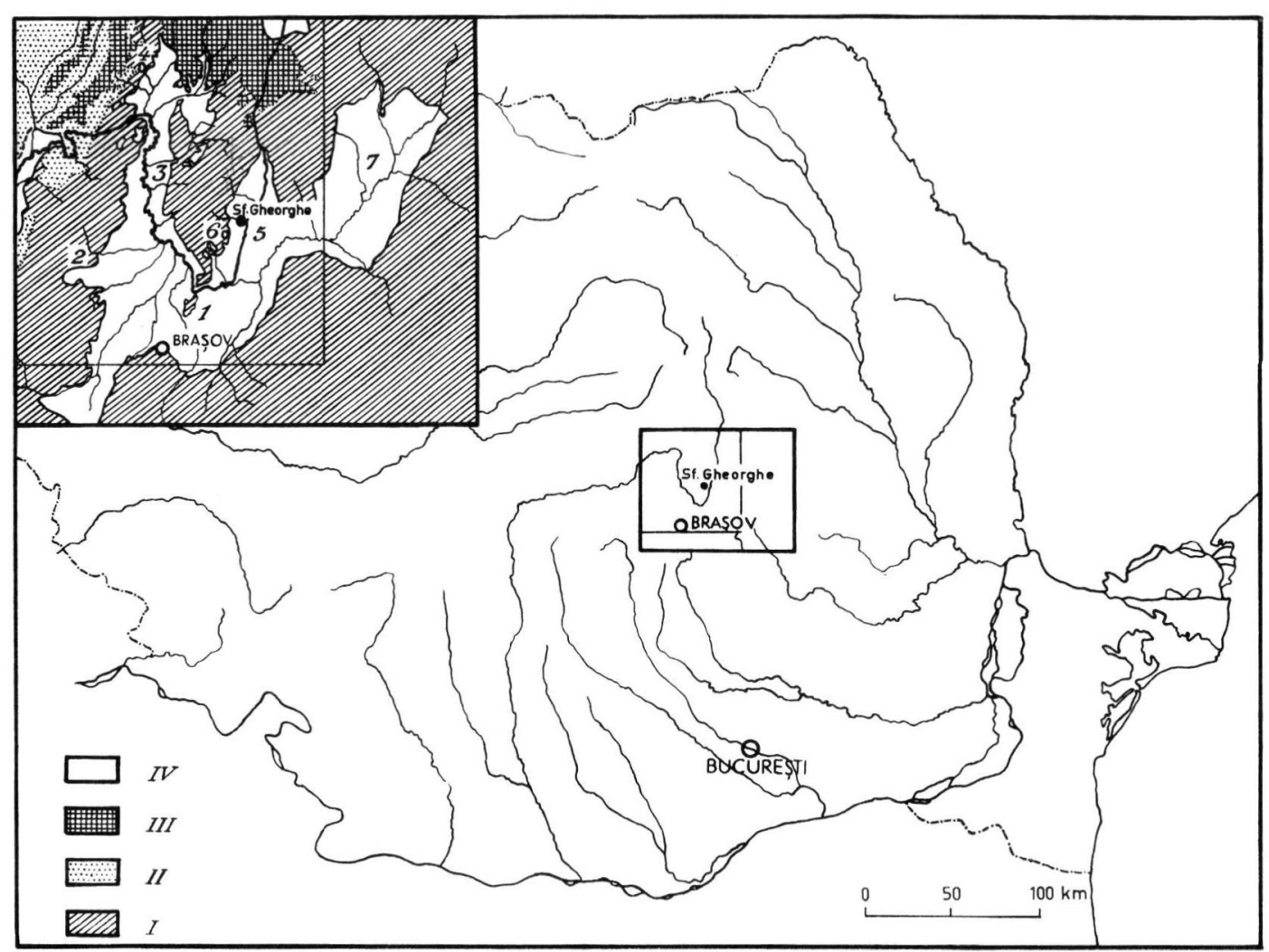

Fig. 1. Carte de la Dépression de Braşov (d'après E. Jekelıus 1932). 1. Bassin de Bîrsa; 2. Bassin de Vlădeni; 3. Bassin de Baraolt; 4. Bassin de Vîrghiş; 5. Bassin de Sfîntu-Gherorghe; 6. Bassin de Ilieni; 7. Bassin de Tîrgu-Secuesc (la partie délimitée par la ligne mince est détaillée dans la fig. 2). I. Prétertiaire; II. Néogène; III. Andésites; IV. Quaternaire.

recherches (fig. 2). Ces deux bassins sont parcourus par l'Olt, le premier en direction NordSud, le deuxième en sens inverse.

Nos principales investigations se rapportent au $\mathrm{B}$ as in $\mathrm{de} \mathrm{B}$ a raolt, qui est le plus riche en restes de Mammifères fossiles. Ce bassin, bordé à l'Ouest par les Monts Perşani, au Nord par le massif éruptif de Harghita, à l'Est par les Monts Baraolt, communique largement vers le Sud avec la Dépression de Bîrsa. Long d'approximativement $45 \mathrm{~km}$, le Bassin de Baraolt est plus large au pied de Harghita $(10 \mathrm{~km})$, se rétrécit entre les localités Căpeni et Măieruş (de 4 à $7 \mathrm{~km}$ ) et s'élargit de nouveau (plus de $15 \mathrm{~km}$ ) au Sud de Feldioara.

Le petit bassin lignitifère de Vîr $\mathrm{g}$ h iş, situé dans le Nord-Ouest, bien que séparé du Bassin de Baraolt par une barrière mésozoïque, forme avec ce dernier un même système.

Le B a s s in de S fînt u-Gheorghe est limité à l'Ouest par les Monts Baraolt et à l'Est par les Monts Bodoc. Vers le Sud il communique à son tour avec la Dépression de Bîrsa et vers le Sud-Est avec le Bassin de Tîrgu-Secuiesc. Plus réduit que le Bassin de Baraolt, il a seulement $30 \mathrm{~km}$ de longueur et $12 \mathrm{~km}$ de largeur maxima.

Quelques petits bassins isolés, parmi lesquels il convient d'appeler l'attention sur celui de Ilien i, se trouvent sur le versant Est des Monts Baraolt et sont étroitement liés à l'évolution du bassin plus grand de Sf. Gheorghe. 


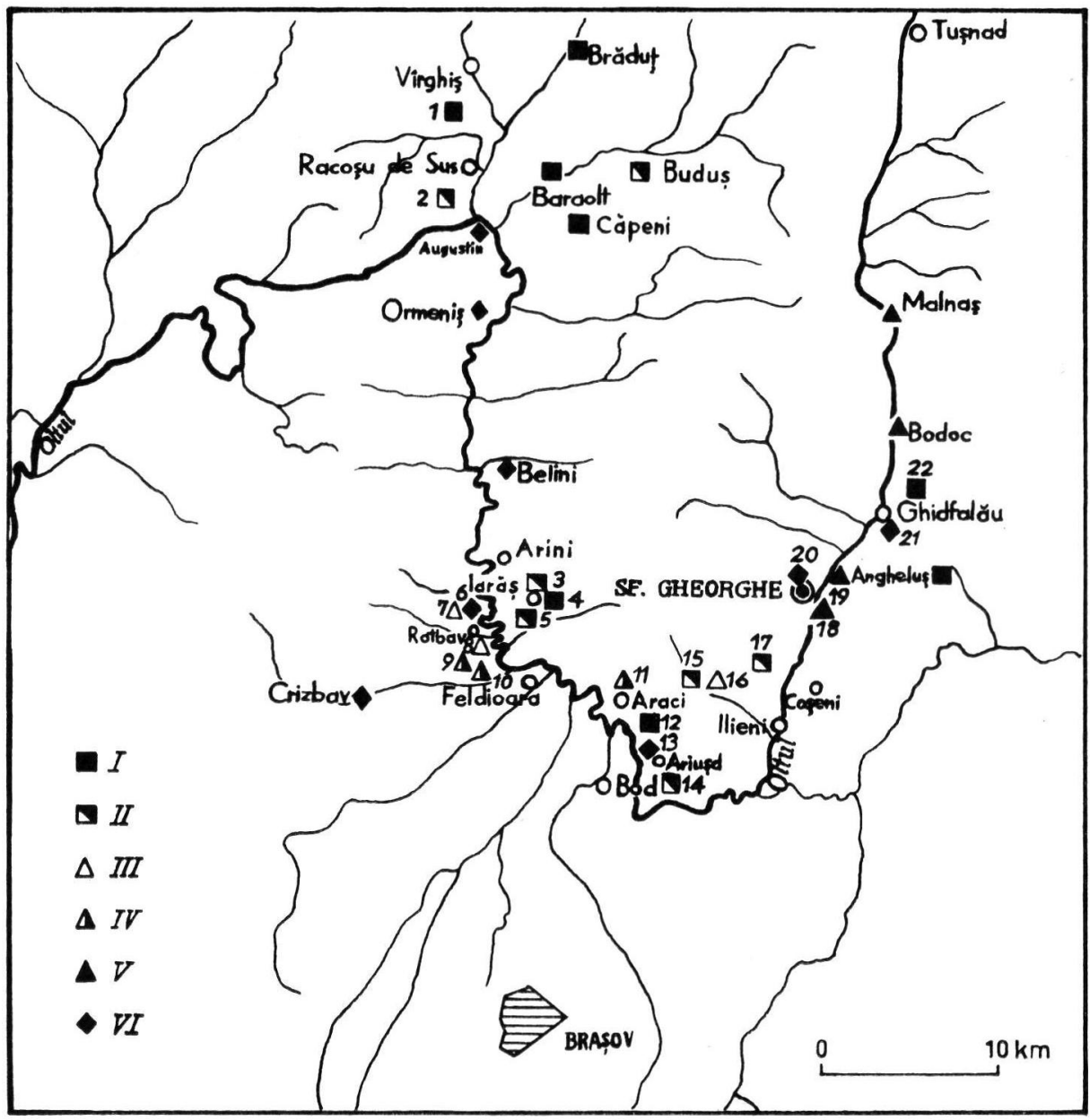

Fig. 2. Carte des points fossilifères des Bassins de Baraolt et Sfîntu-Gheorghe. 1. Vîrghiş I, Secteur Ouest; 2. Racoşul de Sus, Remete; 3. Iarăş, Cariera Nouă; 4. Iarăş, ancienne exploitation de lignite; 5. Iarăs, Cariera Veche; 6. Rotbav, Cariera de sub Brazi, partie supérieure; 7. Rotbav, Cariera de sub Brazi, partie inférieure; 8. Rotbav, Silvestru; 9. Rotbav, Dealul Tiganilor; 10. Feldioara, carrière; 11. Araci, carrière; 12. Araci, Fîntîna Fagului; 13. Ariujd, carriêre; 14. Ariujd, dépôts de l'horizon II; 15. Ilieni, dépôts de lignite; 16. Ilieni, dépôts supérieurs; 17. Sîncrai, dépôts de lignite; 18. Sf. Gheorghe, carrières Sud; 19. Sf. Gheorghe, La Moară; 20. Sf. Gheorghe, dépôts de pente; 21. Ghidfalău, carrière; 22. Ghidfalău, dépôts de l'horizon I en bordure. I. Villafranchien inférieur, phase I; II. Villafranchien inférieur, phase II; III. Pléistocène moyen, phase I (Gênz?); IV. Pléistocène moyen, phase II (Cromérien, Mindel); V. Pléistocène moyen, phase III (Riss); VI. Pléistocène supérieur (Würm).

\section{B. Historique}

Les opinions plus anciennes (datant de la deuxième moitié du XIXe et du commencement du $\mathrm{XX}^{\mathrm{e}}$ siècle) sur la géologie et la stratigraphie de la Dépression de Braşov, concernant surtout le Bassin de Baraolt, furent synthétisées par E. Jekelius (1932) dans son étude, devenue classique, sur la faune de Mollusques d'eau douce de cette région. C'est pourquoi nous n'y revenons plus. 
D'après ce dernier ouvrage, les sédiments sont groupés en trois horizons, qui correspondent aussi à trois phases principales dans l'évolution du bassin lacustre:

- L'horizon inférieur, charbonneux, contenant trois couches principales de lignite (I-III), est limité seulement au centre du Bassin de Baraolt (Căpeni).

- L'horizon moyen est représenté spécialement par des marnes, dans la zone profonde, par des sédiments de faciès variés, même des affleurements de lignite, dans la zone littorale.

- L'horizon supérieur, constitué par des sables et graviers se développe surtout dans la partie centrale de la Dépression de Braşov (Bod).

En 1959, V. Popovici, à la suite de très nombreux forages effectués dans la région septentrionale du Bassin de Baraolt, indique l'existence encore de deux couches charbonneuses supérieures très sporadiques (couches IV et V); ces dernières semblent correspondre à celle qui fut mentionnée par I. Lönenthey (1909) au-dessus de la couche III de lignite de Căpeni.

Le schéma récent de E. Liteanu, N. MihăILă \& T. Bandrabur (1962), tout en complétant les données de E. Jekelius et V. Popovici, en diffère par certaines interprétations nouvelles, dont nous allons signaler les points les plus importants. Ce schéma, bien qu'il se réfère surtout au Bassin de Baraolt, s'étend à toute la Dépression de Braşov. Les auteurs sus-mentionnés y distinguent 5 complexes lithologiques: charbonneux, marneux, sabloargileux, pséphito-psammitique et pséphitique.

Dans le complexe charbonneux sont englobés tous les sédiments qui contiennent des intercalations de lignite (inclusivement les couches IV et $\mathrm{V}$, réunies dans la couche IV). Les affleurements charbonneux de la zone littorale des deux bassins (Baraolt et Sf. Gheorghe), rapportés par E. JeKELIUs à son horizon moyen, sont attribués à la couche III de lignite.

L'horizon supérieur de E. Jekelius (1932) est divisé en un complexe inférieur sabloargileux et un autre supérieur pséphito-psammitique, qui présente deux faciès: le premier alluvionnaire, situé sous la plaine de l'Olt, le deuxième déluvial, dans la zone du relief piedmontan.

Le complexe pséphitique n'entre pas dans la cadre de ce travail, parce qu'il représente les accumulations des réseaux hydrologiques subactuels.

Enfin, le tableau 1 nous dispense de tout autre détail en ce qui concerne les opinions émises sur la succession lithologique générale dans la Dépression de Braşov (spécialement dans les Bassins de Baraolt et Sf. Gheorghe), que nous avons mentionnée plus haut.

\section{Stratigraphie}

Dans la présente étude, en nous appuyant sur les recherches antérieures et sur nos propres observations, ainsi que sur la succession des faunes de Mollusques et notamment de Mammifères (P. SAMSON \& C. RAdulesco 1963, 1965), nous avons adopté un point de vue un peu différent, renforcé aussi par certaines dissemblances qui existent entre les successions lithologiques des Bassins de Baraolt et de Sf. Gheorghe, dont nous signalerons les particularités à leur place.

Nous avons reconnu, dans les sédiments pléistocènes de la Dépression de Braşov, de bas en haut, 4 horizons (Tableau 1).

Horizon I (= Horizon inférieur de E. Jekelius 1932 = Complexe charbonneux p. p. de E. Liteanu, N. MihăILă \& Bandrabur 1962).

Le premier horizon, épais de 50 à $150 \mathrm{~m}$, repose directement sur le socle mésozoïque et comprend, au Nord du Bassin de Baraolt, les dépôts formés de marnes, marnes sableuses, argiles et sables, qui renferment trois couches importantes de lignite, dont la supérieure (couche III) est la plus puissante. Celle-ci a livré une faune malacologique banale de 
marécage, représentée par des coquilles écrasées de Planorbis, Limnea, Pisidium, etc. De cette même couche, ainsi que de l'argile sous-jacente, provient l'association de Mammifères connue dans la littérature de spécialité, dès la fin du dernier siècle, sous le nom de "la faune de Barót-Köpecz" (= Baraolt-Căpeni). Au-dessus de la couche III de lignite, se trouve, en certains points, une marne claire faiblement développée, riche en Valvates, Dreissènes, Néritines, etc.

Vers le Sud, se déposèrent en même temps, dû, semble-t-il, à une subsidence accrue de cette zone, des sédiments à prédominance sableuse, observables surtout en bordure autour de la cote 620 m (Araci-Fîntîna Fagului).

D'une manière générale, les dépôts de l'horizon I se sont formés pendant le stade initial d'évolution du bassin, lorsque les marécages constituaint, spécialement vers le Nord, le faciès dominant (couches de lignite); un enfoncement graduel a permis ensuite l'installation d'un régime d'eau un peu plus profonde et sans végétation (marnes claires au Nord, sables au Sud).

Dans notre acception, ce premier complexe de sédiments prend fin avec les marnes claires, comme l'a proposé E. Jekelius (1932), vu l'importance tout à fait locale des niveaux de lignite IV et $\mathrm{V}$.

Les couches charbonneuses du premier horizon, dans l'état actuel de nos connaissances, sont présentes, comme l'a souligné E. Jekelius (1932) seulement dans le Bassin de Baraolt (mine de Căpeni), mais il faut reconnaître avec E. Liteand, N. MihăILĂ \& T. Bandrabur (1962), que c'est la couche III de lignite qui s'étend, dans ce bassin, largement vers la bordure crétacée, formant les exploitations de Iarăş et Vîrghiş, considérées par E. JEkELłus (1932) comme appartenant au faciès littoral de son horizon moyen.

Les localités fossilifères sont les suivantes: Vîrghiş I-Secteur Ouest (V), Căpeni-Secteur I (C), Araci-Fîntîna Fagului (F. F.); à celles-ci on peut ajouter, d'après les données de la littérature, Brăduţ (Br.) (A. Кoch 1879), Baraolt (B) et Iarăş (I) (G. Schlesinger 1922). L'association faunique générale comporte $\left.{ }^{1}\right)$ :

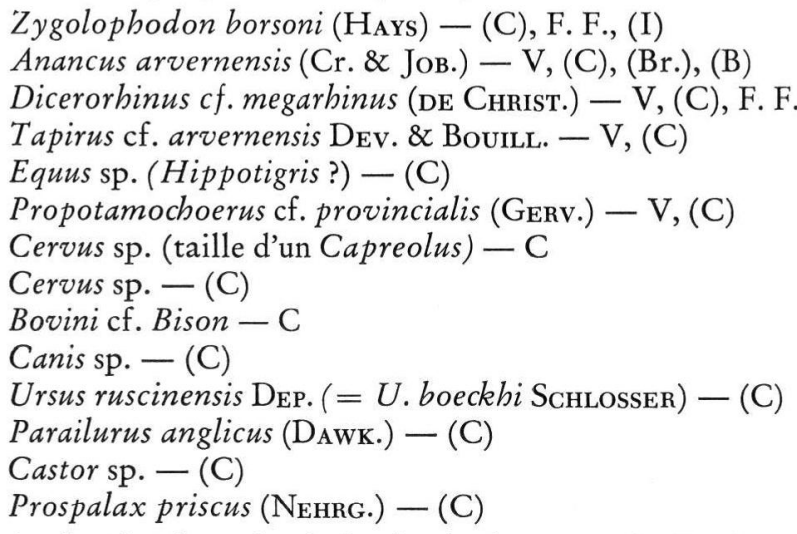

Dans le Bassin de Sf. Gheorghe, le faciès charbonneux de l'horizon I n'a pas encore été mis en évidence. Cependant, ainsi que dans le Bassin de Baraolt, certains dépôts sableux déposés en bordure, approximativement entre les cotes 620 et $650 \mathrm{~m}$, pourraient appartenir à cet horizon.

Les seules localités connues sont Ghidfalău et probablement, d'après A. КосH (1879) et Th. Fuchs (1879), aussi Angheluş qui ont livré Anancus arvernensis (CR. \& Jов.)

1) Entre parenthèses les localités dont les espèces sont reportées à la mesure où une révision a été possible d'après: I. Halavats 1891; M. SChlosser 1899; E. Jekelius 1932; T. Kormos 1933, 1937; M. Mottr 1939; M. KretZoi 1954. 
Horizon I I (= Horizon moyen de E. Jekelius (1932) = Complexe charboneux p. p. + Complexe marneux de E. Liteanu, N. Mihăilă \& T. Bandrabur 1962) Le deuxième horizon, dont l'épaisseur atteint $300 \mathrm{~m}$, comprend les dépôts représentés, dans la zone profonde du bassin, spécialement par des marnes à Limnocardium fuchsi (Neum.), Ostracodes et impressions végétales, rarement par des sables et couches sporadiques de lignite (couches IV et V); dans la zone littorale se déposèrent à la fois des sédiments de faciès bien variés (argiles, sables, graviers, calcaires lacustres, même lignite, etc.), extrêmement riches en Gastropodes et Lamellibranches (Teodoxus, Viviparus, Valvata, Hydrobia, Pyrgula, Bulimus, Melanopsis, Gyraulus, Ancylus, Dreissena, Psilunio, etc.); les restes de Mammifères fossiles n'y manquent non plus. A la limite des zones axiale et marginale on remarque une alternance répétée des formations de profondeur avec celles du littoral.

Pendant la constitution de ces dépôts ont commencé et se sont développés les puissants phénomènes volcaniques de Harghita - témoin les nombreuses intercalations de piroclastites, agglomérats et tufs andésitiques - dont le paroxysme est marqué par l'énorme masse d'agglomérats andésitiques et de coulées de basalte, qui recouvrent au Nord les sédiments lacustres du deuxième horizon.

Cet horizon caractérise une nouvelle phase dans l'évolution du bassin, qui était plus profond par suite des phénomènes d'enfoncement progressif; cela n'a pas exclu l'installation dans la zone axiale même, pour des périodes très courtes et dans des régions très restreintes, de faciès marécageux.

Les sédiments du deuxième horizon ont été mis en évidence tant dans le Bassin de Baraolt que dans celui de Sf. Gheorghe. Le faciès littoral, qui a livré des ossements de Mammifères, se présente sous des aspects divers: sables graveleux dans le Bassin de Baraolt, sables, argiles et dépôts importants de lignite dans les bassins de Sf. Gheorghe et Ilieni; ces derniers dépôts appartiennent, comme l'a supposé E. Jekelius (1932), à son horizon moyen et non pas au complexe inférieur charbonneux (E. LitEANU, N. MIHĂIL А \& T. BANDRABUR) (1962).

Les points fossilifères sont: Racoşul de Sus (R), Iarăş-Cariera Nouă (C. N.), Iarăşi-Cariera Veche (C. V.), Ariujd (A) et d'après la littérature Buduş (Bd.) (G. SCHLESINGER 1922) dans le Bassin de Baraolt, auxquels s'ajoutent deux bassins isolés, Ilienidépôt ligniteux (Il) et, selon E. Jekelius (1932), Sîncrai (S), contigus au grand Bassin de Sf. Gheorghe. Dans l'ensemble la faune est représentée par $\left.{ }^{2}\right)$ :

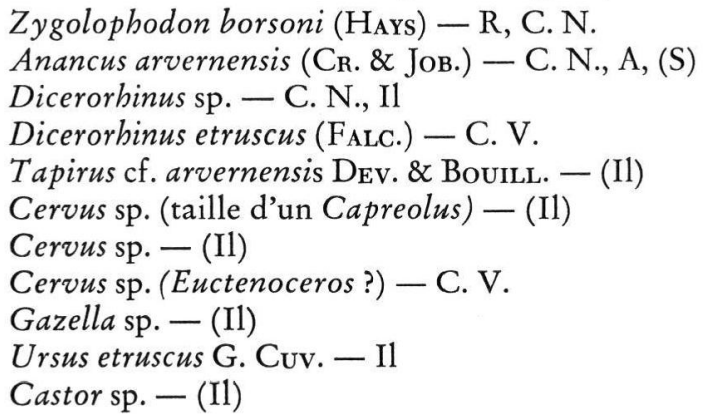

Horizon I I (= Horizon supérieur p. p. de E. Jekelius $1932=$ Complexe sablo-argileux de E. Liteanu, N. MihăIL $\&$ \& T. Banrabur 1962).

Cet horizon consiste en sables et sables argileux avec intercalations d'argile et lentilles de gravier; son développement le plus remarquable (155 m d'épaisseur) se trouve dans la

2) Entre parenthèses les localités dont les espèces sont reportées à la mesure où une révision a été possible d'après: F. Toula 1911, E. JeKELIus 1932. 
partie centrale du Bassin de Baraolt (forage de Bod, E. Jekelius 1923 a, b), mais il s'est conservé partiellement aussi dans les zones marginales. A l'exception des restes de Mammifères, on a trouvé dans ces dépôts des Mollusques appartenant aux genres Valvata, Lithoglyphus, Planorbarius, Helicopsis, Clausilia etc. et Ostracodes (E. Liteanu, N. MIHĂILĂ \& T. BandRABUR 1962). L'horizon III prend fin, comme nous l'avons observé à Rotbav - Dealul Tiganilor, avec des argiles grisâtres à séparations calcaires et Mollusques de marais (Planorbes, etc.).

Les sédiments du troisième horizon correspondent à la phase finale de l'évolution du Bassin de Braşov. Le lac, beaucoup plus restreint, étaint localisé dans la partie Sud de ce bassin, affectée toujours par le phénomène d'enforcement auquel nous avons déjà fait allusion. Durant cette phase, le niveau du lac s'est abaissé considérablement, certaines de ses régions, par suite du matériel détritique apporté par les cours d'eau étant amenées au voisinage de l'assèchement (les argiles grisâtres mentionnées à Rotbav).

Les dépôts de l'horizon III, profondément entaillés par l'Olt, sont observables dans la partie méridionale des deux bassins, de Baraolt et de Sf. Gheorghe; ils forment, entre les cotes 520 et $540 \mathrm{~m}$, de larges surfaces presque planes, situées en contrebas des sédiments du faciès littoral du deuxième horizon. Le troisième horizon commence au Nord de Rotbav et s'étend, sur les deux versants du Bassin de Baraolt, vers le Sud; du côté droit de l'Olt, il se continue dans le Bassin de Sf. Gheorghe jusqu'au Nord de la commune de Ilieni.

Les espèces fossiles, trouvées seulement dans le Bassin de Baraolt, se groupent en deux associations distinctes, la première se rapportant à la partie inférieure de l'horizon III (phase I), la deuxième à sa partie supérieure (phase II).

La faune de la phase I fut découverte dans les points de Rotbav-Silvestru et RotbavCariera de sub Brazi (dépôt basal) et renferme:

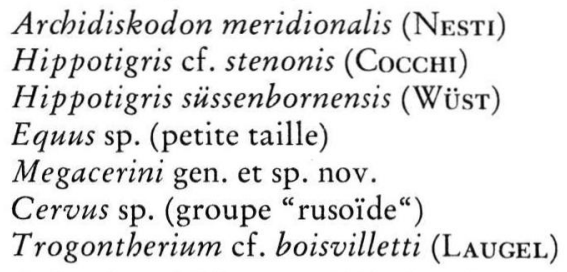

La faune de la phase II fut recueillie dans les points suivants: Rotbav-Dealul Tiganilor (R. T.) avec trois niveaux fossilifères (1-3), Feldioara (F), Araci-Carrière (A) et comprend les espèces ci-dessous:

Parelephas trogontherii (PoHLig), forme archaïque - R. T. 1

Dicerorhinus kirchbergensis (JAEG.) - R. T. 1, A

Equus mosbachensis v. ReICH. - R. T. 1, 3, F

Praealces latifrons (JoHN.) - R. T. 1, F

Dolichodoryceros savini (DAwk.) - A

Capreolus capreolus (L.) - R. T. 1

Cervus sp. (groupe Elaphus) - F, A

Il n'est pas exclu que les dépôts sableux qui recouvrent les lignites du Bassin de Ilieni appartiennent aussi à l'horizon III; ils ont fourni Cervus cf. elaphus L.

Horizon IV (= Horizon supérieur p.p. de E. Jekelius 1932 = Complexe pséphito-psammitique de E. Liteanu, N. MihăıL \& \& T. Bandrabur 1962).

Les sédiments de cet horizon sont de genèse très différente (dépôts torrentiels, fluviatiles, de pente etc.) et ont une composition lithologique bien variée.

Les formations les plus importantes sont dues, dans le Bassin de Sf. Gheorghe, à l'activité de l'Olt. Nous y avons pu séparer deux parties: l'une plus ancienne, inférieure, 
qui représente le puissant cône de déjection de l'Olt, déposé à la suite du perçage de la barrière magmatique de Tuşnad; ce cône, constitué par des sables, graviers et blocs, parfois énormes, s'étend jusqu'au Sud de la commune de Coşeni; l'autre partie, plus récente, - partie supérieure - recouvre les sédiments du cône, étant formée de graviers, sables limoneux etc., à la constitution desquels ont aussi participé les torrents venus des massifs avoisinants (Ghidfalău-Carrière).

A cette partie supérieure nous avons rattaché les divers dépôts torrentiels observables surtout dans le Bassin de Baraolt à Rotbav et spécialement à Arini, où l'accumulation de graviers, provenant des Monts Baraolt, dépasse $12 \mathrm{~m}$ d'épaisseur. Nous y avons rattaché encore les dépôts de pente, largement répandus (Crizbav, Sf. Gheorghe), dont la puissance peut atteindre vers la bordure montagneuse de 10 à $20 \mathrm{~m}$.

Les localités à restes fauniques correspondant à la partie inférieure de l'horizon IV sont: Malnaş (M), Bodoc (Bd), Sf. Gheorghe-La Moară (G. M.) et Sf. Gheorghe-Carrières Sud (G. C.); elles ont livré:

Parelephas trogontherii (PoHLIG), forme évoluée - M, G. M., G. C.

Coelodonta antiquitatis (BLumB.) - Bd., G. C.

Equus sp. (grande taille) - Bd., G. C.

Marmota sp. - G. C.

Les points fossilifères de la partie supérieure du même horizon, dans le Bassin de Baraolt, sont: Rotbav-Cariera de sub Brazi (dépôt supérieur) (R.B.), Crizbav (Cr.), Ariujd (A) et d'après la littérature Belini (Bl.), Ormeniş (O) et Augustin (Ag.). (A. KocH 1876); dans le Bassin de Sf. Gheorghe, Ghidfalău-Carrière (Gd.) et Sf. Gheorghe (G). La faune est la suivante:

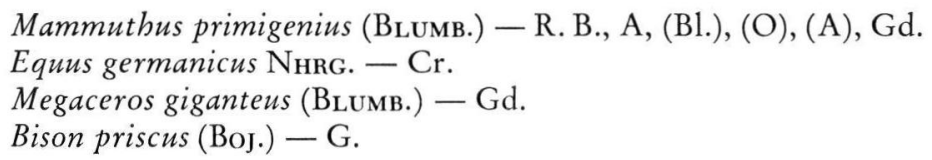

3. Age des dépôt s

Les opinions sur la chronologie des dépôts de la Dépression de Braşov ont été très diverses et ont subi de multiples fluctuations à travers plus d'un siècle de recherches. Le travail de E. JekElıus (1932) nous dispense d'insister sur les interprétations plus anciennes d'après lesquelles, par exemple, les couches ligniteuses de Căpeni furent, tour à tour, considérées d'âge pontien sinon même sarmatien (Fr. Herbich \& M. Neumayr 1875), levantin (I. Lörenthey 1895, 1909; T. Kormos 1917; L. RüGER 1931), encore pontien (M. Schlosser 1899) et méotien (E. Jekelius 1923).

Dans sa belle monographie E. Jekelius (1932) attribue ses horizons inférieur et moyen au Dacien, le supérieur au Levantin et au Pléistocène (Tableau 1).

Plus récemment, la faune de Căpeni a servi à M. KRetzor (1938) pour créer un nouvel étage "Barotium", qui succède à l'Astien, mais appartient encore au Pliocène. Ensuite, M. Kretzor (1953) a situé son étage à la base du Quaternaire. Dans un de ses derniers travaux sur la chronologie du Pléistocène (M. KRETzOr 1961), il englobe le "Barotium" dans une notion plus large: "Villanyium". Enfin, en 1962, M. KREtzor situe de nouveau la faune de Căpeni dans le Pliocène final (= "Csarnotanum" créé par M. Kretzor en 1959).

E. Liteanu, N. MihăILĂ \& T. Bandrabur (1962) assignent à leur complexe charbonneux un âge levantin supérieur (= astien supérieur); le complexe marneux correspond, dans leur schéma, au Villafranchien et peut-être au Saint-Prestien, le complexe sabloargileux au Mindélien et le complexe psammo-pséphitique au Pléistocène supérieur. 
Tableau 1

Dépression de Braşov (Bassins de Baraolt et de Sfîntu - Gheorghe) Succession lithologique, divisions, chronologie

\begin{tabular}{|c|c|c|c|c|c|c|c|c|c|c|}
\hline \multicolumn{3}{|c|}{ E. JEKELIUS 1932} & \multicolumn{3}{|c|}{ E. LiteAnU et collab. 1962} & \multicolumn{5}{|c|}{ P. SAMSON et C. Radulis SCO 1963 + nouvelles données } \\
\hline $\begin{array}{c}\text { Bassin de } \\
\text { Baraolt }\end{array}$ & $\mid \begin{array}{c}\text { Bassin de } \\
\text { Sf.Gheorghe }\end{array}$ & Age & $\begin{array}{c}\text { Bassin de } \\
\text { Baraolt }\end{array}$ & $\begin{array}{c}\text { Bassin de } \\
\text { Sf.Gheorghe }\end{array}$ & Age & $\begin{array}{c}\text { Bassin de } \\
\text { Baraolt }\end{array}$ & $\begin{array}{c}\text { Bassin de } \\
\text { Sf.Gheorghe }\end{array}$ & \multicolumn{2}{|c|}{ Age } & $\begin{array}{c}\text { Phases } \\
\text { fauniques }\end{array}$ \\
\hline \multirow{2}{*}{$\begin{array}{l}\text { Hor } \\
\text { supé }\end{array}$} & izon & \multirow{2}{*}{ 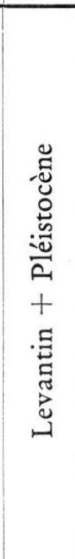 } & \multicolumn{2}{|c|}{$\begin{array}{c}\text { Complexe } \\
\text { pséphito-psammitique }\end{array}$} & 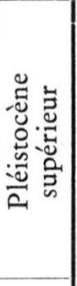 & \multicolumn{2}{|c|}{$\begin{array}{l}\text { Dépots torrentiels, } \\
\text { fluviatiles, de pente } \\
\text { Ho riz o n I V } \\
\qquad \begin{array}{c}\text { Cône } \\
\text { de déjection } \\
\text { de l'Olt }\end{array}\end{array}$} & 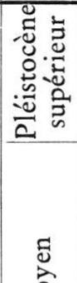 & 莙 & 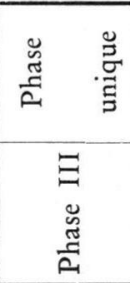 \\
\hline & rieur & & $\begin{array}{r}\text { Com } \\
\text { sablo-a } \\
\text { (localisé }\end{array}$ & $\begin{array}{l}\text { plexe } \\
\text { rgileux } \\
\text { au Sud) }\end{array}$ & 吾 & $\begin{array}{r}\text { H o r i z } \\
\text { sables, argi } \\
\text { (localisé }\end{array}$ & $\begin{array}{l}\text { o n I I I } \\
\text { es, graviers } \\
\text { au Sud) }\end{array}$ & 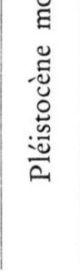 & 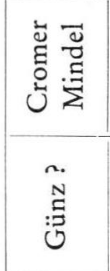 & 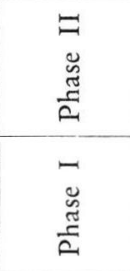 \\
\hline $\begin{array}{r}\text { Horizo } \\
\text { (lignite e }\end{array}$ & $\begin{array}{l}n \text { moyen } \\
n \text { bordure) }\end{array}$ & $\Xi$ & $\begin{array}{l}\text { Couche IV } \\
\text { de lignite }\end{array}$ & $\begin{array}{l}\text { plexe } \\
\text { neux }\end{array}$ & 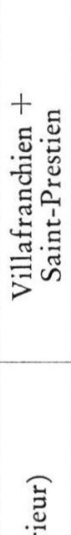 & $\begin{array}{c}\text { Agglomérats } \\
\text { andésitiques } \\
\text { Coulées de } \\
\text { basalte } \\
\text { (au Nord) } \\
\text { H o r i z } \\
\text { faciès de p } \\
\text { marnes; fac } \\
\text { sables, gra } \\
\text { lacustre, di } \\
\text { Couches IV } \\
\text { et V } \\
\text { de lignite }\end{array}$ & $\begin{array}{l}\text { o n I I } \\
\text { rofondeur: } \\
\text { iès littoral: } \\
\text { viers, craie } \\
\text { atomite etc. }\end{array}$ & 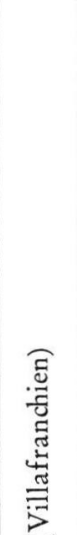 & 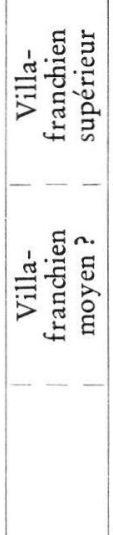 & 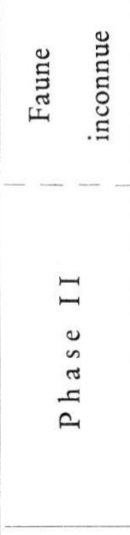 \\
\hline 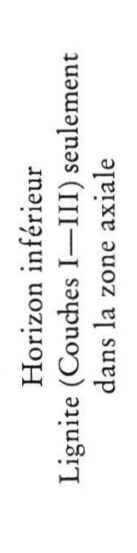 & & $\ddot{\tilde{n}}$ & $\begin{array}{r}\text { Extensi } \\
\text { Couche II } \\
\text { en bo } \\
\text { charbo }\end{array}$ & $\begin{array}{l}\text { on de la } \\
\text { de lignite } \\
\text { rdure }\end{array}$ & 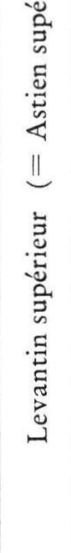 & 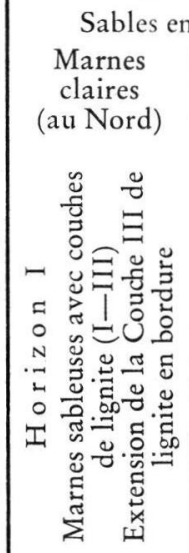 & bordure & 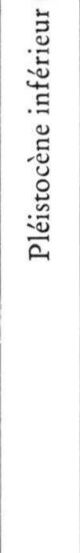 & 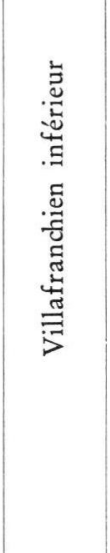 & 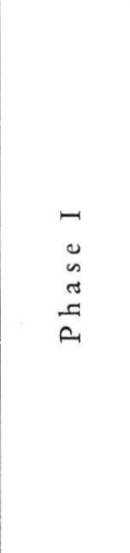 \\
\hline
\end{tabular}


Dans une récente esquisse de corrélation des principaux gisements fossilifères mammalogiques de Roumanie (P. SAMsón \& C. Radulesco 1963), nous avons considéré les horizons I et II comme pléistocènes inférieurs (villafranchiens) et l'horizon III comme pléistocène moyen. Il faut ajouter à cette esquisse l'horizon IV d'âge pléistocène moyen et supérieur (Tableau 1).

Ce sera le but même de ce travail de confirmer et de développer les prémisses de 1963 par l'étude d'une faune de Mammifères plus riche et de tenter une corrélation plus précise entre les divers niveaux fossilifères de la Dépression de Braşov.

\section{Paléontologie}

Dans l'étude paléontologique nous décrirons les espèces fossiles de Mammifères de la Dépression de Braşov groupées en complexes, pour mieux faire ressortir leur succession chronologique et pour en faciliter à la fois les comparaisons. C'est ainsi que nous avons pu séparer trois complexes fauniques principaux, correspondant au Pléistocène inférieur, moyen et supérieur. La faune du Pléistocène inférieur (Villafranchien) comporte deux phases rapportables, l'une à l'horizon I, l'autre à la partie inférieure de l'horizon II. Dans le cadre du Pléistocène moyen nous avons distingué trois phases appartenant, la première à la base de l'horizon III, la seconde à la partie terminale de celui-ci (P. SAMson \& C. RADUlescu 1965) et la troisième à la partie inférieure de l'horizon IV. Le complexe pléistocène supérieur se rapporte à la partie supérieure de l'horizon IV.

1. Faune du Pléistocène inférieur (=Villafranchien)

A. Phase I (Horizon I)

$$
\begin{gathered}
\text { Ord. Proboscidea } \\
\text { Zygolophodon borsoni ( } \left.\mathrm{H}_{\mathrm{AYs}}\right)
\end{gathered}
$$

Matériel: Araci-Fîntîna Fagului - Uncinatum sin. fragmentaire.

Les faces antérieure et postérieure de l'os sont un peu endommagées du côté interne, ce qui ne nous a permis de prendre qu'approximativement son diamètre antéro-postérieur $(\sim 136 \mathrm{~mm})$; en revanche, nous avons pu mesurer le diamètre transverse maximum qui atteint $134 \mathrm{~mm}$; la hauteur, en arrière de la facette d'articulation pour le magnum, devrait avoir $120 \mathrm{~mm}$ environ.

Généralement, la morphologie et les proportions excluent la possibilté que cet os appartienne à un Eléphant et plaident en faveur de son rattachement à un Mastodonte; les grandes dimensions et le rapport longueur/largeur $<1$ montrent nettement que la pièce de Fîntîna Fagului ne pouvait pas provenir d'un Anancus arvernensis; nous l'attribuons par conséquent à Zygolophodon borsoni. Il convient de souligner encore les étroites affinités de cet os avec l'onciforme du spécimen de petite taille de Z. borsoni de Vialette (J. VIRET 1954).

\section{Anancus arvernensis (CRoizet \& Jobert)}

Matériel: Vîrghiş I - Secteur Ouest $-\mathrm{M}_{3}$ dext. fragmentaire

Ghidfalău

$-\mathrm{M}_{3}$ sin. fragmentaire

- M2 dext. (Pl. I, fig. 2)

La morphologie des dents de Vîrghiş I, très caractéristique, nous dispense d'en faire toute description. L'état trop fragmentaire des pièces nous a empêché de prendre des mensurations et nous signalons seulement la largeur de la $\mathrm{M}_{3}$ dext. qui est de $94 \mathrm{~mm}$.

La pièce de Ghidfalău représente le germe de $\mathrm{M}_{2}$ dext. Ses dimensions sont indiquées ci-dessous:

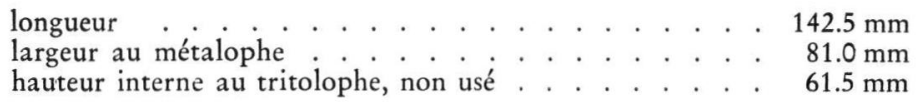




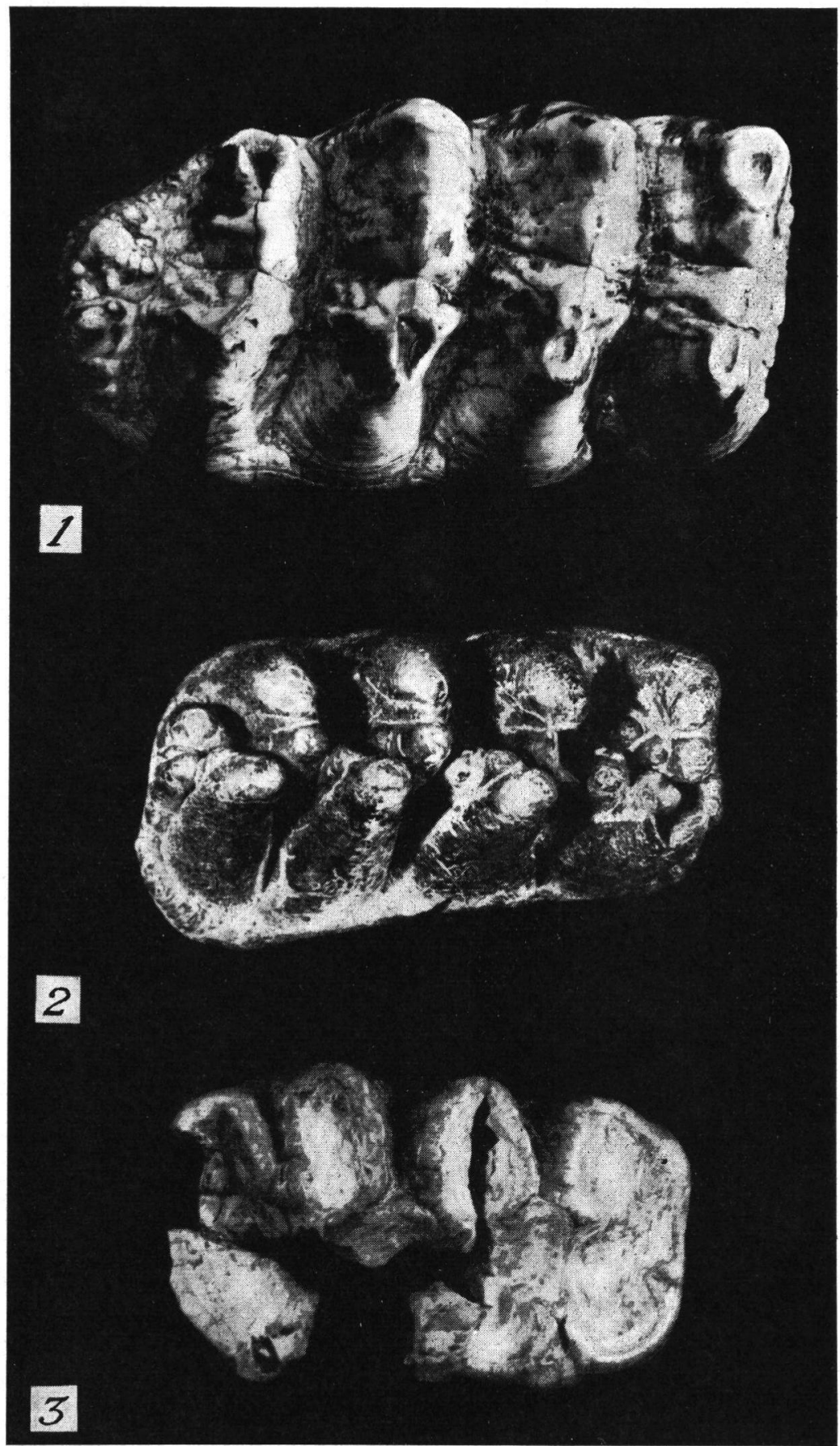

Planche I. Fig. 1. Zygolophodon borsoni (Hays). Racoşul de Sus (Bassin de Baraolt). $\mathrm{M}_{3}$ dext., vue occlusale. Fig. 2: Anancus arvernensis (Cr. et Joв.). Ghidfalău (Bassin de Sf. Gheorghe). $\mathrm{M}_{2}$ dext., vue occlusale. Fig. 3: Anancus arvernensis (Cr. et Job.). Ariujd (Bassin de Baraolt). M1 dext., vue occlusale. $(1 / 2)$. 


\section{Ord. Perissodactyla \\ Dicerorbinus cf. megarbinus (DE CHRISTOL)}

Matériel: Araci-Fîntîna Fagului - Crâne et mandibules fragmentaires, $\mathrm{M}^{2}, \mathrm{M}^{3}$ et $\mathrm{M}_{3}$, d'un même sujet sénile (Pl. II, fig. 1; fig. 3-5).

Vîrghiş I-Secteur Ouest $\quad-\mathrm{M}^{2}$ dext. fragmentaire (Pl. II, fig. 2)

$\mathrm{C}$ rân e. De la tête osseuse brisée nous avons seulement les nasaux, conservés entièrement, presque tout le toit cranien et l'arcade zygomatique gauche.

Nous décrirons surtout les nasaux qui permettent une série d'observations importantes concernant les caractères utilisés habituellement dans la systématique des Rhinocéros. Ces os sont allongés et relativement étroits (tableau 3); leur face supérieure, relevée en bosse pour soutenir la corne antérieure, possède de nombreuses rugosités, généralement serrées et basses, qui forment une sorte de plaque compacte; celle-ci, délimitée nettement à sa partie antérieure et sur les côtés, devient graduellement lisse en arrière et se confond avec la partie postérieure des nasaux. Cette plaque, à son extrémité proximale, présente deux sillons symétriques, disposés latéralement, qui commencent chacun au bord du nasal et avancent vers la ligne médiane sans l'atteindre. Au voisinage du point de départ du sillon gauche il y en a encore un autre, dirigé obliquement en haut et en avant, qui finit près du sommet rugueux. Ce deuxième sillon donne naissance à une ramification qui décrit un

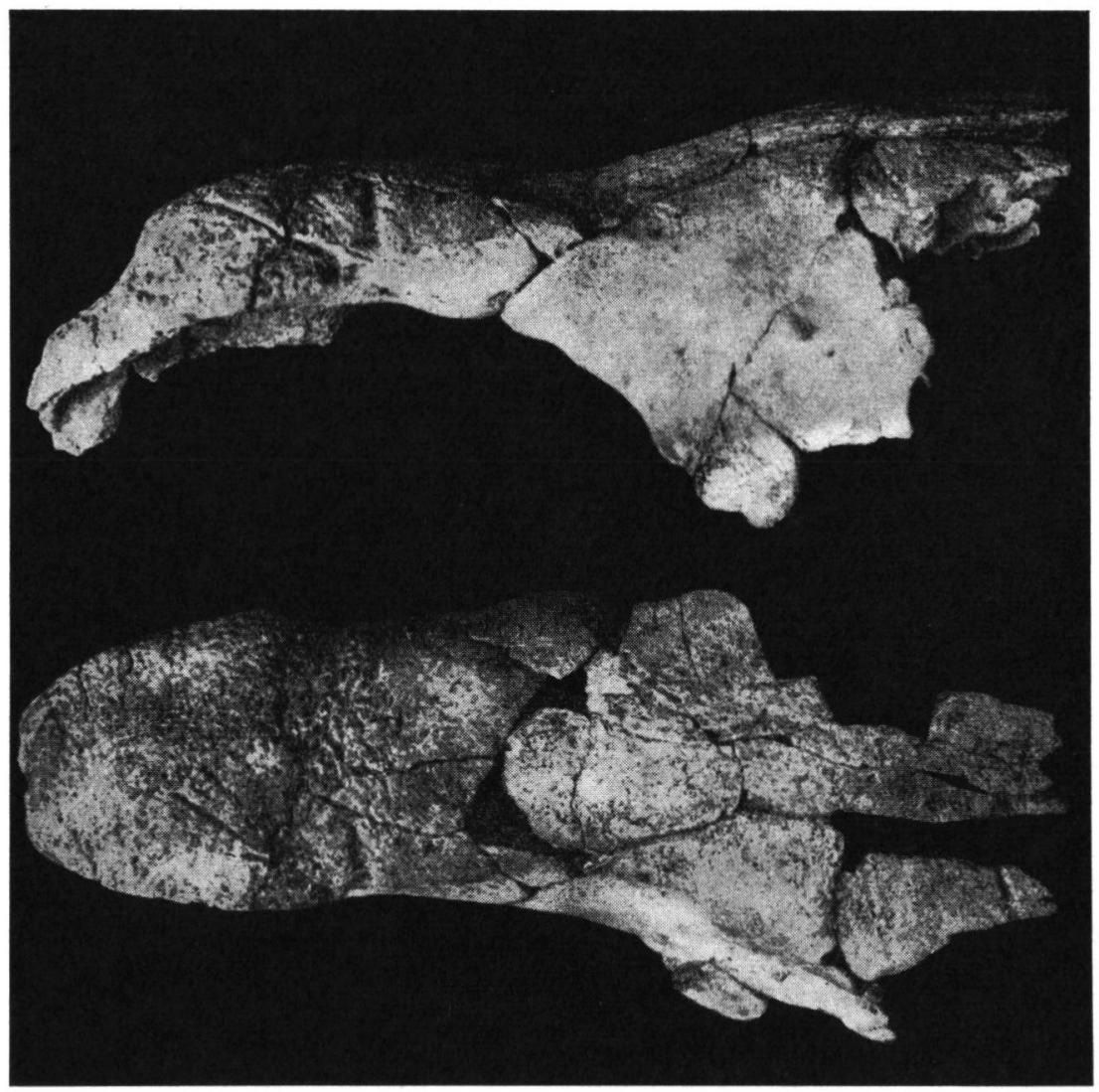

Fig. 3. Dicerorbinus cf. megarbinus (DE CHRIST.), femelle. Araci-Fîntîna Fagulu (Bassin de Baraolt). Crâne, partie antérieure: face latérale (en haut), face supérieure (en bas) $(1 / 4)$. 
lange arc de cercle le long du bord nasal correspondant. Du côte droit, on n'observe aucune trace de telle formation (fig. 3 ).

Une structure semblable, mais plus régulière, a été décrite par E. Thenius (1955) sur des exemplaires femelles de Dicerorbinus megarbinus provenant de Hajnačka et Montpellier.

Sur la face inférieure des nasaux, à leur partie antérieure, se conservent les traces d'une cloison ossifiée, relativement mince, dont la longueur mesure $128 \mathrm{~mm}$. Il semble cependant, autant que l'on en puisse juger par l'état fragmentaire de la pièce, que la cloison proprement dite était plus courte, sa partie postérieure étant formée par une protubérance de renforcement. De chaque côté de la moité proximale de la cloison, se trouve une dépression qui s'atténue vers la partie postérieure; dans cette portion, les bords des nasaux sont faiblement saillants. Deux sections transversales, la première au niveau de la cloison, la deuxième en arrière de celle-ci montrent cette conformation (fig. $4 \mathrm{~A}, \mathrm{~B}$ ). L'échancrure nasale est très profonde.

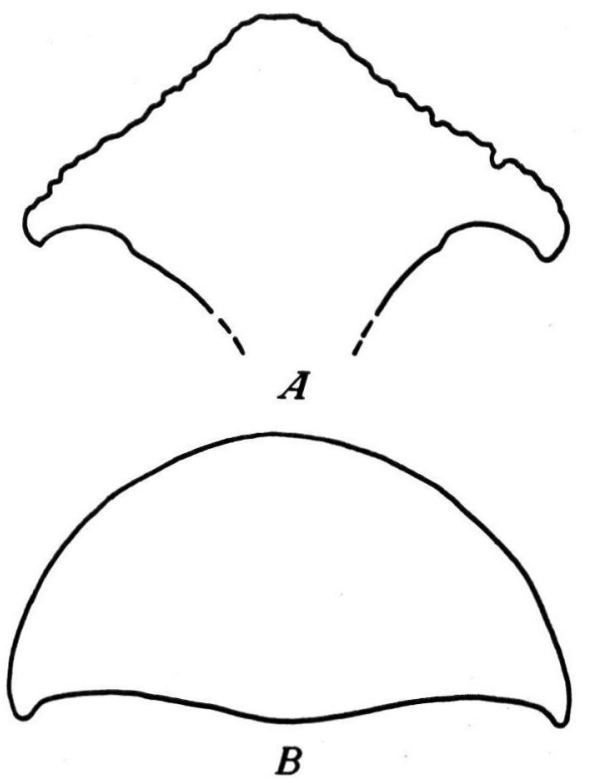

liig. 4. Dicerorbinus cf. megarbinus (DE CHRIST.), femelle. Araci-Fîntîna Fagului (Bassin de Baraolt). Sections transversales des nasaux: A. au niveau de la cloison nasale; $B$. en arrière de la cloison nasale. $(1 / 2)$.

Les frontaux présentent, eux aussi, une proéminence médiane, plus réduite, qui supportait la corne.

En ce qui concerne la partie postérieure du crâne, nous relevons seulement que les crêtes pariétales sont très atténuées.

Malgré la forte taille du spécimen, le crâne, dans l'ensemble, reste assez gracile. L'étroitesse des nasaux, le maigre développement des bosses d'insertion pour les cornes et les crêtes pariétales très réduites fournissent des arguments qui prouvent le sexe femelle de l'individu. L'usure très poussée des dents, ainsi que l'effacement complet des sutures montrent son âge bien avancé.

Mandibule. Seuls deux fragments de la même mandibule droite valent d'être décrits. Le premier représente la partie postérieure de la branche horizontale avec $\mathrm{M}_{3}$ et la paroi distale de $\mathrm{M}_{2}$ (fig. 5). Ce qui frappe à la mandibule c'est l'épaisseur trés accusée au niveau de la dernière molaire (voir le tableau 3). 


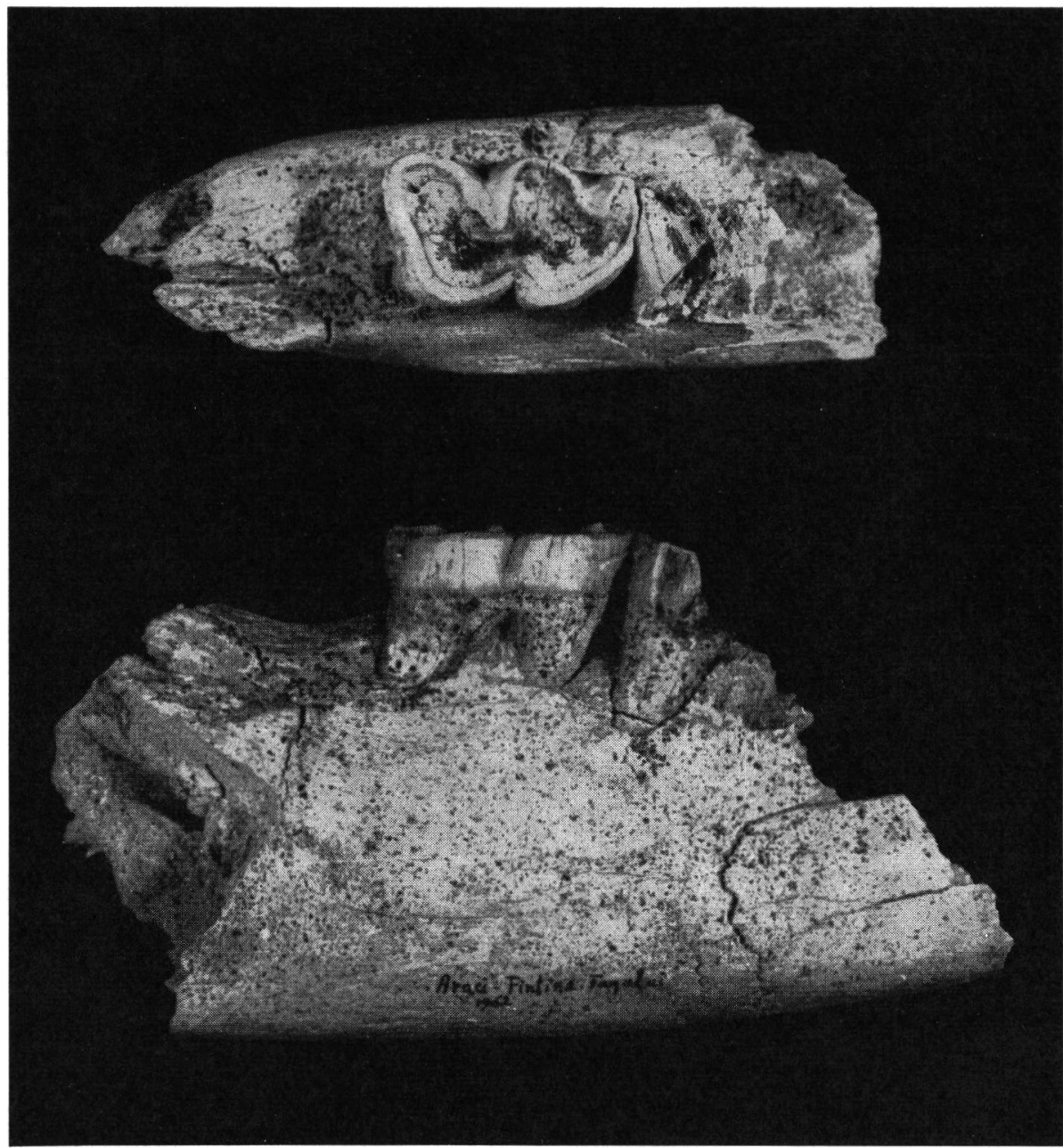

Fig. 5. Dicerorbinus cf. megarbinus (DE CHRIST.), femelle. Araci-Fîntîna Fagului (Bassin de Baraolt). Mandibule, branche horizontale dext., fragment postérieur avec $\mathrm{M}_{3}$ : vue occlusale (en haut), vue externe (en bas). ( $1 / 2)$.

On peut conclure que le Rhinocéros de Fîntîna Fagului se distingue nettement par la massiveté de la mandibule, surtout comparativement à D. etruscus.

Le deuxième fragment représente la partie antérieure de la branche horizontale à laquelle nous nous sommes rapportés. On remarque les alvéoles de $P_{2}$ et $P_{3}$. En avant et en dessous de $\mathrm{P}_{2}$, il y a un double trou mentonnier.

Dentition supérie ure. ${ }^{3}$ ) Parmi les jugales recueillies avec le crâne que nous venons de décrire, il y en a dont le crochet forme un angle très ouvert avec le métalophe (Pl. II, fig. 1). C'est là probablement, comme l'ont montré entre autres H. FALCONER (1868), P. Leonardi (1947) et tout récemment A. Azzaroli (1963), un trait caractéristique de Dicerorbinus megarbinus.

3) Les dimensions ont été prises ainsi: longueur $=$ longueur de l'ectolophe à $1,5-2 \mathrm{~cm}$ au-dessus du collet; largeur = largeur à la base de la couronne (voir aussi W. O. Dietrich 1945 et U. LeHMANN 1954). 
La $\mathrm{M}^{2}$ droite de Vîrghiş I (Pl. II, fig. 2) complète les données que nous possédons sur la dentition du grand Rhinocéros de la Dépression de Braşov. Le crochet a la base large et l'extrémité pointue; ainsi que dans les dents de Fîntîna Fagului, l'angle entre le métalophe et le crochet est très ouvert et présente une petite excroissance. L'ectolophe présente aussi deux minces excroissances (les "combing plates" de H. Falconer 1868); ces dernières et le crochet sont convergents. Cette morphologie, jointe aux grandes dimensions, approche sensiblement la dent de Vîrghiş des molaires de Montpellier décrites minutieusement par H. FALCONER (1. c.).

Dentition inférieu re ${ }^{4}$ ) La $\mathrm{M}_{3}$ du fragment de mandibule droite de Fîntîna Fagului, bien que très usée, permet quelques observations (fig. 5): sa paroi labiale est séparée en deux parties à peu près égales par un sillon qui s’arrête à $5 \mathrm{~mm}$ au-dessus du collet; nous signalons ce caractère parce que les $\mathrm{M}_{3}$ de Dicerorhinus sp. (Iarăş-Cariera Nouă) et de D.etruscus, que nous utilisons pour des fins comparatives, présentent le même sillon jusqu'à la base de la couronne. Le cingulum, à position presque horizontale (H. G. Stehlin 1930), est limité aux parois mésiale et distale de la dent. L'épaisseur de l'émail est remarquable $(4 \mathrm{~mm})$. Les dimensions de la molaire sont indiquées dans le tableau 3.

La longueur alvéolaire de $P_{2}$ et $P_{3}$ mesure respectivement 31 et $40 \mathrm{~mm}$.

Dans l'ensemble, les dents, autant supérieures qu'inférieures, sont encore assez brachyodontes.

R a p ports e t différ e n c es. Le Rhinocéros de Fîntîna Fagului, par ses dimensions craniennes et dentaires, se range près de grands spécimens de Dicerorbinus megarbinus de Montpellier-Roussillon. Par la présence d'une cloison nasale ossifiée, notre exemplaire se distingue suffisamment de D. megarhinus, tel que l'ont fait connaître depuis G. Cuvier toute une série de savants. Il semble toutefois que certains sujets, probablement de sexe mâle du Roussillon, avaient déjà un commencement de septum nasal, si l'on tient compte de la découverte de Millas (E. Thenius 1955).

Les représentants plus tardifs de D. megarbinus de Hajnačka paraissent avoir constamment une cloison nasale partiellement ossifiée chez les mâles.

Une fructueuse parallèle nous a permis le Rhinocéros de Vialette, chez lequel les deux sexes semblent pourvus d'une cloison nasale, plus ou moins développée.

L'exemplaire de Fîntîna Fagului se rapproche beaucoup, par la grande extension de son échancrure nasale, du spécimen femelle de Vialette, figuré par E. Thenius (1. c., planche, fig. 3 et 4), ayant, comparativement à ce dernier, les nasaux un peu plus épais et plus larges, mais sans atteindre les proportions du sujet mâle de la même localité. Il faut mentionner encore que la cloison nasale est beaucoup moins étendue vers la partie postérieure chez notre spécimen. Cela lui confère apparemment un cachet plus archaïque.

En présence des molaires seulement, nous n'aurions pas hésiter à réunir notre matériel à l'espèce de Montpellier-Roussillon. Les caractères craniens nous imposent cependant plus de prudence.

En conclusion, on peut accepter que le Rhinocéros de Araci-Fîntîna Fagului et Vîrghiş I est très probablement un descendant de D. megarbinus du Pliocène, ainsi que le Rhinocéros de Vialette avec lequel il a les affinités les plus étroites, malgré sa taille un peu plus grande.

Notre spécimen est de taille nettement supérieure à celle de D.etruscus villafranchien et c'est pourquoi il nous semble inutile d'insister sur leurs caractères différentiels.

4) Les mensurations ont été prises comme suit: longueur = longueur de la paroi interne à 1,5-2 $\mathrm{cm}$ au-dessus du collet; largeur = largeur maxima aux lobes antérieur et postérieur à la base. 


\section{T a pirus cf. arvernensis Devèze \& Boulllet}

Matériel: Vîrghiş I-Secteur Ouest - Deux fragments du même arc mandibulaire avec $P_{3}, P_{4}$ fragmentaire, $M_{1}$ et $M_{2}$ sin. (fig. 6)

Description. Les fragments représentent, le premier la région symphisaire, le second une grande partie de la branche horizontale gauche.

La région symphisaire est détériorée à l'avant, où se sont conservés seulement les alvéoles des canines. Le diamètre transverse dans la zone rétrécie, en arrière des canines, atteint $33.5 \mathrm{~mm}$. La branche horizontale gauche est cassée en avant des alvéoles de $\mathrm{P}_{2} ; \mathrm{P}_{3}$, $\mathrm{P}_{4}$ dont la moitié postérieure manque, $\mathrm{M}_{1}$ et $\mathrm{M}_{2}$ sont les seules dents en place; en arrière de $\mathrm{M}_{2}$ la mandibule est également brisée.

Les mensurations dentaires sont les suivantes:

\begin{tabular}{|c|c|c|c|c|c|}
\hline & & $\mathrm{P}_{3}$ & $\mathrm{P}_{4}$ & $\mathrm{M}_{1}$ & $\mathrm{M}_{2}$ \\
\hline or & & 20.2 & 21.5 & 22.5 & $23.8 \mathrm{~mm}$ \\
\hline largeur antérieure & & . . 15.3 & 17.0 & 16.5 & $17.3 \mathrm{~mm}$ \\
\hline postérieure & & . . 16.0 & - & 15.6 & $16.0 \mathrm{~mm}$ \\
\hline
\end{tabular}

La longueur alvéolaire de $P_{2}$ atteint $21.0 \mathrm{~mm}$.

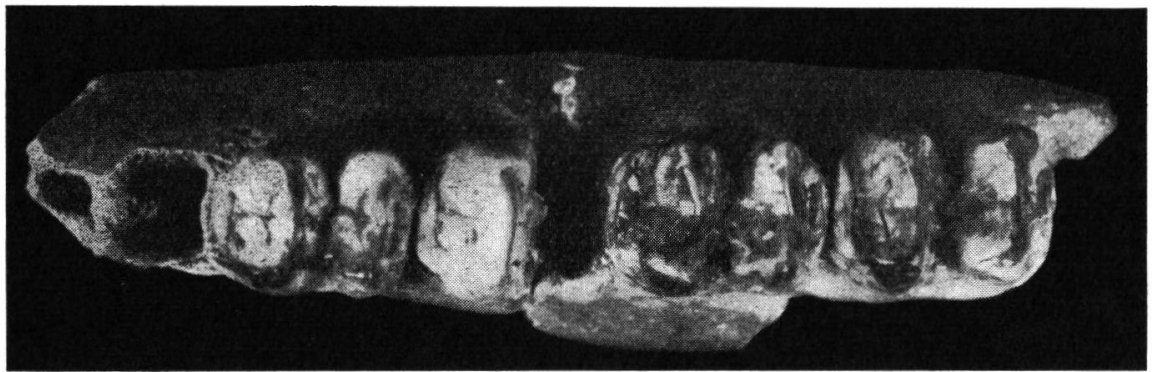

Fig. 6. Tapirus cf. arvernensis Dev. et BouIlL. Vîrghiş I, Secteur Ouest (Bassin de Vîrghiş). Mandibule, branche horizontale sin., avec $\mathrm{P}_{3}-\mathrm{M}_{2}$, vue occlusale. (1/1).

$\mathrm{R}$ a p ports et différences. Il est difficile de se faire une idée très exacte sur l'appartenance spécifique du Tapir de Vîrghiş seulement d'après les restes que nous venons de décrire. Pour le moment, nous ne connaissons pas la structure de son crâne qui aurait été décisive dans ce problème.

Les espèces susceptibles d'avoir existé dans notre région au commencement du Pléistocène, dans l'état actuel des connaissances, sont Tapirus hungaricus v. MAYER et T.arvernensis DEv. \& BouilL. D'après les mensurations des dents, on peut convenir que notre spécimen a plus d'affinités avec $T$. arvernensis, présentant comme celui-ci une taille plus robuste ( $\mathrm{H}$. v. Meyer $1867, \mathrm{D}$. del CAMPana 1910) par rapport à T. hungaricus. Bien que l'on puisse convenir aussi que ce critérium n'est pas toujours suffisant, jusqu'à la découverte d'un nouveau matériel plus significatif, nous attribuons les deux fragments de mandibule de Vîrghiş à T. arvernensis.

Dans les listes successives sur la faune de Căpeni, qui représente le même horizon qu'à Vîrghiş, on constate des vues différentes sur les Tapiridés: T. Konmos (1935) mentionne un Tapir, mais ses réserves sur l'appartenance spécifique de celui-ci s'expriment par un point d'interrogation; M. MotTL (1939) signale T. bungaricus; M. KRETzor (1954), en revanche, s'abstient de toute détermination précise indiquant un Tapirus sp. indet.

Bien que les deux espèces $T$. hungaricus et $T$. arvernensis soient représentées, toutes les deux, en Tchécoslovaquie dans l'association faunique de Hajnačka (O. FEJFAR 1962), il nous semble, d'après notre documentation actuelle, prématuré d'admettre cette coexistence aussi dans le Bassin de Baraolt. Il est bien possible au contraire que l'on soit à Căpeni et Vîrghiş en présence d'une seule espèce inséparable de Tapirus arvernensis. 


\section{Ord. Artiodactyla \\ Propotamochoerus cf. provincialis (Gervais)}

Matériel: Vîrghiş I-Secteur Ouest - Humérus dext., fragment de diaphyse.

Propotamochoerus provincialis a été déjà indiqué dans l'association faunique de Căpeni par 'T. Konmos (1935). Plus tard, M. MotrL (1939) mentionne deux $\mathrm{M}^{3}$ de la même localité qu'elle attribue à la race minor de cette espèce. La liste dressée par M. Kretzor (1954) comprend aussi $P$. cf. provincialis.

Il semble par suite bien probable que le fragment d'humérus de Suidé de taille modeste, que nous possédons, dénote la présence de la même espèce, qui aurait persisté au commencement du Pléistocène, non seulement dans la Dépression de Braşov, mais aussi dans le Sud de la Moldavie à Măluşteni (I. Simionescu 1930).

\section{Cervus sp. (taille d'un Capreolus)}

Matériel: Căpeni - Mandibule dext. fragmentaire avec $\mathrm{P}_{2}-\mathrm{M}_{3}$.

Description. La mandibule est assez mal conservée, de toute la série jugale seulement $\mathrm{P}_{3}$ étant complète; les autres dents sont plus ou moins endommagées.

La rangée dentaire mesure $69.4 \mathrm{~mm}$ de longueur aux alvéoles et $66 \mathrm{~mm}$ à la surface masticatrice. A. Косн (1880) indique des dimensions semblables pour une mandibule qu'il attribue à Cercus capreolus L. fossilis, provenant aussi du lignite de Căpeni (longueur $\left.\mathrm{P}_{2}-\mathrm{M}_{3}=65 \mathrm{~mm}\right)$.

Notre pièce frappe, à première vue, par le degré général de brachyodontie et par la persistance du pli palaeomeryx sous une forme atténuée; on observe encore que $\mathrm{P}_{2}$ est assez développée; $\mathrm{P}_{3}$ et $\mathrm{P}_{4}$ ont les longueurs à peu près égales; en jugeant par son empreinte en lignite, $\mathrm{P}_{4}$ avait le métaconide soudé au paraconide (type molarisé).

Le cingulum est assez bien exprimé et toutes les molaires possèdent une colonnette externe relativement puissante; à $\mathrm{M}_{3}$, entre le second et le troisième lobe, il n'y a que l'esquisse d'une telle formation.

Dans l'ensemble, la dentition se rapproche beaucoup, par sa morphologie et les dimensions, de celle du Chevreuil actuel et c'est pourquoi A. Косн (1880) avait inscrit C. capreolus fossilis dans l'association faunique de Căpeni.

$\mathrm{R}$ a p ports et différ e n ces. La détermination, non seulement spécifique, mais encore générique, du petit Cerf de Căpeni est très délicate d'après cet unique document et nos comparaisons avec les Cervidés de la fin du Pliocène et du commencement du Pléistocène n'ont pas donné un résultat concluant.

Il convient de rappeler cependant l'attention sur la découverte, dans l'Est européen, de quelques Cervidés primitifs pourvus de traces du pli palaeomeryx. Dans notre pays, ils apparaissent à Măluşteni et Bereşti en Moldavie méridionale (Capreolus australis DE SERREs, d'après I. Simionescu 1930, 1932); on les retrouve également en Pologne (Cervocerus wenzensis, T. Czyzewska 1960) et ils ne manquent non plus dans l'Union Soviétique (Cervus [Rusa] moldavicus, N. M. JanovsKaja 1954).

Il s'agit, paraît-il, d'un groupe, encore peu connu, à caractères archaïques, peut-être descendant des Pliocervinés. Le problème se complique en plus par la persistance, très possible dans les mêmes régions, des Capreolini primitifs de type Procapreolus (M. SCHLOSSER 1924).

Dans ces circonstances, pour discerner les rapports possibles de l'espèce de Căpeni avec ces différents Cervidés, nous préférons être mieux documentés. ${ }^{5}$ )

5) La révision des petits Cervidés du Sud de la Moldavie, ainsi que l'étude du matériel récemment découvert dans les dépôts villafranchiens d'Olténie par Mr. M. FERU, nous permettrons peutêtre quelques précisions dans ce domaine (C. R. et P.S.) 


\section{Bovini cf. Bison}

Matériel: Căpeni-Secteur I - Métacarpe sin., extrémité distale (fig. 7).

Le fragment représente l'articulation distale dont la morphologie exclue sa provenance d'un Cervidé, mais justifie son attribution à un Boviné de grande taille, probablement un Bison. La largeur de la pièce est indiquée dans le tableau 2.

T a ble a u 2

Dimensions comparées du canon antérieur de Bison ? de Căpeni (Bassin de Baraolt)

\begin{tabular}{l|c|c|c|c|c}
\hline & $\begin{array}{c}\text { Bison? } \\
\text { Căpeni-Sect.I }\end{array}$ & $\begin{array}{c}\text { Leptobos } \\
\text { elatus } \\
\text { Perrier }\end{array}$ & $\begin{array}{c}\text { Leptobos } \\
\text { stenometopon } \\
\text { Saint-Vallier } \\
\text { (J.VIRET 1954) }\end{array}$ & $\begin{array}{c}\text { Leptobos } \\
\text { etruscus } \\
\text { Senèze } \\
\text { (P. TEILHARD DE CHARDIN et } \\
\text { J. PIVETEAd 1930) }\end{array}$ & $\begin{array}{c}\text { Bison } \\
\text { palaeosinensis } \\
\text { Nihowan }\end{array}$ \\
\hline largeur de l'extrémité distale & 66.5 & $52.81)-58.02)$ & $57.0-67.0$ & 61.0 & 65.0 \\
\hline
\end{tabular}

1) J. Viret 1954; 2) P. Teilhard de Chardin et J. Piveteau 1930. Dans tous les tableaux les mensurations sont en $\mathrm{mm}$.

Afin de faciliter les comparaisons, nous avons introduit dans ce tableau encore quelques valeurs concernant les métacarpes de Leptobos de Perrier (Villafranchien inférieur) - le gisement le plus proche chronologiquement de celui de Căpeni - de Saint-Vallier (Villafranchien moyen) et de Senèze (Villafranchien supérieur). Nous avons emprunté aussi à P. Teilhard de Chardin \& J. Piveteau (1930) certaines mensurations relatives à Bison palaeosinensis, un des plus anciens Bisons connus en Asie.

On peut constater, en examinant ce tableau, que par sa largeur distale, le métacarpe de Căpeni dépasse visiblement les pièces correspondantes du Leptobos de Perrier. On peut encore noter que Saint-Vallier a fourni un seul document comparable au nôtre. Les métacarpes de $B$. palaeosinensis égalent par leurs dimensions la pièce de Baraolt.

Pour donner encore un argument en faveur de l'attribution du fossile qui nous intéresse à un Bison, nous ferons appel à la découverte d'une phalange I, très puissante, à Măluşteni, dépôt synchrone avec celui de Căpeni. Cette phalange, décrite et figurée par I. Simionescu (1930), a le rapport longueur/largeur de la diaphyse de 2, 37; le même rapport, d'après les données de G. MerLa (1949), pour Leptobos etruscus oscille de 2,66



Fig. 7. Bovini cf. Bison. Căpeni, Secteur I (Bassin de Baraolt). Canon antérieur sin., extrémité distale, vue antérieure. $(1 / 1)$. 


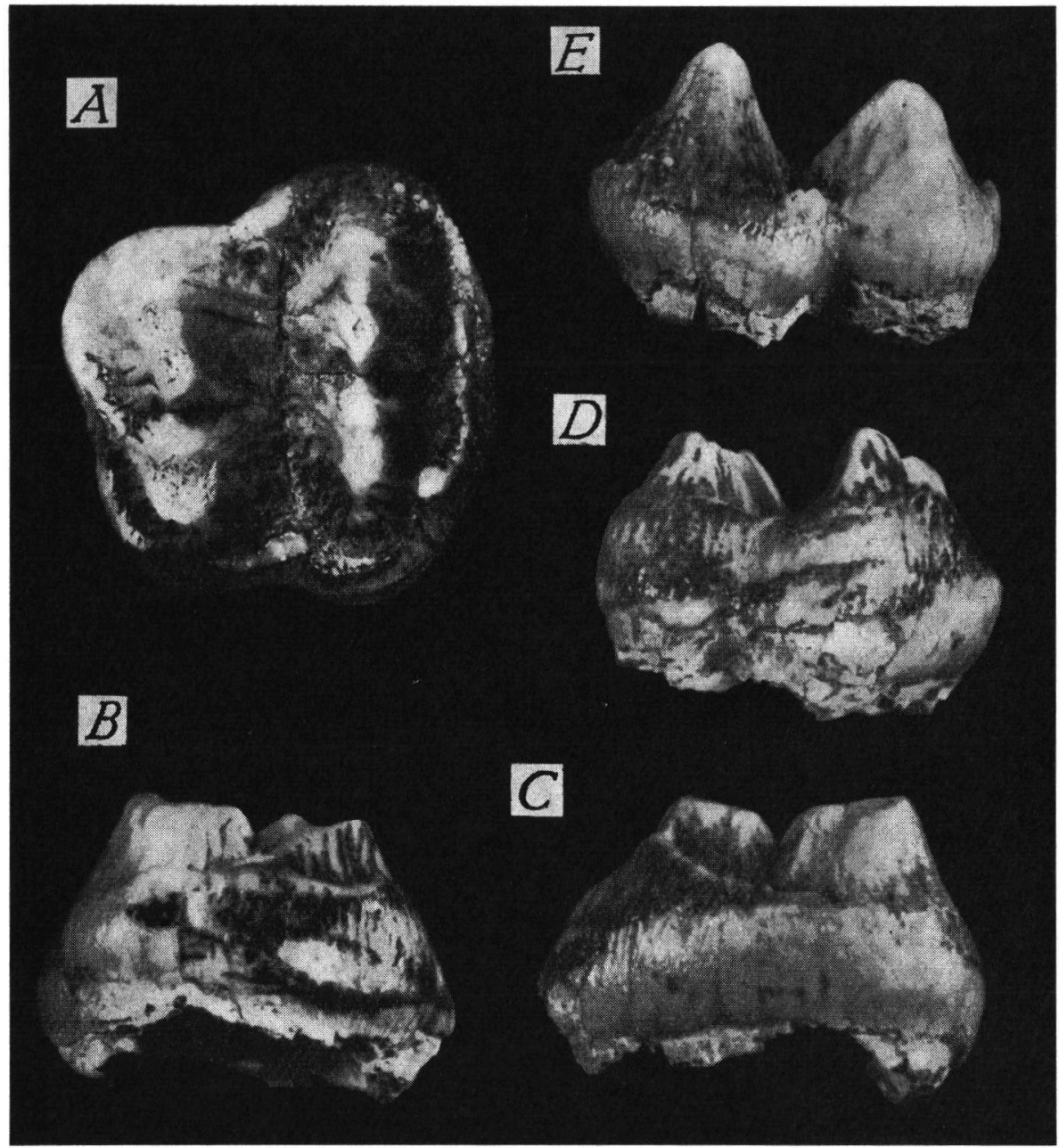

Fig. 8. Zyglophodon borsoni (HAys). Iarăs - Cariera Nouă (Bassin de Baraolt). D3 sin.: A. vue occlusale; B.vue antérieure; C.vue postérieure; D.vue interne; E.vue externe. (1/1).

Anancus arvernensis (CRolzet \& Jobert)

Matériel: Iarăş-Cariera Nouă Ariujd Ilieni
- Défenses très fragmentaires

- $\mathrm{M}^{1}$ dext. (Pl. I, fig. 3)

- Deux fragments de molaires.

De ce matériel nous ne décrirons que les pièces mieux conservées. Nous mentionnons toutefois, en jugeant d'après plusieurs fragments d'une même défense, que celle-ci pouvait atteindre jusqu'à $3 \mathrm{~m}$ de longueur.

La M1 dext. de Ariujd, usée complètement et endommagée du côté postéro-interne, comporte les dimensions suivantes:

longueur . . . . . . . . . . . . . $113.0 \mathrm{~mm}$

largeur du métalophe . . . . . . . . . . . . . $66.0 \mathrm{~mm}$

épaisseur de l'émail . . . . . . . . . . . 3 à $4 \mathrm{~mm}$ 
Une $\mathrm{M}^{1}$, également droite, qui nous a servi pour comparaison, signalée de la commune de Vladimir en Olténie par S. Athanasiu (1909), bien que plus fraîche, présente une morphologie tout à fait semblable et presque les mêmes dimensions que la molaire de Ariujd.

$$
\begin{gathered}
\text { Ord. Perissodactyla } \\
\text { Dicerorbinus sp. }
\end{gathered}
$$

\section{Matériel: Iarăş-Cariera Nouă $\quad-\mathrm{M}^{2} \sin$. (Pl. II, fig. 3) \\ Ilieni $\quad-\mathrm{P}_{3}($ ?) $\sin$.}

D e s c ription. La molaire supérieure de Cariera Nouă ressemble beaucoup à celles de Araci-Fîntîna Fagului et Vîrghiş I autant par sa morphologie que par sa robustesse. L'usure étant peu avancée, on observe que la crochet présente une base large et devient pointu à son extrémité; son angle de divergence avec le métalophe est assez ouvert; enfin, les mêmes "combing plates" apparaissent. Il y a cependant certaines différences entre cette molaire et celle de Vîrghiş qui se reflètent dans l'hypsodontie plus marquée et les dimensions un peu moindres de la première (tableau 3).

Le fragment de mandibule indique aussi un spécimen assez robuste. Dans l'ensemble, les dents sont plus hypsodontes et se distinguent facilement de celles de Araci-Fîntîna Fagului. $\mathrm{La} \mathrm{P}_{4}$ (long. $\mathrm{x}$ larg. ant. $\mathrm{x}$ larg. post. $=39.5 \times 28.0 \times 29.7 \mathrm{~mm}$ ) se caractérise par son cingulum bien développé, qui n'est pas restreint aux parois mésiale et distale, mais s'étend, bien que moins exprimé, aussi à la face labiale de la dent. La $\mathrm{M}_{3}$ présente, à son tour, un cingulum assez puissant dans sa partie antérieure, mais qui devient beaucoup moins accusé à sa paroi postérieure. Généralement, les formations cingulaires mésiale et distale sont situées assez haut et disposées obliquement.

$\mathrm{Du}$ lignite de Ilieni, nous possédons une $\mathrm{P}_{3}$ (?) gauche, qui se distingue par certaines particularités en quelque sorte inattendues pour un Dicerorhinus. Ainsi, la paroi externe de son lobe antérieur n'est pas convexe comme dans ce genre, mais sensiblement aplatie, même un peu concave à la limite avec le lobe postérieur. A cause de cette morphologie, le sillon qui sépare du côté labial les deux croissants s'efface dans son tiers médian.

Pour le moment, par manque de matériel comparatif plus complet, l'importance de ces modifications nous échappe; cependant, il n'est pas exclu qu'il s'agisse d'un cas extrême de variation individuelle. En raison de sa longueur $(=38 \mathrm{~mm})$, nous avons attribué provisoirement cette prémolaire à l'espèce de Iarăş-Cariera Nouă.

Dans la description des fossiles de Ilieni, F. Toula (1911) a mentionné, sous le nom de "Rhinoceros (Aceratherium ?) $\mathrm{spec}$ " une $\mathrm{P}_{2}$ gauche (long. $\mathrm{x}$ larg. $=33 \times 21 \mathrm{~mm}$ ). D'après l'ensemble de la faune et la position stratigraphique des couches ligniteuses, telle que nous l'avons définie précédemment, la présence d'un Aceratberium est tout à fait invraisemblable. Il est plus probable que cette dent appartienne aussi à l'espèce de IarăşCariera Nouă.

$\mathrm{R}$ a p ports et différences. Il est bien difficile à présent de pouvoir se faire une idée précise sur la physionomie du spécimen de Iarăş-Cariera Nouă; il se place au point de vue de la taille entre Dicerorbinus cf. megarbinus de Araci-Fîntîna Fagului et D. etruscus, tel que nous le connaissons de Iarăş-Cariera Veche où apparaissent des exemplaires très proches de ceux du Valdarno superiore. S’il faut chercher des affinités métriques, notre matériel correspond assez bien à Dicerorhinus "megarbinus" du Valdarno inferiore (A. Azzaroli 1963).

Dans le tableau 3, nous avons mis en parallèle les principales mensurations concernant les Rhinocéros du Pléistocène inférieur de la Dépression de Braşov; comme terme de comparaison nous avons choisi certaines pièces de notre pays et de l'étranger, afin de fournir une base plus exacte à nos remarques précédentes. 
Ta ble a u 3

Dimensions comparées craniennes et dentaires des Dicerorbinus villafranchiens du Bassin de Baraolt

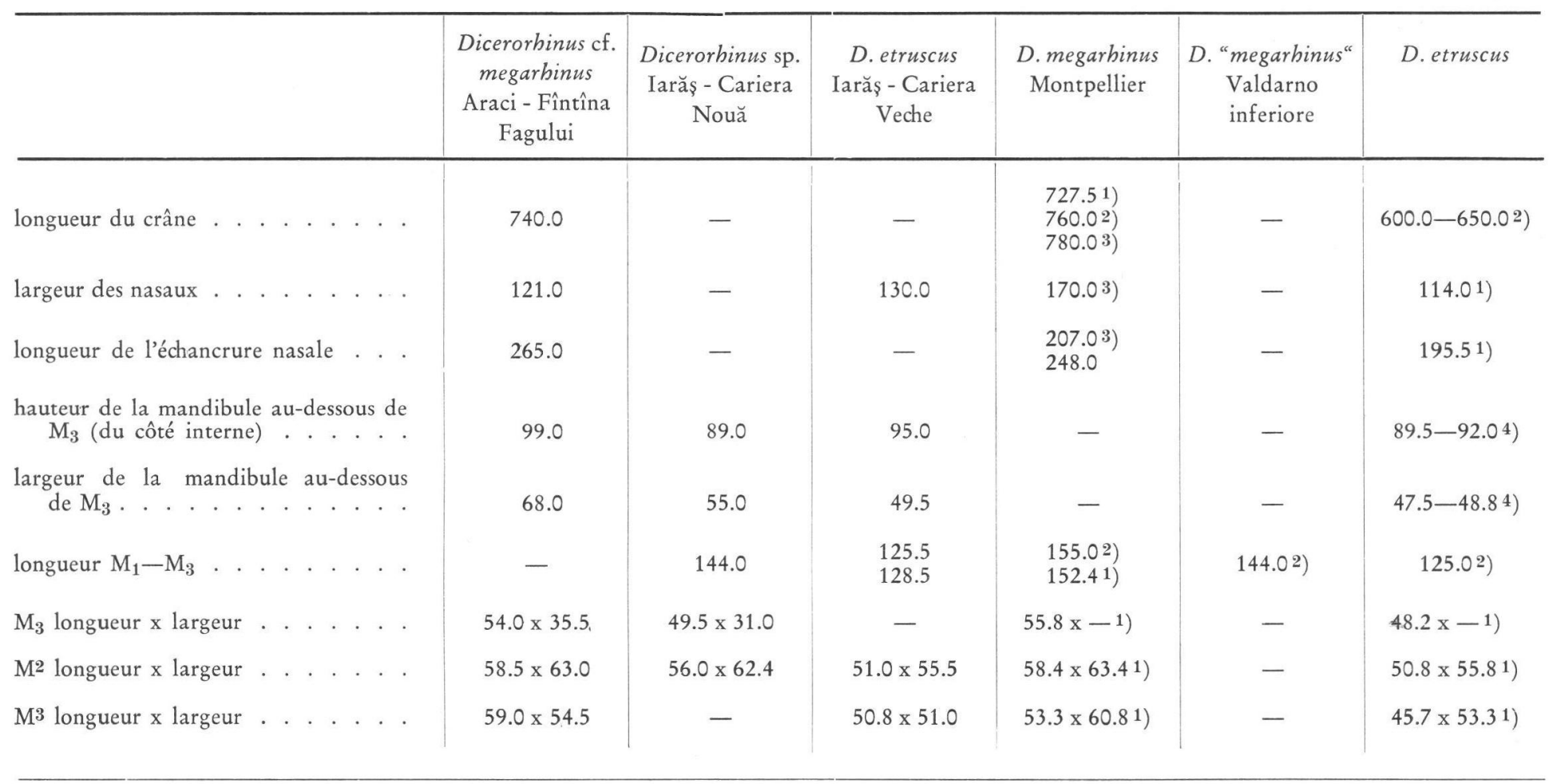

1) H. Falconer 1868; 2) A. Azzaroli 1963; 3) P. Gervats 1859; 4) matériel de Covrigi (Olténie) 
A l'exclusion de tout critérium de taille, assez significatif cependant, l'espèce de Cariera Nouă se distingue de D. megarhinus par des traits progressifs (hypsodontie plus manifeste,développement des formations dues au cingulum); elle se distingue à la fois de D. etruscus par certains caractères, que l'on peut qualifier d'archaïques (morphologie du crochet, angle plus ouvert entre ce dernier et le métalophe). Nous espérons que de nouvelles découvertes, plus importantes, nous fournissent l'occasion de revenir sur la place systématique du spécimen dont nous venons de nous occuper.
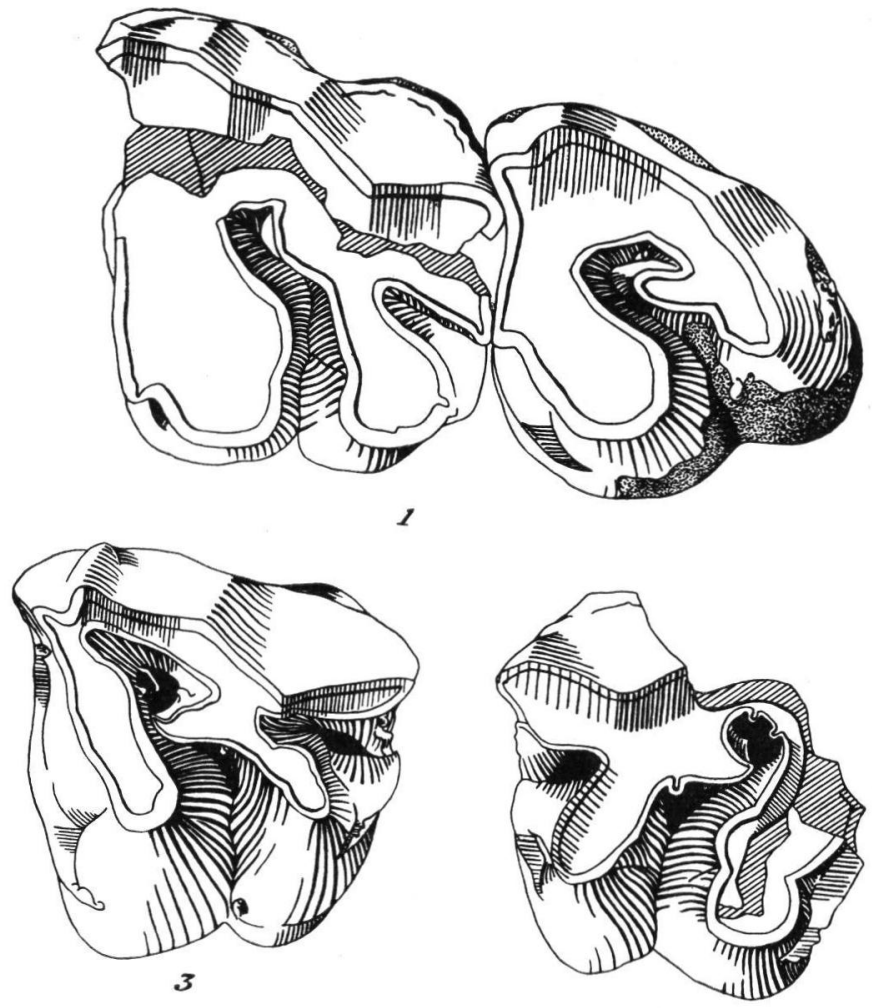

3

2



Planche II. Fig. 1: Dicerorhinus cf. megarbinus (DE CHrist.). Araci- Fîntîna Fagului (Bassin de Baraolt). M2-M3 sin., vue occlusale. Fig. 2: Dicerorhinus cf. megarbinus (DE CHRIst.). Vîrghiş I, Secteur Ouest (Bassin de Vîrghiş). M² dext., vue occlusale. Fig. 3: Dicerorhinus sp. Iarăş - Cariera Nouă (Bassin de Baraolt). M2 sin., vue occlusale. Fig. 4: Dicerorhinus etruscus FALc. Iarăş - Cariera Veche (Bassin de Baraolt). M1 $1 \mathrm{M}^{3}$ sin., vue occlusale. $\left({ }^{3 / 4}\right)$. 


\section{Dicerorbinus etruscus (FALCONER)}

Matériel: Iarăş-Cariera-Veche - Nasal sin. fragment (fig. 9)

- $\mathrm{M}^{1}-\mathrm{M}^{3}$ sin. (Pl. II, fig. 4)

- Mandibules fragmentaires, droite avec $\mathbf{P}_{3}-\mathbf{P}_{4}$ et gauche édentée. Toutes ces pièces proviennent très probablement d'un même individu.

$\mathrm{Nasal}$. Le fragment qui nous intéresse représente la portion proximale du nasal avec la partie postérieure de la région rugueuse pour l'insertion de la corne.

Comparativement au Rhinocéros femelle de Fîntîna Fagului, on observe que les rugosités sont très puissantes et nettement délimitées en arrière; des trois sillons latéraux, le médian, qui est le plus développé, se dirige obliquement en haut et en avant, mais s'efface bien vite après avoir pénétré dans la zone marginale rugueuse; las autres sillons, très courts, sont à peine indiqués. Malgré l'état fragmentaire de la pièce, on peut encore constater, sur sa face inférieure, que la cloison nasale était beaucoup plus forte et le bord latéral plus épais et plus proéminent.

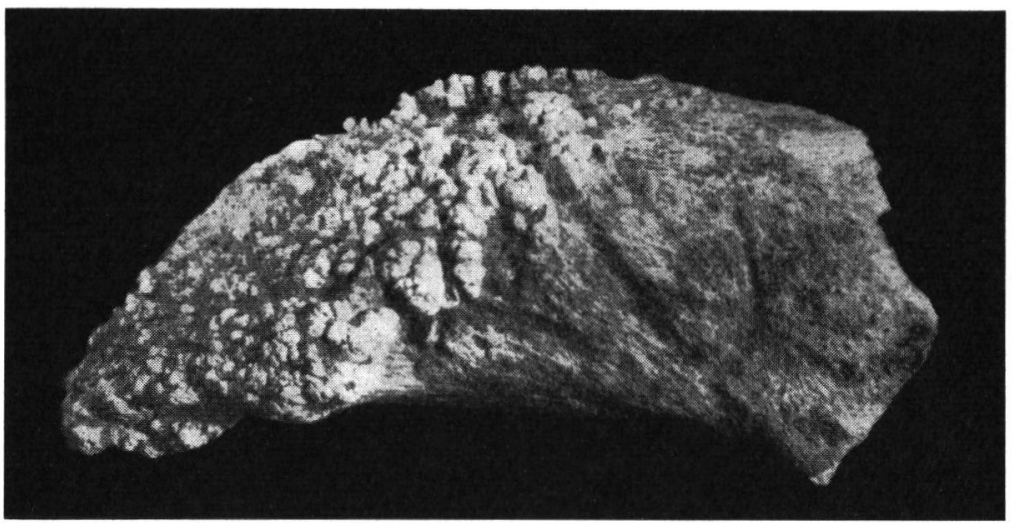

Fig. 9. Dicerorbinus etruscus (FALc.), mâle. Iarăş - Cariera Veche (Bassin de Baraolt). Nasal sin., vue latérale. $(1 / 2)$.

Toutes ces différences morphologiques et la grande largeur des nasaux, qui dépasse même en valeur absolue celle du spécimen de Fîntîna Fagului d'une taille évidemment plus grande, démontrent l'appartenance du matériel de Iarăş-Cariera Veche à un sujet mâle (tableau 3).

Mandibule. Les deux mandibules sont représentées seulement par les branches horizontales. La mandibule, la mieux conservée, nous a permis une comparaison utile avec la même pièce des autres Rhinocéros du Pléistocène inférieur du Bassin de Baraolt. Comme il résulte du tableau 3, la mandibule de D.etruscus montre des proportions différentes, parce qu'à une hauteur sensiblement égale, elle est moins épaisse, ayant par suite une allure plus élancée.

Dents su périeures. Pour ce qui est des $\mathrm{M}^{1}-\mathrm{M}^{3}$ (Pl. II, fig. 4), nous désirons indiquer seulement certaines caractéristiques permettant de les distinguer des mêmes dents de D. megarbinus.

Ainsi, dans l'ensemble, ces molaires, à part leur moindre taille, sont plus hypsodontes et le crochet forme avec le métalophe un angle moins ouvert, qui diminue encore avec l'usure.

Dents inférieures. La mandibule gauche possède seulement deux dents en place: $\mathrm{P}_{3}$ et $\mathrm{P}_{4}$. Ces prémolaires se caractérisent par un cingulum assez bien développé, qui est présent aussi sur la face labiale, spécialement du croissant antérieur. 
Voici les dimensions des prémolaires de Iarăş-Cariera Veche:

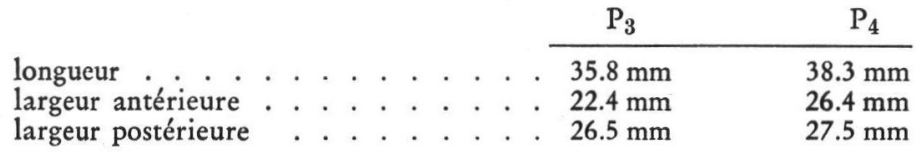

\section{Ord. Artiodactyla \\ Cervus sp. (Euctenoceros?)}

Matériel: Iarăş-Cariera Veche - Métacarpe sin. fragmentaire.

L'os est brisé à partie proximale, immédiatement au-dessous de la surface articulaire. Nous n'avons trouvé aucune différence par comparaison à un métacarpien de Euctenoceros des dépôts villafranchiens supérieurs de Bugiulești (Olténie).

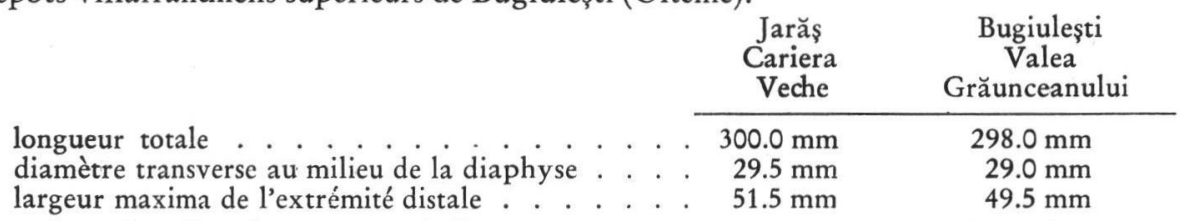

De même, la pièce de Iarăş ne diffère pas sensiblement du canon antérieur des autres Euctenoceros de l'Europe (A. Azzaroli 1947, J. Viret 1954).

Nous n'avons pas encore une opinion ferme sur l'appartenance spécifique de ce grand Cerf de Iarăş et l'unique document qui le représente est trop insuffisant pour en tirer une conclusion. Il est cependant très possible que l'on soit en présence d'une espèce de Euctenoceros.

$$
\begin{gathered}
\text { Ord. Carnivora } \\
\text { Ursus etruscus G. Cuvier }
\end{gathered}
$$

Matériel: Ilieni - I ${ }^{2}$ fragmentaire, C sup. dext., C sup. sin., $\mathrm{P}^{4}$ sin. fragmentaire, $\mathrm{M}^{1}$ sin. fragmentaire, $\mathrm{M}^{2}$ dext. et $\mathrm{M}^{2}$ sin., provenant d'un même individu (fig. 10).

L'usure des dents n'étant pas trop avancée, on peut reconnaître certains aspects morphologiques propres au stade évolutif des Ursidés du Pléistocène inférieur de notre

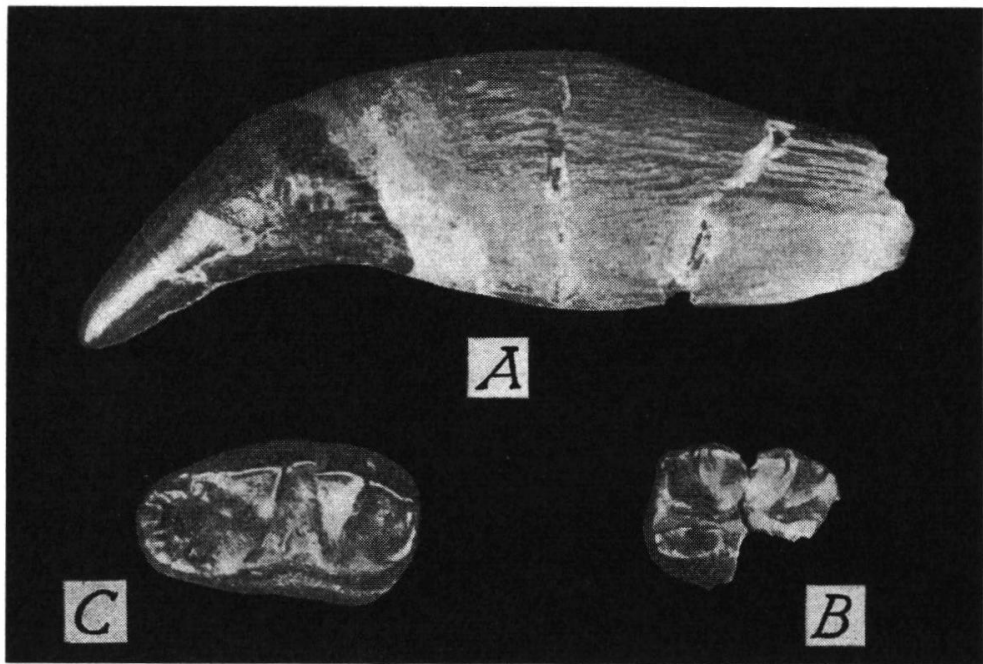

Fig. 10. Ursus etruscus G. Cuvier. Ilieni (Bassin de Ilieni). A. C supérieure sin., vue externe; B.M1 sin., vue occlusale; C.M2 dext., vue occlusale. (1/1). 
continent. Comparativement à l'Ours brun, on observe sur nos pièces, malgré la fluctuation des caractères, une brachyodontie plus visible, la forme sensiblement carrée de $\mathrm{M}^{1}$, $\mathrm{M}^{2}$ à talon encore réduit.

Les canines, par leur diamètre transverse pris au collet, semblent donner un caractère de différenciation entre les sexes (F.-E. Koвy 1949). Dans notre cas, il est possible d'accepter la présence d'un individu mâle.

Les dimensions des dents sont groupées ci-dessous:

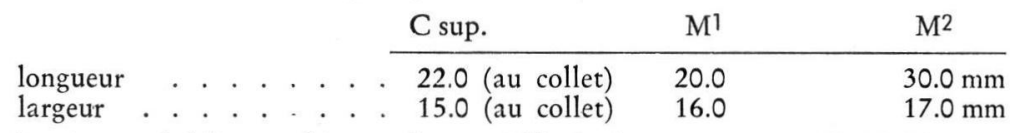

La volumineuse bibliographie sur les Ursidés (voir entre autres D. P. ERdBrink 1953), particulièrement les descriptions minutieuses du matériel du Valdarno superiore (G. RistoRi 1897), nous dispense d'insister sur les détails de la morphologie des dents trouvées à Ilieni. L'Ursidé de ce bassin pourrait offrir, tout au plus, encore une nuance, mais il ne dépasse pas les limites de variabilité de l'espèce et les men urations indiquent l'appartenance de notre matériel à un exemplaire de taille "normale" (J. VIRET 1954).

2. Faunes du Pléistocène moyen

A. Phase I (Horizon III - partie inférieure)

Ord. Proboscidea

Archidiskodon meridionalis (Nesti)

Matériel: Rotbav-Silvestru - Arc mandibulaire avec $\mathrm{M}_{3}$, fragmentaire (fig. 11)

- $\mathrm{P}_{4}$ sin., fragmentaire

- Scapulum sin., extrémité inférieure

- Fragments de mandibules, vertèbres, os longs.

L'arc mandibulaire est représenté par les branches horizontales avec les dernières molaires $\left(\mathrm{M}_{3}\right)$ en place, au niveau desquelles la paroi interne de la mandibule manque complètement, étant brisée. La symphyse, assez profondément cannelée sur sa face supérieure, se continue avec un bec dont le bout est cassé; à en juger par sa base, le rostre relativement court se dirigeait en avant et modérément en bas. Les quelques mensurations que nous avons pu prendre sont les suivantes:

\begin{tabular}{|c|c|c|}
\hline $\begin{array}{l}\text { rgeur maxima de l'arc mandibulaire en arrière de } \\
\text { rgeur maxima de la gouttière symphysaire } \\
\text { auteur de la branche horizontale au milieu de } \mathrm{M}_{3} \\
\text { auteur de la branche horizontale en avant de } \mathrm{M}_{3} \text {. } \\
\text { gole de convergence des branches horizontales }\end{array}$ & . & $\begin{array}{r}560 \mathrm{~mm} \\
82 \mathrm{~mm} \\
170 \mathrm{~mm} \\
198 \mathrm{~mm} \\
77^{\circ}\end{array}$ \\
\hline
\end{tabular}

Les dents de l'arc mandibulaire $\left(\mathrm{M}_{3}\right)$, dans un état très avancé d'usure, sont cassées dans la partie antérieure. Leur aspect est caractéristique pour $A$. meridionalis: la couronne large, les lames épaisses, l'émail légèrement plissé formant de petits sinus médians opposés, les figures d'abrasion tripartites à ellipses latérales. Voici quelques données concernant ces pièces:

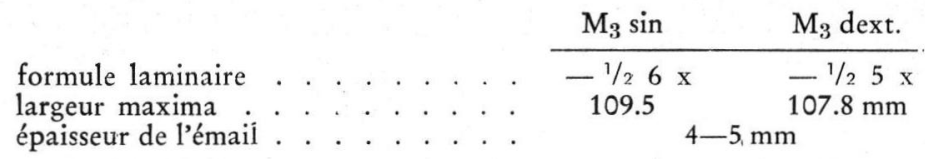

Ce qui frappe, de prime abord, c'est le desserrement accentué des lames (fig. 11) qui détermine une fréquence laminaire très basse, approximativement 4 . En considérant ce chiffre à lui seul, sans d'autres remarques, on pourrait se méprendre sur le degré d'évolution de l'Eléphant méridional de Rotbav. Il faut absolument tenir compte du fait que 


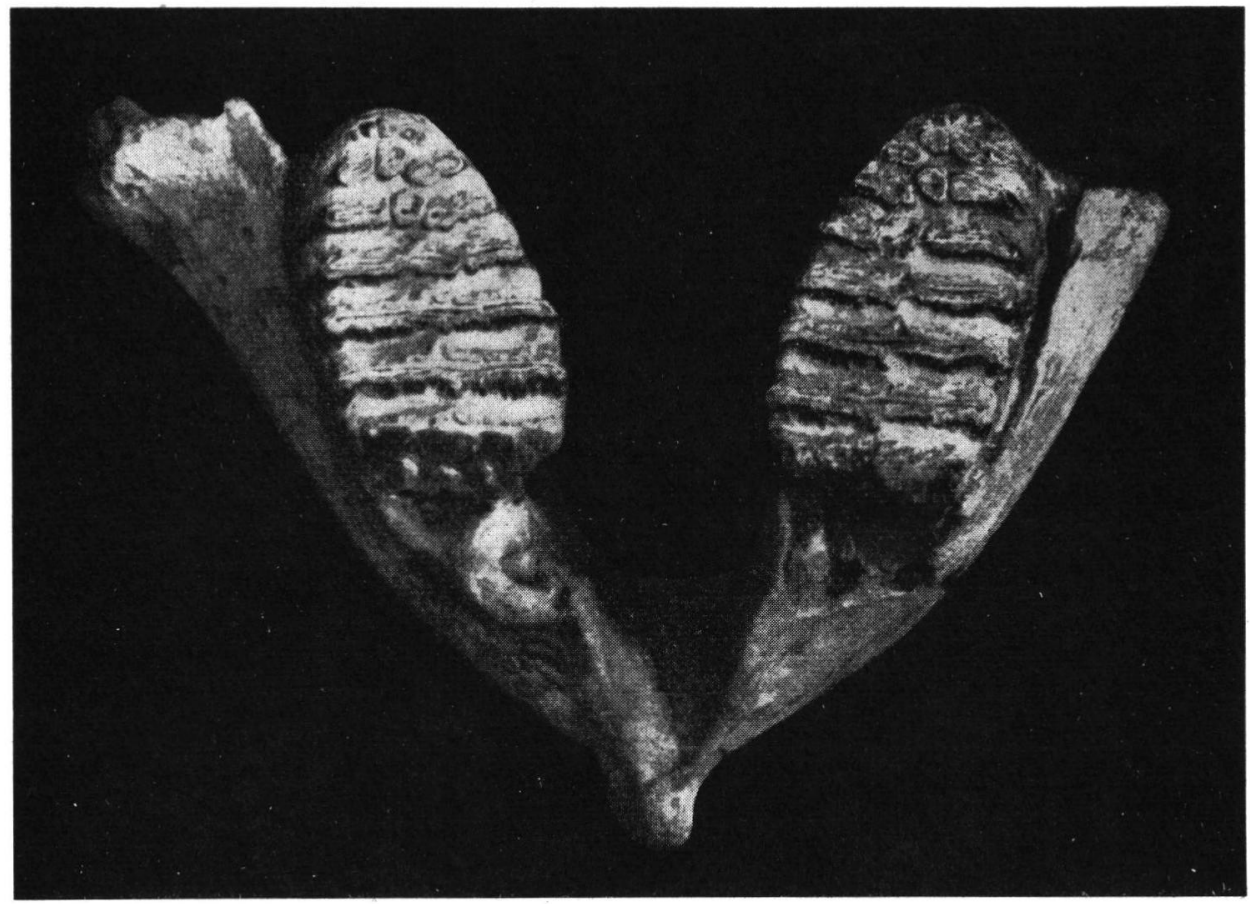

Fig. 11. Archidiskodon meridionalis (NESTI). Rotbav - Silvestru (Bassin de Baraolt). Arc mandibulaire avec $\mathrm{M}_{3}$, vue supérieure. (1/4).

nous sommes en présence des molaires inférieures très usées et spécialement de leur partie postérieure où la disposition en évantail des lames est plus accusée; dans ce cas la fréquence laminaire peut se réduire d'un tiers environ (H. F. Osborn 1942, R. VAufrey 1958 etc.).

La $\mathrm{P}_{4}$, très usée-même, est aussi brisée à sa partie antérieure. On n'observe que 5 lames assez épaisses et desserrées, dont l'émail à la tendance de former des sinus; la largeur maxima de la dent atteint $67 \mathrm{~mm}$.

Le fragment de scapulum, avec la cavité articulaire pour l'humérus, comporte les dimensions suivantes:

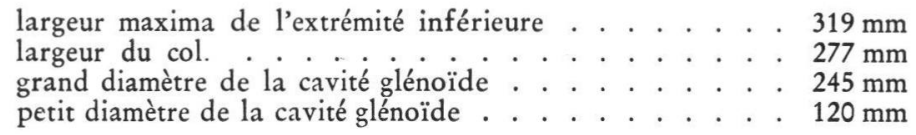

$$
\begin{gathered}
\text { Ord. Perissodactyla } \\
\text { Hippotigris cf. stenonis (CocchI) }
\end{gathered}
$$

Matériel: Rotbav-Silvestru - M sup. sin. (M1 ?) (fig. $12 \mathrm{~A}$ ).

La dent, par son protocône très court, suggère à première vue son rattachement à Hippotigris stenonis.

Nous donnons ci-dessous les mensurations de la pièce:

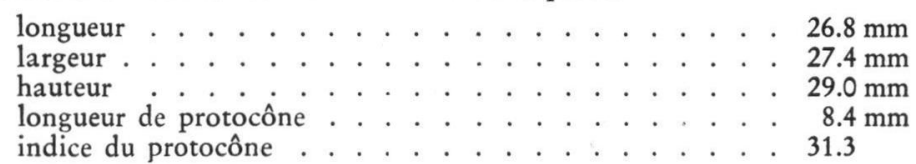




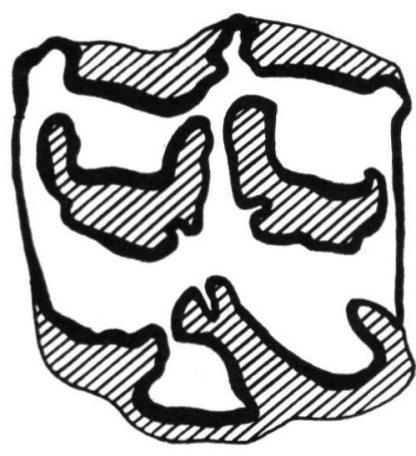

$A$

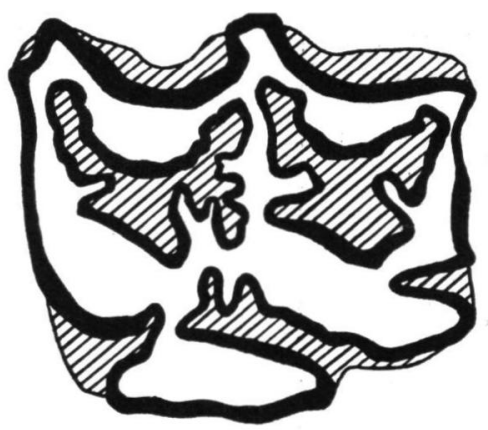

$B$

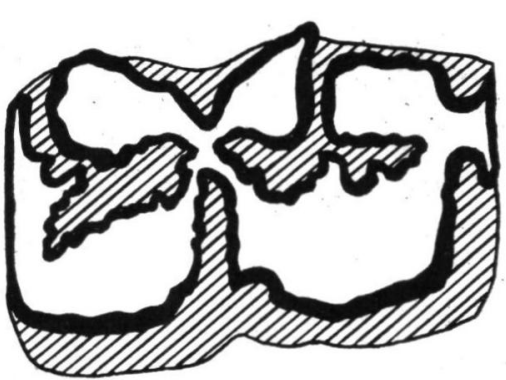

C

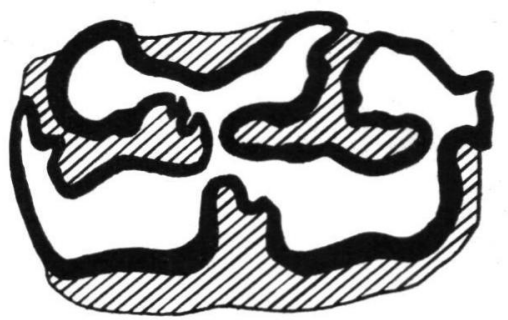

$E$

\section{$D$}

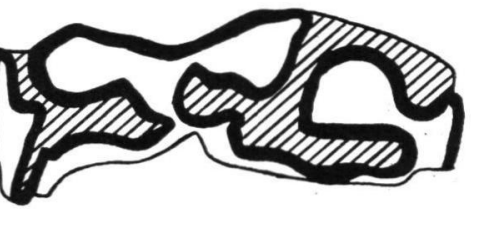

Fig. 12. A. Hippotigris cf. stenonis (CoccHI). Rotbav - Silvestru (Bassin de Baraolt). M1 ? sin., vue occlusale; B. Equus mosbachensis v. ReICH. Feldioara (Bassin de Baraolt). M2 ? sin., vue occlusale; C. Hippotigris süssenbornensis (Wüst). Rotbav - Cariera de sub Brazi, partie inférieure (Bassin de Baraolt). $\mathrm{P}_{4}$ sin., vue occlusale; D. Equus mosbachensis v. REICH. Rotbav - Dealul Tiganilor (Bassin de Baraolt). $\mathrm{P}_{2}-\mathrm{P}_{3}$ sin., vue occlusale; E. Equus sp. Bodoc (Bassin de Sf. Gheorghe). $\mathrm{P}_{3}$ sin,, vue occlusale. $(3 / 2)$ 
Il convient de reconnaître que l'usure très avancée de la molaire rend difficile une détermination spécifique exacte. L'indice du protocône (31.3), ainsi que les proportions générales, penchent en faveur de son attribution à un $H$. stenonis de taille moyenne.

Comme on l'a répété maintes fois, aucun critérium morphologique dentaire, à lui seul, n'est pas décisif pour caractériser un spécimen. C'est pourquoi nous remarquons encore, à part la brièveté du protocône, la tendance des styles à devenir bifides, ce dédoublement étant visible surtout au parastyle. C'est là un trait, semble-t-il, plus progressif. Outre cela, l'existence, bien que pour le moment incertaine, de plusieurs espèces de type zébrin en Europe durant le Pléistocène moyen (W. v. Reichenau 1915), vient compliquer considérablement le problème.

Encore que la persistance de H.stenonis au début du Pléistocène moyen ne soit pas totalement à écarter, nous préférons avoir des documents plus significatifs avant de l'affirmer avec certitude.

$$
\text { Hippotigrissüssenbornensis (Wüst) }
$$

Matériel: Rotbav-Cariera de sub Brazi - $\mathrm{P}_{4}$ sin. (fig. $12 \mathrm{C}$ )

Rotbav-Silvestru - Tibia dext.

La morphologie et les dimensions de $\mathrm{P}_{4}$ montrent son appartenance à l'espèce de Süssenborn. Comme on peut le voir dans la figure $12 \mathrm{C}$, le sinus interne est en forme de "V"; le métastylide est allongé en arrière et vers l'extérieur, ce qui lui donne un aspect différent par rapport au métaconide; la paroi interne de l'entoconide est sensiblement aplatie; l'émail des fossettes centrales très plissé.

Voici les mensurations de la prémolaire de Rotbav-Cariera de sub Brazi, comparées à celles de $\mathrm{P}_{4}$ de $H$. süssenbornensis de la localité éponyme.

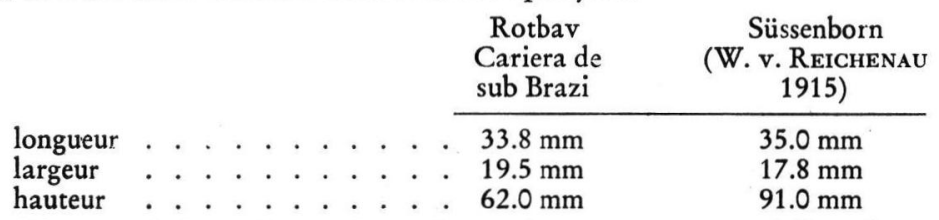

La ressemblance métrique de ces deux dents s'accentue encore si l'on tient compte du fait que la longueur de la prémolaire de Süssenborn se réduit graduellement vers la base de la couronne: à $51 \mathrm{~mm}$ de hauteur elle mesure $33.6 \mathrm{~mm}$ (W. v. ReICHenau 1915).

Nous attribuons à la même espèce un tibia droit qui présente de grandes dimensions:

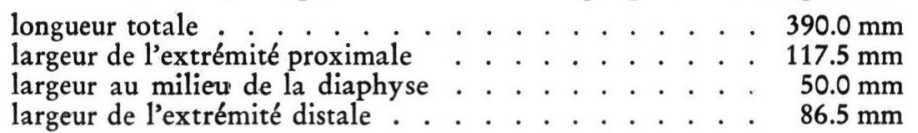

L'os se caractérise par la hauteur de l'épine tibiale, ce qui l'approche du tibia de H. stenonis; cependant, la fosse pour le ligament rotulien moyen est peu profonde et la malléole interne moins développée comparativement à cette dernière espèce, morphologie qui donne au tibia de Silvestru un aspect légèrement caballin.

Matériel: Rotbav-Silvestru

Equ us sp. (petite taille)

- M sup. sin. ( $\mathrm{M}^{2}$ ?)

- $\mathrm{P}$ inf. dext. ( $\mathrm{P}_{4}$ ?)

Ces deux jugales sont les seules pièces de notre matériel qui prouvent l'existence, au commencement du Pléistocène moyen, d'un petit Cheval dont les affinités nous restent encore obscures. Il semble représenter la même forme que nous avons rencontré en Olténie à la même période (C. Radulesco \& P. SAMson 1962 a) ${ }^{6}$ )

6) Nous pensons avoir affaire à une nouvelle espèce qui fera l'objet d'une publication à part. (C. R. et P. S.) 


$$
\begin{gathered}
\text { Ord. Artiodactyla } \\
\text { Cervus sp. (groupe "rusoïde") }
\end{gathered}
$$

Matériel: Rotbav-Silvestru - Bois de mue sin., fragment basilaire.

Description. A cause de certaines particularités de la pièce, nous insisterons un peu plus sur les détails.

Le fragment de bois étant légèrement roulé, les traces de la meule, bien que reconnaissables, sont très faibles. Le premier andouiller, qui se trouve à une distance de $88.5 \mathrm{~mm}$ par rapport à la rose, est brisé à sa naissance. Entre la meule et cet andouiller, la perche se courbe doucement en dehors et en arrière; après le départ de l'andouiller, elle continue sa course vers l'extérieur en se dirigeant plus en arrière encore. Sur tout son trajet, la perche présente sa face externe aplatie, tandis que la face interne est convexe. Au-dessus de l'andouiller, la section du bois est ovoïdale à partie postérieure allongée.

Les mensurations de la pièce fournissent les chiffres suivants:



$\mathrm{R}$ a p ports e t différe nces. Il est bien difficile de préciser la place systematique de l'espèce à laquelle appartient le fossile de Rotbav-Silvestru. En écartant la possibilité d'être en présence d'un individu juvénile - parce que tous les bois adultes, trouvés dans le même gisement, se rapportent à un Cerf encore inédit dont les phases plus jeunes présentent une morphologie différente du type que nous venons de décrire - il nous semble possible de rapprocher notre forme des Cerfs d'aspect "rusoïde" du Villafranchien d'Europe et nous pensons spécialement à Cervus philisi (S. SCHaub 1941). Une identification avec cette dernière espèce est pour le moment problématique ayant en vue non seulement l'insuffisance de la documentation, mais encore la taille moindre de notre exemplaire et son âge géologique plus récent. De plus, dans les associations funiques du Pléistocène moyen de notre continent, le groupe "rusoïde" semble ne plus apparaître. Toutefois, il n'est pas exclu que notre spécimen représente un descendant tardif du petit Cervidé de Senèze, auquel nous avons fait allusion plus haut.

En tout cas, le Cerf de Rotbav-Silvestru, dont les affinités sont incertaines, confère un cachet archaïque à l'ensemble de la faune de cette localité.

$$
\text { Me g a c e rini gen. et sp. nov. }
$$

Un important matériel (fragments de crâne, de bois, d'os longs etc.), provenant de Rotbav-Silvestru, indique l'apparition d'un type mégacérin primitif qui sera décrit dans une étude spéciale (C. R. \& P. S.).

Ce nouveau type semble caractériser le début du Pléistocène moyen autant dans notre pays (P. Samson \& C. Radulesco 1963, 1965), que dans l'Ouest de l'Union Soviétique où quelques découvertes isolées montrent l'existence de la même forme.

$$
\begin{gathered}
\text { Ord. Rodentia } \\
\text { Trogontberium cf. boisvilletti (LaugeL) }
\end{gathered}
$$

Matériel: Rotbav-Silvestru - I inf. sin., fragment apical (fig. 13).

Description. Généralement, par ses caractères les plus significatifs, cette pièce appartient sans conteste à un Trogontherium. On observe que la structure de l'émail et de 


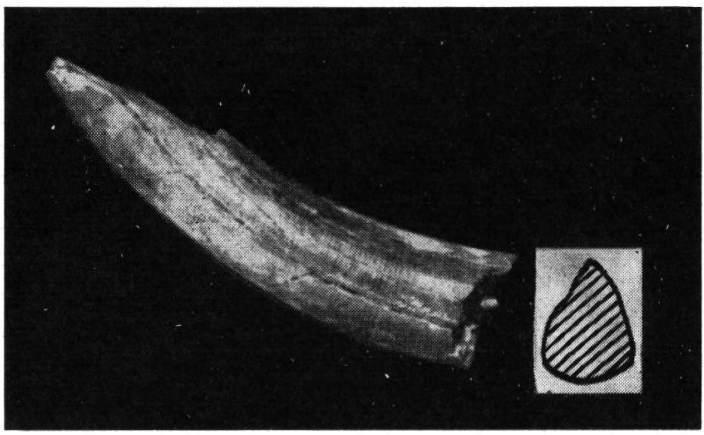

Fig. 13. Trogontherium cf. boisvilletti (LAUGEL). Rotbav - Silvestru (Bassin de Baraolt). I inférieure sin., fragment apical, vue externe et section transversale. $\left({ }^{1} / 1\right)$.

la dentine, l'aspect de la section transversale et de la surface d'usure correspondent aux traits invoqués, le plus souvent, pour ce genre.

Le fragment représente environ le tiers antérieur de l'incisive. La surface d'usure montre les caractéristiques indiquées par A. Schreuder (1929), ayant le bord interne presque rectiligne, tandis que son bord externe décrit une demi-ellipse. Longue d'approximativement $20 \mathrm{~mm}$, cette surface est composée de deux facettes, l'une antérieure plus grande, l'autre postérieure très réduite, ce qui prouve l'âge encore jeune du spécimen.

La section transversale de l'incisive est plus ou moins piriforme: le côté antérieur couvert par la couche d'émail est puissamment convexe; les deux autres correspondant à la dentine sont, l'interne presque droit, l'externe, parcouru d'un petit sillon longitudinal, de nouveau convexe.

Les diamètres maxima antéro-posterieur et latéral de notre pièce, ainsi que ceux de plusieurs incisives choisies comme terme de comparaison sont réunis dans le tableau 4.

$\mathrm{R}$ a p ports et différe n ces. En ce qui concerne son diamètre artéro-postérieur, le fragment de Rotbav-Silvestru ne diffère pas sensiblement des incisives de T. cuvieri ou de T. boisvilletti, bien qu'il se range vers leur limite inférieure de variabilité. En revanche, par son diamètre latéral assez réduit, il se distingue nettement de la première espèce pour se rappocher de la seconde. D'après ce caractère, qui semble être essentiel dans la distinction des deux espèces, l'incisive de Rotbav-Silvestru montre des affinités évidentes avec Trogontherium boisvilletti.

La présence de T. boisvilletti dans le Pléistocène moyen de l'Europe soulève toute une série de problèmes. D'une manière générale et par rapport à T. cuvieri, cette espèce est considérée comme plus ancienne et mois spécialisée (A. Schreuder 1951); son extension était limitée à l'Ouest européen et Erpfinger Höhle représentait, dans le Villafranchien supérieur, le point le plus avancé vers l'Est (U. Lehmann 1957). Cependant, T. boisvilletti semble avoir existé, pendant le "Calabrien", même en Hongrie à Kislang (M. Kretzor 1954).

T. cuvieri, espèce probablement plus récente, était répandu dans l'Europe Orientale et Centrale, sa présence en Hollande indiquant la limite extrême occidentale de son extension pendant l'Interglaciaire Mindel-Riß (D. A. HoojJer 1959).

Dans l'état actuel de nos connaissances et du moins en Transylvanie, T.cuvieri découvert à Băile Episcopiei (Püspökfürdö), localité classique pour l'optimum du Cromérien, succède à $T$. cf. boisvilletti de Rotbav-Silvestru qui, d'après son association faunique, se place au début du Pléistocène moyen. 


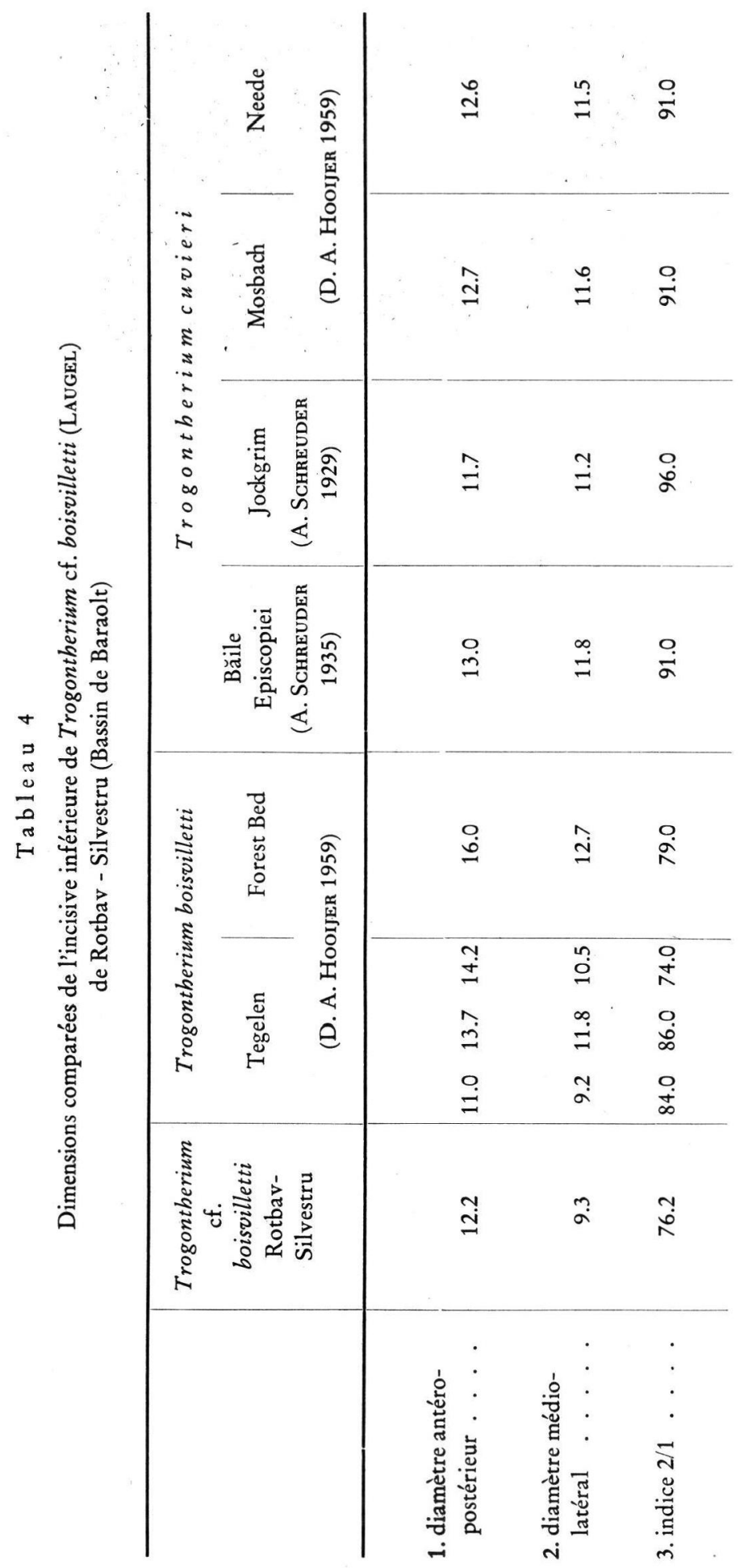


B. Ph a s e I I (Horizon III - Partie supérieure)

$$
\begin{gathered}
\text { Ord. Proboscidea } \\
\text { Parelephas trogontberii (PoHLig) }
\end{gathered}
$$

(forme archaïque)

Matériel: Rotbav-Dealul Tiganilor Niveau $1-\mathrm{M}^{3}$ dext. et $\mathrm{M}^{3}$ sin., d'un même sujet (fig. 14).

- $\mathrm{M}_{3}$ sin., fragment postérieur.

Les deux molaires supérieures sont très bien conservées et se trouvent au commencement de leur usure; le plan de la surface occlusale, formant avec l'axe long des lames un angle de $57^{\circ}$, les sectionne très obliquement; par suite, les figures d'abrasion deviennent assez épaisses. L'émail, modérément plissé, a un contour sinueux avec une expansion médiane et postérieure. Les dennières lames (XVIII-XIX) et le talon sont anormalement constitués, étant appliqués contre la paroi interne de la dent. Le cément, bien développé, recouvre presque toute la molaire à l'exception de son tiers postérieur.

Les caractéristiques de ces deux molaires sont indiquées ci-dessous ${ }^{7}$ ):

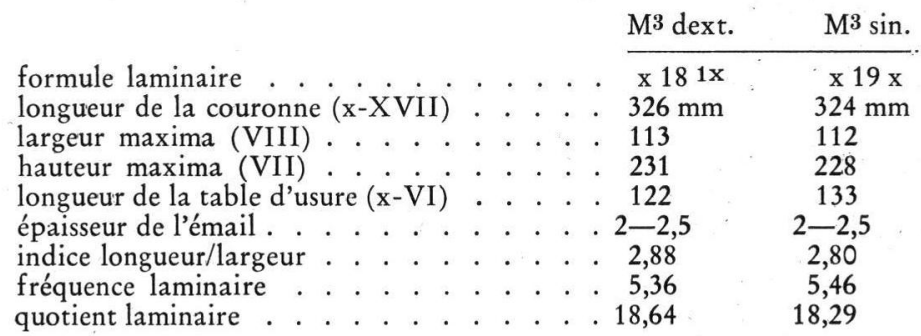

La molaire inférieure, trop fragmentaire pour fournir des mensurations, est représentée par les 4 dernières lames, à peine usées; leur disposition en évantail, très marquée, amène le talon, formé par deux petites lamelles, dans un plan horizontal.

$$
\begin{gathered}
\text { Ord. Perissodactyla } \\
\text { Dicerorbinus kirchbergensis (JAEger) }
\end{gathered}
$$

Matériel: Rotbav-Dealul Tiganilor, Niveau 1 - Nasaux, fragment

Araci-Carrière

- Humérus sin., extrémité distale

- Magnum sin., fragmentaire

- Radius dext., fragments proximal et distal.

Tous ces restes indiquent l'existence, dans le Pléistocène moyen, d'un grand Rhinocéros que nous avons identifié à $D$. kirchbergensis (JAEGER).

Un fragment distal des nasaux, un peu plus complet, présente la face supérieure recouverte de rugosités compactes; sa face inférieure donne naissance à une cloison ossifiée, épaisse d'environ $22 \mathrm{~mm}$ à sa partie antérieure.

Le magnum gauche, dont l'apophyse postérieure et une partie de la facette d'articulation pour le scaphoïde sont brisées, correspond assez bien par sa morphologie et ses dimensions à la même pièce de D. kirchbergensis de Fontéchevade, figurée par C. AramBOURG (1958). On peut seulement remarquer, sur notre échantillon, la facette articulaire pour le métacarpien III un peu plus concave et la hauteur de l'os légèrement plus grande.

7) Les mensurations des dents d'Eléphant sont prises selon les indications de H. F. OsBonN (1942); la fréquence laminaire $=$ nombre des lames $\times 100 /$ longueur totale de la dent. 


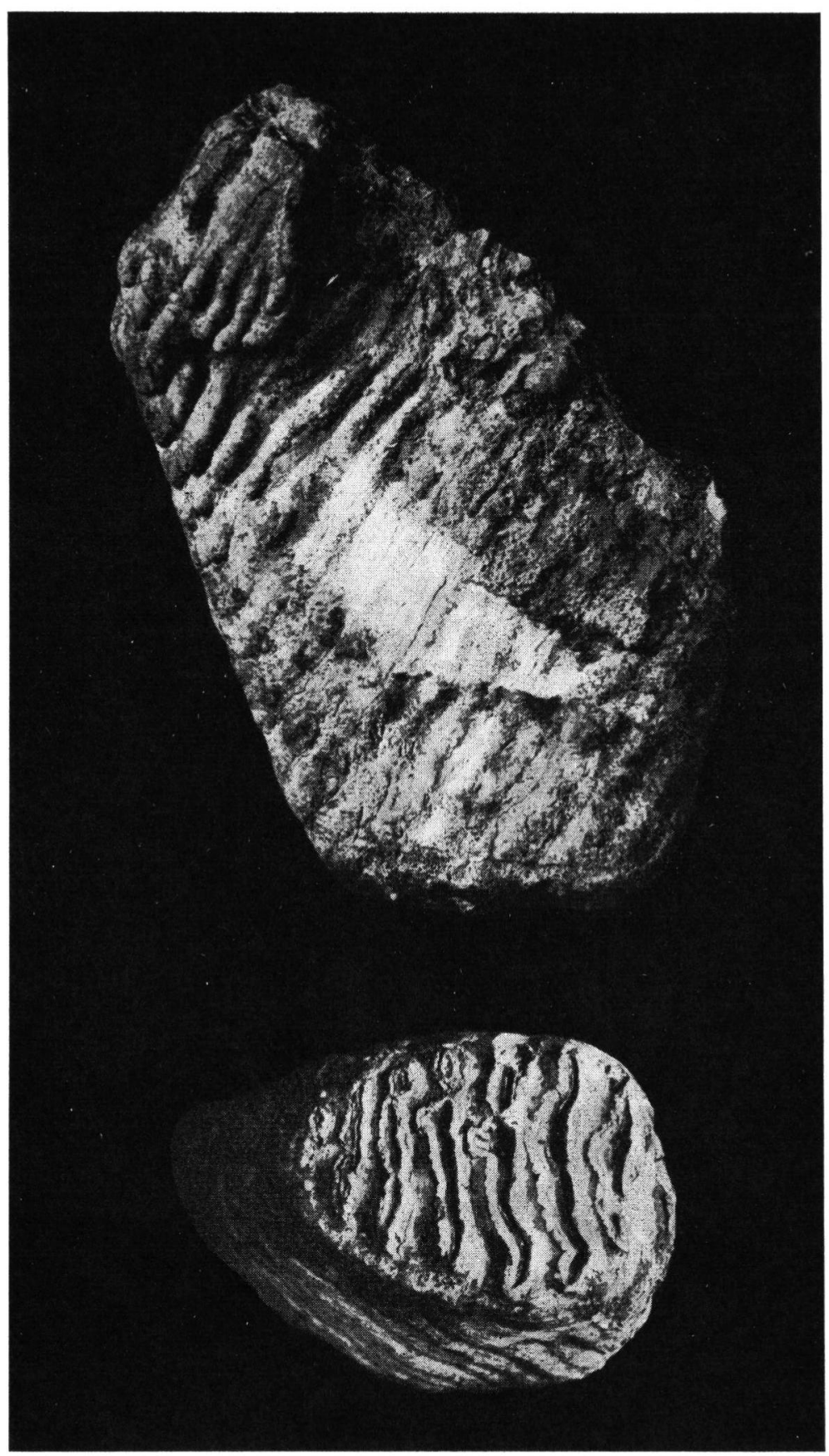

Fig. 14. Parelephas trogontherii (PoHLIG), forme archaïque. Rotbav - Dealul Tiganilor (Bassin de Baraolt). $M^{3}$ sin.: vue interne (en haut), vue occlusale (en bas). ( $1 / 3$ ). 
Les fragments d'humérus, et de radius, de la Carrière de Araci, indiquent un Rhinocéros extrêmement robuste et les mensurations ci-dessous sont destinées à mettre en évidence, comparativement, ses grandes dimensions:

\begin{tabular}{|c|c|c|c|}
\hline & Araci & $\begin{array}{c}\text { Taubach } \\
\text { (A. Portis } \\
1878)\end{array}$ & $\begin{array}{c}\text { Daxland } \\
\text { (H. v. MEYER } \\
1864)\end{array}$ \\
\hline \multicolumn{4}{|l|}{ Humérus: } \\
\hline $\begin{array}{l}\text { largeur de l'extrémité distale } \\
\text { largeur de la surface articulaire distale }\end{array}$ & $\begin{array}{l}164 \\
123\end{array}$ & $\begin{array}{l}155 \\
111\end{array}$ & $\begin{array}{l}156 \mathrm{~mm} \\
112\end{array}$ \\
\hline \multicolumn{4}{|l|}{ Radius: } \\
\hline $\begin{array}{l}\text { largeur de l'extrémité proximale } \\
\text { diamètre antéro-postérieur de l'extrémité proximale } \\
\text { largeur de l'extrémité distale } \\
\text { diamètre antéro-postérieur de l'extrémité distale }\end{array}$ & $\begin{array}{r}118 \\
78 \\
123 \\
80\end{array}$ & $\begin{array}{r}120 \\
80 \\
125 \\
80\end{array}$ & $\begin{array}{l}- \\
- \\
-\end{array}$ \\
\hline
\end{tabular}

Par suite, la présence, pendant le Pléistocène moyen de la Dépression de Braşov, de D. kirchbergensis, apparaît indubitable. Il convient de souligner encore, que les spécimens de cette région se situent parmi les plus forts de l'espèce.

$$
\text { Equus mosbachensis von REICHENAU }
$$

Matériel: Feldioara, Niveau $1 \quad-M$ sup. sin. ( $M^{2}$ ?) (fig. 12 B)

Rotbav-Dealul Tiganilor

$$
\begin{array}{ll}
\text { Niveau } 1 & - \text { Astragal dext., fragmentaire } \\
\text { Niveau } 3 & - \text { Fragments de dents d'un même arc mandibulaire } \\
& \text { (fig. } 12 \mathrm{D} \text { ). }
\end{array}
$$

La dent supérieure de Feldioara se caractérise par le dédoublement des styles et le protocône assez allongé; ce dernier, à partie antérieure encore réduite, est bien développé en arrière. Dans l'ensemble, la morphologie ainsi que les dimensions de cette molaire, comme les chiffres ci-dessous le font ressortir, permettent de l'attribuer à E. mosbachensis.

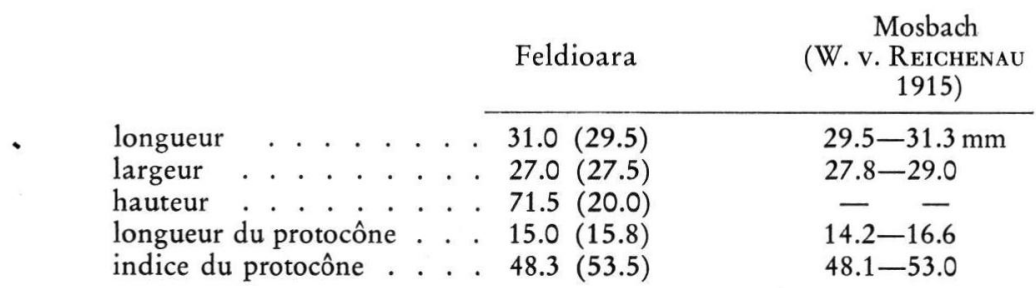

Entre parenthèses sont indiquées les mensurations prises à $2 \mathrm{~cm}$ au-dessus du collet (U. LehMANn 1954).

Les mesures, que l'état fragmentaire de l'astragal nous a permis de prendre, comparativement à celles de la pièce correspondante de E.mosbachensis type, sont les suivantes:

\begin{tabular}{lcc} 
& $\begin{array}{c}\text { Rotbav } \\
\text { Dealul } \\
\text { Tiganilor }\end{array}$ & \multicolumn{1}{c}{$\begin{array}{c}\text { Mosbach } \\
\text { (W. v. ReICHENAU } \\
\text { 1915) }\end{array}$} \\
\cline { 2 - 3 } longueur de la grande diagonale de la poulie articulaire & 88.6 & $84.5-86.8 \mathrm{~mm}$ \\
largeur de la facette articulaire pour le naviculaire . & 59.3 & $58.5-59.0$
\end{tabular}

Les dents inférieures sont, sans exception, bien fragmentaires. On peut observer cependant que le sinus interne est de type caballin, c'est-à-dire en forme de "U“. Les pièces moins endommagées, par leur robustesse, indiquent la taille puissante du spécimen auquel 
elles avaient appartenu. Ainsi que dans le cas de la molaire supérieure, la morphologie et les dimensions montrent les caractéristiques de E. mosbachensis.

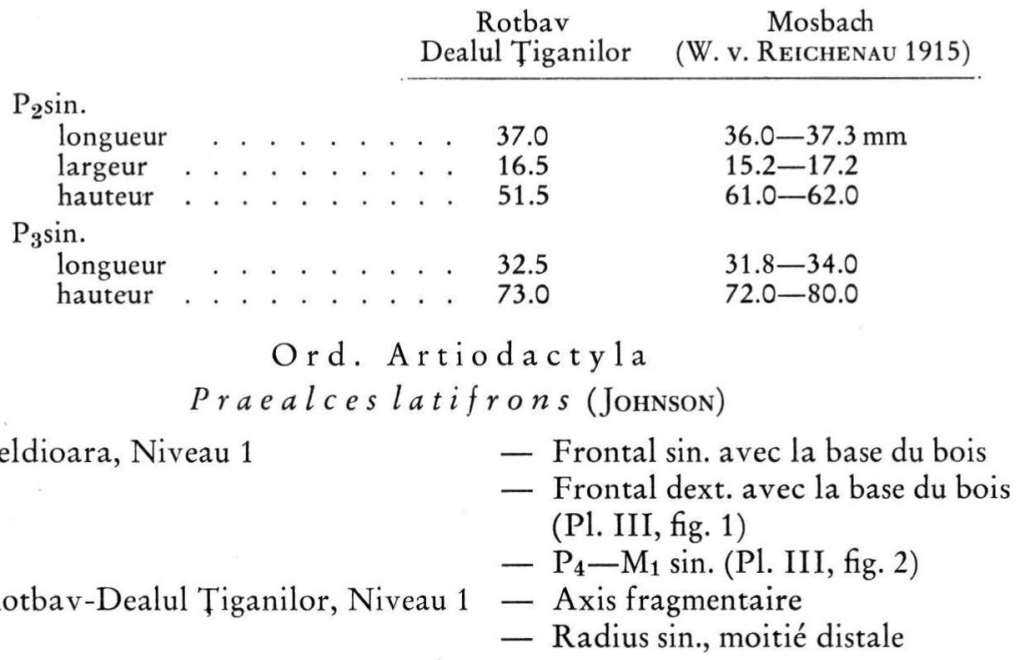

$\mathrm{C}$ rân e. Le fragment le mieux conservé comprend le frontal droit, depuis le plafond de l'orbite jusqu'à la suture avec le pariétal, ainsi que la partie basilaire du bois correspondant. On peut noter sur cette pièce la fosse frontale assez profonde et plus marquée comparativement à celle de Praealces gallicus (Azzaroli); l'épaisseur de l'os (40 mm) est aussi plus grande que chez cette dernière espèce.

Le bois, légèrement recourbé en avant, présente une meule bien développée, à grandes perlures sur le côté antérieur. La surface du merrain, à partir de la rose, est sculptée de cannelures bien délimitées, mais qui tendent à disparaître distalement.

Le deuxième fragment de crâne, très semblable au premier, est représenté par le frontal gauche d'un spécimen également robuste. Les caractères morphologiques sont les mêmes dans le deux cas et il serait inutile d'en revenir.

Dans le tableau 5, nous avons réuni les dimensions de ces deux pièces, comparées, quand cela a été possible, avec celles de P. latifrons de Mosbach et Süssenborn.

Dentition. Les deux dents, $P_{4}$ et $M_{1}$ d'un même sujet, correspondent par leur morphologie à celles de P.latifrons. Nous signalons cependant, en ce qui concerne $\mathrm{P}_{4}$, la présence d'une colonnette interlobaire externe très réduite. La première molaire a, sauf la colonnette labiale, une autre accessoire, très faible, située à la partie linguale de la dent; il faut encore mentionner une vague trace de pli palaeomeryx qui rappelle le caractère de la denture de $P$. gallicus.

Les deux jugales, par leurs dimensions, se rangent vers la limite supérieure de variabilité de l'espèce, comme il ressort des mensurations suivantes où nous avons comparé nos pièces aux exemplaires les plus robustes de Süssenborn et Tiraspol:

\begin{tabular}{|c|c|c|c|}
\hline & Feldioara & $\begin{array}{l}\text { Süssenborn } \\
\text { (H. D. KAHLKE } \\
\text { 1956) }\end{array}$ & $\begin{array}{c}\text { Tiraspol } \\
\text { (M. PAVLOV } \\
\text { 1906) }\end{array}$ \\
\hline $\begin{array}{l}\mathrm{P}_{4} \sin . \\
\text { longueur } \\
\text { largeur }\end{array}$ & 35.0 & 34.2 & $33.0 \mathrm{~mm}$ \\
\hline $\begin{array}{l}\text { largeur } \\
\mathrm{M}_{1} \text { sin. } \\
\text { longueur } \\
\text { largeur du lobe I } \\
\text { largeur du lobe II }\end{array}$ & $\begin{array}{l}26.0 \\
\\
\\
33.0 \\
. \quad 25.0 \\
. \quad 26.5\end{array}$ & $\begin{array}{l}35.2 \\
28.1 \\
26.0\end{array}$ & $\begin{array}{l}28.0 \\
-\end{array}$ \\
\hline
\end{tabular}




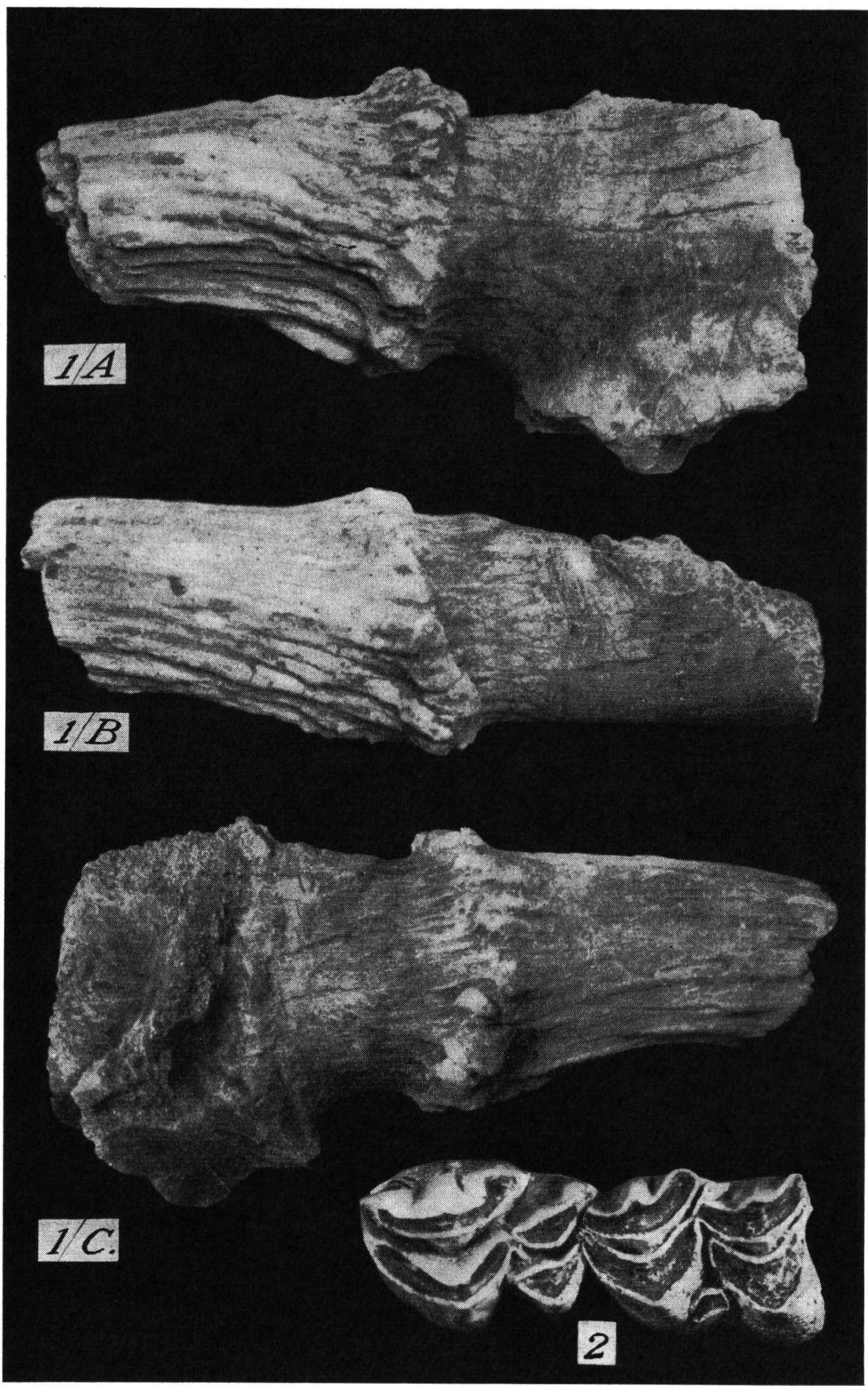

Planche III. Praealces latifrons (JoHN.). Feldioara (Bassin de Baraolt). Fig. 1: Frontal dext. avec la base du bois: $A$. vue antérieure; $B$. vue supérieure; $C$. vue postérieure. $1 / 3$. Fig. $2: P_{4}-M_{1}$ sin., vue occlusale. $(1 / 1)$. 
Squelette post-cranien. Axis. Le corps de la vertèbre est complet, l'arc dorsal manque et les expansions articulaires pour l'atlas sont brisées à leur partie supérieure. Voici quelques mensurations:

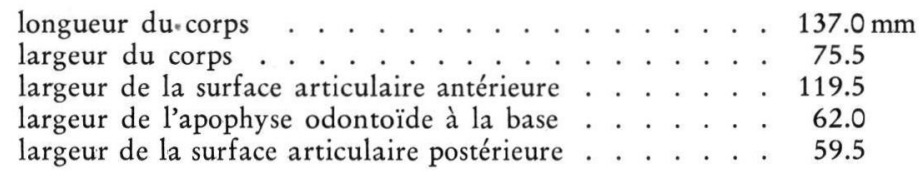

$\mathrm{R}$ a dius. Le fragment représente environ la moitié distale de l'os. La diaphyse est brisée irrégulièrement en son milieu et aussi du côté interne au-dessus de l'articulation; l'extrémité articulaire est bien conservée. Nous avons pris les mensurations suivantes:

\begin{tabular}{|c|c|c|}
\hline & $\begin{array}{c}\text { Rotbav } \\
\text { Dealul } \\
\text { Tiganilor }\end{array}$ & $\begin{array}{c}\text { Süssenborn } \\
\text { (H. D. KAHLKE } \\
1959)\end{array}$ \\
\hline milieu $\mathrm{c}$ & 61.0 & $63.2 \mathrm{~mm}$ \\
\hline amètre antéro-postérieur de la diaphyse & 41.0 & 42.0 \\
\hline largeur de l'extrémité distale . . & 92.0 & 95.0 \\
\hline lamètre antéro-posterieur de l'extrémité distal & 69.0 & 73.0 \\
\hline
\end{tabular}

$\mathrm{R}$ a p ports et différences. Dans l'ensemble, le matériel que nous venons de décrire présente les caractères rencontrés habituellement chez P.latifrons; ses grandes dimensions, l'élargissement accentué du frontal, ainsi que son profil le destinguent suffisamment de L'Elan proprement dit (genre Alces) et il n'est pas le cas d'en insister davantage.

Les opinions sur l'appartenance générique de l'espèce latifrons sont encore contradictoires, A. Azzaroli $(1953,1961)$ plaidant en faveur de Libralces, H. D. KahlKe (1958), en revanche, pour Alces, en raison surtout du manque de pli palaeomeryx. Dans cette controverse, nous avons adopté les vues de A. Azzaroli qui nous paraissent plus exactes, avec la seule modification du nom générique qui n'est pas Libralces Azzaroli 1951, mais, conformément aux lois de priorité, Praealces A. Pontis 1920, appliqué, avec valeur de sous-genre, par cet auteur à l'espèce Cervus latifrons JoHn.

A l'exception de la taille, par les proportions générales de son crâne, P. latifrons est très proche de P. gallicus (voir A. Azzaroli 1953, p. 25, fig. 9). Nous avons constaté cette ressemblance aussi par l'examen des restes fossiles de Baraolt et du matériel de $P$. gallicus du Villafranchien d'Olténie (P. SAMson \& C. Radulesco, sous presse). Il nous semble, par suite, préférable de ne pas accorder le rôle décisif dans l'attribution générique seulement à la dentition et surtout à la présence ou à la présence ou à l'absence du pli palaemeryx dont les fluctuations sont d'ailleurs assez importantes.

Bien que les dents soient presque toujours les parties les mieux conservées et les plus fréquentes, tandis que les crânes représentent plutôt des raretés précieuses, les découvertes échelonnées durant plus d'un demi-siècle, nous renseignent assez bien sur la morphologie cranienne des Elans quaternaires, pour accepter l'identité générique des espèces gallicus et latifrons. Les caractéristiques observables dans leur dentition - et qui s'expliquent par leur degré différent d'évolution - ne s'opposent pas à l'encadrement de ces deux espèces dans un même genre.

\section{Dolichodorycerossavini (Dawkins) (= Dolichodoryceros süssenbornensis KAHLKE)}

Matériel: Araci-Carrière - Bois de mue dext., fragmentaire (Pl. IV, fig. 1)

- Bois de mue sin., juvénile, fragments basilaires

- Phalange II, fragmentaire. 
T a b l e a u 5

Dimensions comparées du frontal et des bois de Praealces latifrons (JoHn.) de Feldioara (Bassin de Baraolt)

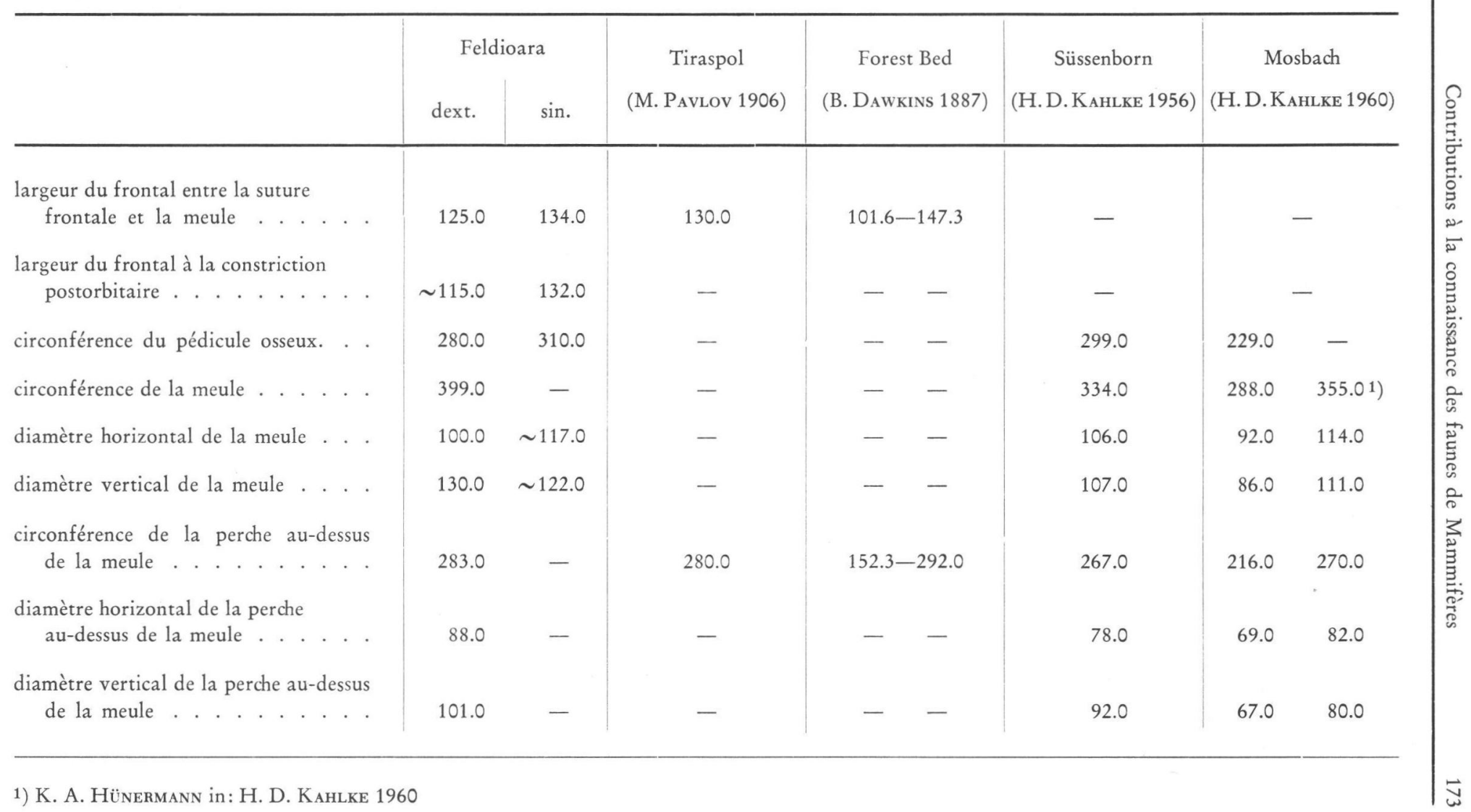


Description. La pièce la plus importante, un bon fragment de bois dext., provient d'un spécimen exceptionnellement robuste, comme on peut le constater d'après les mensurations du tableau 6.

Le fragment représente le merrain avec deux andouillers brisés à leur insertion, le premier naissant tout près de la meule, le second situé bien plus haut. Les bases de ces deux ramifications, très aplaties, se trouvent à la partie antérieure de la perche dans le même plan, ce qui traduit un caractère important du genre Dolichodoryceros.

Le merrain, dirigé latéralement et en arrière, a une section subcirculaire au-dessus de l'andouiller basilaire et s'aplatit graduellement vers son exarémité supérieure. L'andouiller basilaire formait, très probablement, une palette horizontale à section triangulaire.

Ta ble a u 6

Dimensions comparées du bois de Dolichodoryceros savini (Dawk.) de Araci-Carrière (Bassin de Baraolt)

\begin{tabular}{|c|c|c|c|c|}
\hline & $\begin{array}{l}\text { Araci - } \\
\text { Carrière }\end{array}$ & $\begin{array}{c}\text { Süssenborn } \\
\text { (H.D. KAHLKE } \\
1956)\end{array}$ & \begin{tabular}{|c|} 
Voigtstedt \\
$($ H.D. KAHLKE \\
$1958)$
\end{tabular} & $\begin{array}{c}\text { Forest Bed } \\
\text { (B. DAwkins } \\
1887)\end{array}$ \\
\hline circonférence de la meule . . . . & $\sim 350.0$ & 220.0 & $\sim 272.0$ & $218.41)$ \\
\hline diamètre maximum de la meule. . & $\sim 118.0$ & - & $\sim 92.0$ & - \\
\hline $\begin{array}{l}\text { diamètre horizontal de la perche } \\
\text { au-dessus du premier andouiller }\end{array}$ & 88.0 & 48.0 & 75.0 & - \\
\hline $\begin{array}{l}\text { diamètre vertical de la perche au- } \\
\text { dessus du premier andouiller. . }\end{array}$ & 72.0 & 45.0 & 67.0 & - \\
\hline $\begin{array}{c}\text { circonférence de la perche au-dessus } \\
\text { du premier andouiller . . . . }\end{array}$ & 250.0 & - & 221.0 & $182.81)$ \\
\hline $\begin{array}{l}\text { distance entre l'andouiller basilaire } \\
\text { et le deuxième andouiller. . . }\end{array}$ & 300.0 & - & - & $\left.190.4^{2}\right)$ \\
\hline
\end{tabular}

1) exemplaire de British Museum; 2) exemplaire de Trimingham

Du bois gauche juvénile, un fragment antérieur avec la base du premier andouiller, est le plus significatif. On remarque la taille considérablement moindre par rapport au spécimen décrit plus haut, ainsi que certaines particularités dues à son âge moins avancé. L'andouiller basilaire, également aplati dans un plan horizontal, est situé à $10 \mathrm{~mm}$ audessus de la meule et après son départ, le merrain est creusé d'une dépression longitudinale assez exprimée.

La phalange II, cassée dans sa partie postéro-supérieure, nous a permis de prendre quelques mensurations qui indiqent un exemplaire de grande taille.

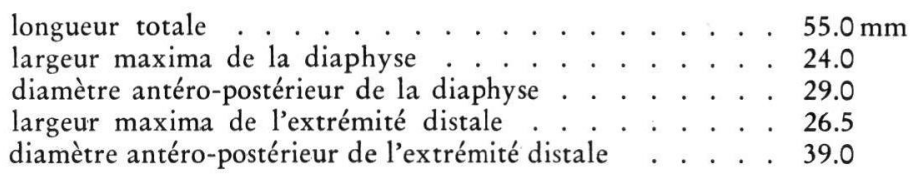

Les termes de comparaison qu'on pourrait utiliser ont seulement une valeur relative, la coexistence de plusieurs Mégacérins dans les gisements pléistocènes moyens de l'Europe rendant difficile l'attribution spécifique exacte de certaines pièces du squelette. 
$\mathrm{R}$ a p p o r t s e t différe n ces. Nos comparaisons se sont limitées aux seules deux espèces décrites jusqu'à présent, Megaceros savini (DAwk.) en Angleterre et Dolichodoryceros süssenbornensis KAHLKE en Allemagne. Il semble cependant que le matériel de ces deux pays appartienne en réalité à une même et seule espèce - savini selon les règles de la nomenclature - surprise en deux phases différentes de développement (A. Azzaroli 1961, H. D. KaHLKE 1958).

En faveur de ce point de vue, nos pièces fournissent encore un argument par l'existence dans le même dépôt des sujets de taille différente qui reflète les diverses étapes du développement individuel. Il est possible d'admettre, par suite, que les exemplaires en pleine maturité pouvaient atteindre une robustesse supérieure même à celle des plus grands Mégacérins.

En 1952, H. D. Kahlke a séparé, à juste raison, une partie des Cerfs mégacéroïdes du Pléistocène moyen sous le nom générique de Dolichodoryceros, ayant pour type $D$. süssenbornensis KahlKe. Plus tard (H. D. KaHLKe 1956), il a inclu dans ce genre aussi l'espèce du Forest Bed, D. savini (Dawkins).

Vu la synonimie de $D$. sïssenbornensis et $D$. savini, le Mégacérin, dont nous venons de nous occuper, doit être désigné sous la dénomination de $D$. savini (DAwKINs).

$$
\text { Cervus sp. (groupe Elaphus?) }
$$

Matériel: Feldioara, Niveau $1 \quad-\mathrm{P}^{4}$ et $\mathrm{M}^{2}$ sin. fragmentaires, $\mathrm{M}^{2}$ dext., probablement du même individu.

$$
\text { Araci-Carrière } \quad \text { - Phalange I, fragment proximal. }
$$

La morphologie des jugales ne présente rien de significatif qui puisse faciliter leur attribution spécifique. $\mathrm{La} \mathrm{P}^{4}$, avec la fossette lunaire divisée inégalement par un éperon interne, ne nous offre, à son tour, aucun caractère discriminatif précis.

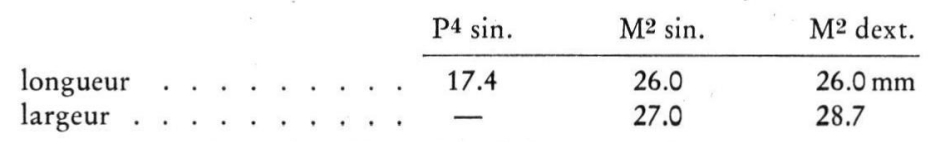

D'après leurs mensurations, les pièces de Feldioara seraient un peu trop grandes pour être attribuées à Cervus acoronatus Beninde, tel qu'il a été décrit d'Allemagne (H. D. KAHLKE 1956); elles correspondraient, en revanche, aux dents des Cervidés mégacéroïdes de Süssenborn et Mosbach.

Avant de conclure, nous désirons remarquer d'une part, l'absence du groupe Verticornis dans le Pléistocène moyen de la Dépression de Braşov et aussi la taille extrêmement puissante présentée par Dolichodoryceros de cette région, d'autre part, la robustesse notable atteinte par Cervus cf. elaphus de Ilieni, comme nous le ferons observer plus loin (Appendice).

Nous avons rappelé tous ces détails pour montrer que l'appartenance dés trois dents de Feldioara à un Cerf du groupe Elaphus n'est pas absolument exclue.

L'état très fragmentaire de la phalange I de Araci, n'a pas permis de prendre des mensurations. Nous observons cependant qu'elle est plus petite que celle des Elaphes würmiens, utilisée pour comparaison; au contraire, elle conviendrait à un Cerf noble actuel de taille moyenne, montrant ainsi des dimensions moindres que les phalanges correspondantes attribuées à C. acoronatus d'Allemagne (H. D. KAHLKE 1956, 1958, 1960).

En face de ces données, assez contradictoires, nous devons attendre des découvertes plus significatives, elles seules pouvant apporter l'éclaircissement désirable sur les Cervidés du groupe Elaphus du Pléistocène moyen de la Dépression de Braşov. 


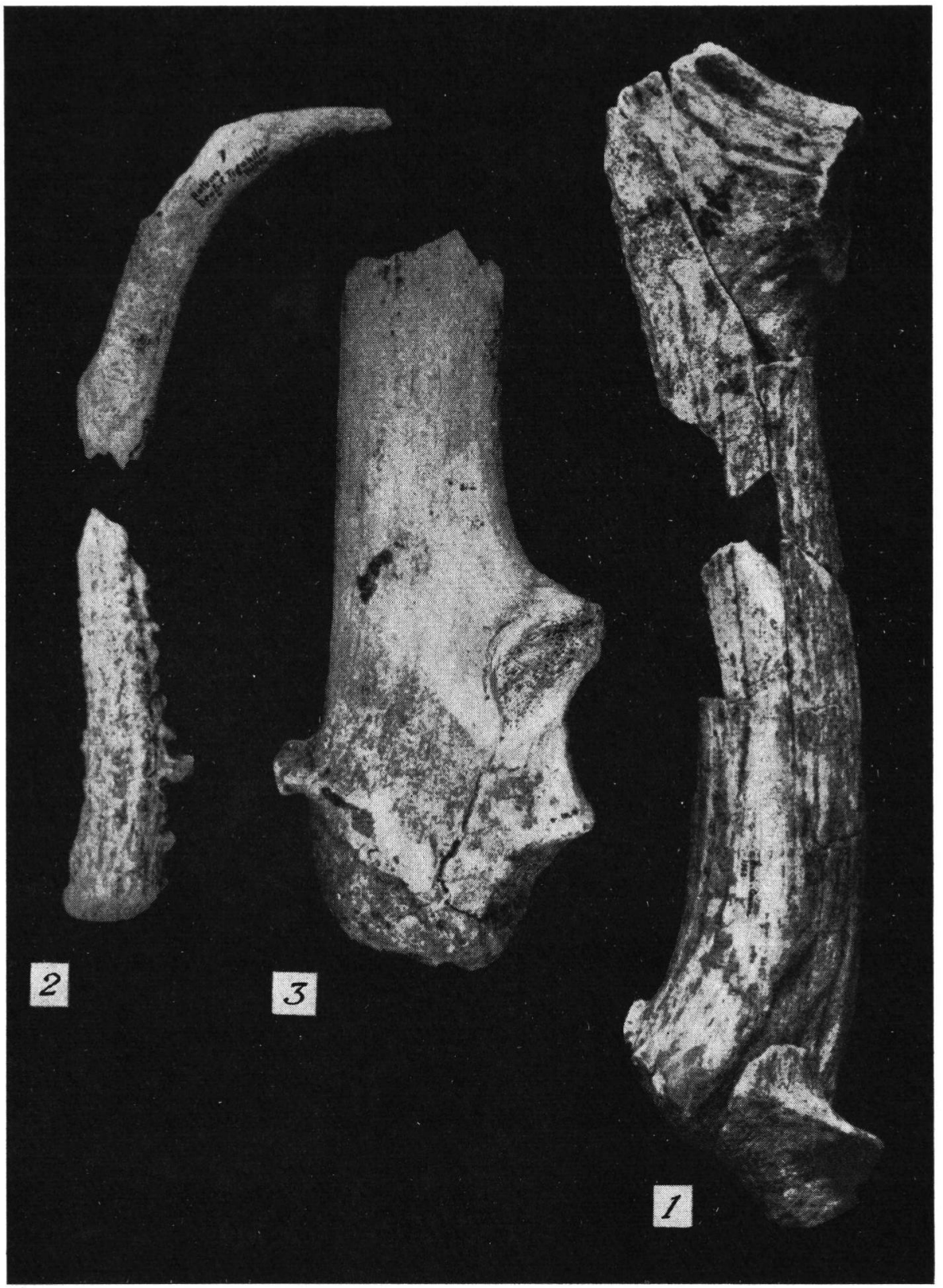

Planche IV. Fig. 1: Dolichodoryceros savini (DAwk.). Araci-Carrière (Bassin de Baraolt). Bois de mue dext., fragmentaire, vue inférieure. (1/3). Fig. 2: Capreolus capreolus L. Rotbav - Dealul Tiganilor (Bassin de Baraolt). Bois de mue dext., fragmentaire, vue interne. (1/2). Fig. 3 : Cervus cf. elaphus L. Ilieni (Bassin de Ilieni). Bois de mue dext., fragment basilaire, vue externe. (1/4). 
Matériel: Rotbav-Dealul Tiganilor

$$
\begin{gathered}
\text { Capreolus capreolus (Linnaeus) } \\
\text { (= C. süssenbornensis KaHLKe) }
\end{gathered}
$$

Niveau $1-$ Bois de mue dext., deux fragments (Pl. IV, fig. 2)

Description. Le premier fragment correspond à la moitié inférieure du bois avec la meule très endommagée; la surface du merrain est sillonnée profondément et possède des perlures saillantes du côté postéro-interne.

Le deuxième fragment représente la partie supérieure du même bois dont seule la pointe postérieure s'est conservée, les autres pointes étant brisées à leur insertion. La face externe du merrain est plus convexe comparativement à la face interne de celui-ci; cette dernière tend sensiblement à s'aplatir. Entre la chevillure et la pointe antérieure il y a une faible carène; les cannelures du bois, très effacées au niveau de la chevillure, disparaissent complètement vers la partie supérieure.

Rapports et différ e nces. Dans l'ensemble, les bois du Chevreuil de Baraolt ne diffèrent par aucun caractère important de ceux de l'espèce actuelle. Nous avons mis en parallèle les fragments que nous venons de décrire avec 20 bois récents (collections de l'Institut de Spéologie et du Musée de Sf. Gheorghe), mais sans pouvoir faire ressortir de cette comparaison des différences constantes et suffisamment amples qui permettent une séparation satisfaisante. C'est pourquoi nous n'avons pas adopté le nom spécifique nouveau, C. süssenbornensis, proposé par H. D. KahLKe (1956) pour le Chevreuil du Pléistocène moyen d'Allemagne.

$\mathrm{T}$ a b 1 e a u 7

Dimensions comparées du bois de Capreolus capreolus (L.) de Rotbav-Dealul Tiganilor

\begin{tabular}{|c|c|c|c|c|c|}
\hline \multirow[b]{2}{*}{ longueur totale . . . . . . } & \multirow{2}{*}{$\begin{array}{l}\text { Rotbav- } \\
\text { Dealul } \\
\text { Tiganilor } \\
\sim 250.0\end{array}$} & \multicolumn{2}{|c|}{$\begin{array}{c}\text { S ü s s e n b o r n } \\
(\text { H.D. KAHLKE 1956) }\end{array}$} & \multicolumn{2}{|c|}{$\begin{array}{c}\text { Mos b a c h } \\
\text { (H.D.KAHLKE 1960) }\end{array}$} \\
\hline & & 312.0 & 198.0 & 270.0 & 224.0 \\
\hline circonférence de la meule . . . . & $\sim 118.0$ & 134.0 & - & - & 95.0 \\
\hline diamètre maximum de la meule. & $\sim 40.0$ & 47.0 & - & - & 32.0 \\
\hline $\begin{array}{l}\text { circonférence de la perche au-dessus } \\
\text { de la meule }\end{array}$ & 74.0 & 94.0 & 75.0 & 79.0 & 71.0 \\
\hline $\begin{array}{l}\text { distance entre la meule et le premier } \\
\text { andouiller }\end{array}$ & $\sim 120.0$ & 121.0 & 79.0 & 132.0 & 85.0 \\
\hline $\begin{array}{l}\text { circonférence de la perche entre le } \\
\text { premier et le deuxième andouiller }\end{array}$ & 50.0 & 79.0 & 72.0 & 78.0 & 78.0 \\
\hline $\begin{array}{l}\text { grand diamètre de la perche entre le } \\
\text { premier et le deuxième andouiller }\end{array}$ & 17.5 & 28.0 & 26.0 & 29.0 & 26.0 \\
\hline $\begin{array}{l}\text { petit diamètre de la perche entre le } \\
\text { premier et le deuxième andouiller }\end{array}$ & 12.7 & 18.0 & 17.0 & 16.0 & 19.0 \\
\hline longueur de l'andouiller postérieur & 47.0 & 71.0 & - & 57.0 & 27.0 \\
\hline $\begin{array}{l}\text { circonférence basilaire de l'andouil- } \\
\text { ler postérieur }\end{array}$ & 34.0 & 41.0 & 37.0 & 51.0 & 36.0 \\
\hline $\begin{array}{l}\text { grand diamètre de l'andouiller } \\
\text { postérieur } . . . . .\end{array}$ & 13.0 & 15.0 & 14.0 & 18.5 & 12.0 \\
\hline $\begin{array}{l}\text { petit diamètre de l'andouiller } \\
\text { postérieur } . . . . .\end{array}$ & 8.5 & 11.0 & 10.0 & 9.0 & 8.0 \\
\hline
\end{tabular}
(Bassin de Baraolt) 
Pour le moment, l'existence de cette espèce nous semble entachée d'une incertitude qui n'est pas dissipée, ni par la robustesse relative de ses bois, ni par les caractères (pli antérieur simple) fluctuants de sa $\mathrm{P}_{3}$.

En somme, toutes ces modifications ne dépassent pas le cadre spécifique du Chevreuil de nos jours. C'est à la suite de cette manière de voir que nous avons attribué le matériel de Rotbav à Capreolus capreolus (L.)

Appendice

$$
\text { Cervus cf. elaphus Linnaeus }
$$

Matériel: Ilieni - Bois de mue dext., fragment (Pl. IV, fig. 3).

Comme nous l'avons déjà mentionné, cette pièce provient de la partie terminale des sédiments du Bassin de Ilieni. Par manque de toute association faunique, il est difficile d'établir son âge géologique exact, d'autant plus que l'isolement de ce bassin empêche un raccord sûr entre ses dépôts supérieurs et ceux du reste de la Dépression de Braşov.

Ayant en vue la morphologie de ce bois, qui indique un Cerf évolué, et sa position stratigraphique au-dessus du niveau à faune villafranchienne, il nous semble possible de l'attribuer au Pléistocène moyen, sans pouvoir préciser la phase à laquelle il se rattache.

Description. Le fragment de bois présente la meule et une portion de la perche. Le premier andouiller, brisé à sa base, prend naissance immédiatement au-dessus de la rose. Le deuxième andouiller, beaucoup moins robuste, brisé également, occupe la même position que le surandouiller du Cerf élaphe. Après le départ de cette ramification, la perche à section subcirculaire se continue encore sur $90 \mathrm{~mm}$ jusqu'à la surface de cassure.

Voici quelques mensurations:

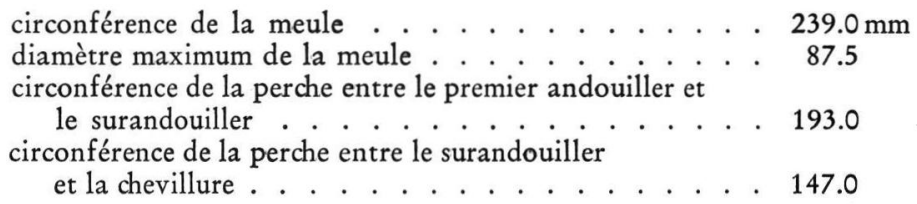

$\mathrm{R}$ apports et différences. Comme on vient de le voir, le fragment de bois de Ilieni se caractérise par la présence de deux andouillers basilaires, morphologie qui évoque l'idée d'un Cervus elaphus. Il se distingue toutefois, comparativement à ce dernier, par le contour de la meule; dans notre cas celle-ci est visiblement ellipsoïdale, tandis que les bois de mue des Elaphes ont généralement une meule à contour à peu près circulaire. Nous avons mentionné cette différence sans pouvoir lui attribuer une signification précise.

Il convient de rappeler que les représentants du groupe Elaphe apparaissent dès la première partie du Pléistocène moyen: dans le Forest Bed de Cromer (A. Azzaroli 1953), à Solilhac (Teilhard de Chardin \& J. Piveteau 1930), Voigtstedt, Mosbach, Süssenborn (H. D. KaHLKe 1956, 1958, 1960).

Le matériel du Forest Bed a été décrit sous la dénomination de Cervus cf. elaphus L. Les exemplaires d'Allemagne, plus complets, réunis sous le nom spécifique de Cervus acoronatus BENINDE, se caractérisent par leurs bois encore simples, dépourvus d'une véritable empaumure en coupe, l'apanage du vrai Cerf élaphe.

La pièce que nous avons décrite, par son état fragmentaire, ne nous offre, en ce qui concerne la partie terminale du bois, aucune indication. Cette incertitude mise de côté, le Cerf de Ilieni diffère comparativement à C. acoronatus par le moindre développement du surandouiller. Ce trait contribue en revanche à le rapprocher des spécimens du Forest Bed, qui présentent comme lui un andouiller basilaire mieux développé. 
C. Ph a s e I I I (Horizon IV - partie inférieure)

$$
\begin{gathered}
\text { Ord. Proboscidea } \\
\text { Parelephas trogontberii (PonLig) }
\end{gathered}
$$

(forme évoluée)

Matériel: Malnaș

Sf. Gheorghe-La Moară

Sf. Gheorghe-Carrières Sud
- $\mathrm{M}_{2}$ dext.

- $M_{3}$ dext. (fig. 15)

- Mi dext.

- $\mathrm{P}_{4}$ dext.

L'argument décisif de la présence de P.trogontherii dans le Bassin de Sf. Gheorghe nous a été fourni par les $\mathrm{M}_{2}$ et $\mathrm{M}_{3}$, bien conservées, qui montrent les caractéristiques de cette espèce. Il est très probable que les autres pièces $\left(\mathrm{P}_{4}\right.$ et $\left.\mathrm{M}_{1}\right)$, qui se prêtent mal à une détermination spécifique exacte, appartiennent, d'après leur position stratigraphique, au même Eléphant.

Les données les plus importantes concernant toutes ces dents sont synthétisées dans le tableau 8.

La $\mathrm{M}_{3}$ droite de La Moară fait partie d'une mandibule très détériorée; sur la surface de mastication on observe les lames, assez étroites, dont l'émail modérément plissé forme une vague dilatation postérieure et médiane à disposition irrégulière.

Pour $\mathrm{M}_{2}$ droite de Malnaş, nous signalons seulement la configuration un peu particulière des lames; celles-ci présentent, sur la ligne médiane de la dent, une flexion bien exprimée qui rejette plus en arrière que d'habitude la moitié externe des lames.

En examinant les fréquences et les quotients laminaires mentionnés dans le tableau 8 , on constate, comparativement à $P$. trogontherii de Rotbav-Dealul Tiganilor - plutôt archaïque - que les molaires du Bassin de Sf. Gheorghe peuvent être attribuées à une forme terminale de la même espèce.

$$
\text { Table a u } 8
$$

\begin{tabular}{|c|c|c|c|c|}
\hline & \multirow{3}{*}{$\begin{array}{l}\mathrm{Ma} \ln \text { a } s \\
\mathrm{M}_{2} \text { dext. }\end{array}$} & \multicolumn{3}{|c|}{ Sfîntu-Gheorghe } \\
\hline & & \multirow{2}{*}{$\begin{array}{r}\text { La Moară } \\
M_{3} \text { dext. }\end{array}$} & \multicolumn{2}{|c|}{ Carrières Sud } \\
\hline & & & $\mathrm{P}_{4}$ dext. & $M_{1}$ dext. \\
\hline formule laminaire . . & 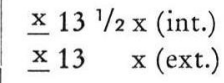 & $\underline{x} 18 x$ & $x 12$ & $\sim 13 \mathrm{x}$ \\
\hline longueur de la couronne & $\sim 220.0$ & $\sim 300.0$ & 138.5 & 178.0 \\
\hline largeur maxima ... & $72.5(\mathrm{VI})$ & 93.5 (VII) & 59.0 (VII) & 79.0 (VIII) \\
\hline hauteur maxima . . . & $75.0(\mathrm{XII})$ & $150.0(\mathrm{XV})$ & $66.0(\mathrm{XI})$ & 85.0 (XII) \\
\hline $\begin{array}{c}\text { longueur de la table } \\
\text { d'usure } . . .\end{array}$ & $\sim 145.0(\mathrm{I}-\mathrm{XI})$ & $\sim 220.0(\mathrm{I}-\mathrm{XV})$ & $134.0(x-X I I)$ & $174.0(\mathrm{I}-\mathrm{XIII})$ \\
\hline lames fusionnées . . . & I+II (médian) & - & I+II (int. et ext.) & $\mathrm{I}+\mathrm{II}+\mathrm{III}$ (int.) \\
\hline épaisseur de l'émail . . & $1.5-2$ & 2 & $1-1.5$ & $1.5-2$ \\
\hline indice longueur/largeur & $\sim 3.03$ & $\sim 3.20$ & 一 & 一 \\
\hline fréquence laminaire. . & 6.36 & 6.45 & - & - \\
\hline quotient laminaire . . & 15.71 & 15.50 & - & 一 \\
\hline
\end{tabular}

Dimensions des dents de Parelephas trogontherii (Pohlig) forme évoluée du Bassin de Sfîntu - Gheorghe 


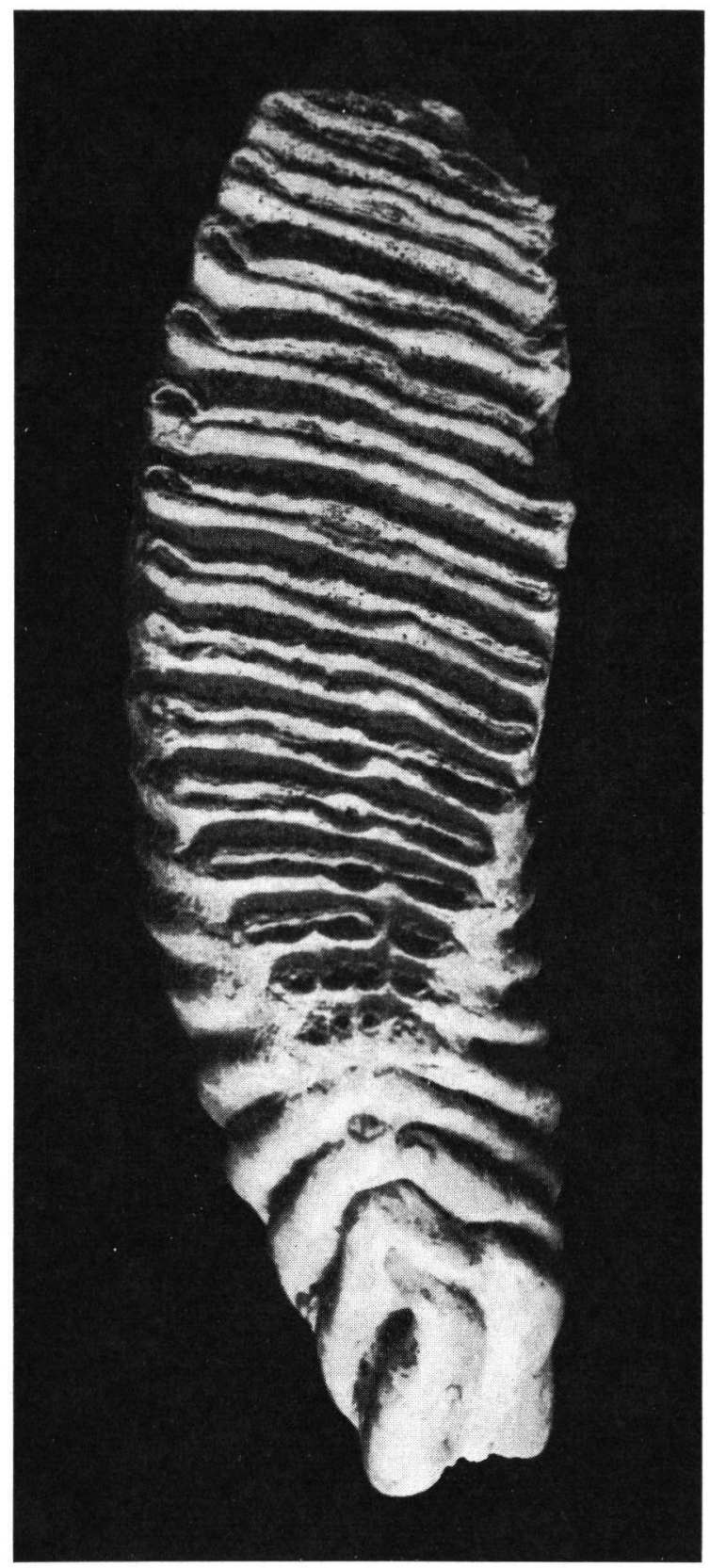

Fig. 15. Parelephas trogontherii (Pohlig), forme évoluée. Sf. Gheorghe - La Moară (Bassin de Sf. Gheorghe). $M_{3}$ dext., vue occlusale. (1/2). 


\section{Ord. Perissodactyla \\ Coelodonta antiquitatis (BLUMENBACH)}

Matériel: Bodoc

$-\mathrm{M}_{3}$ dext. (fig. 16)

Sf. Gheorghe-Carrières Sud $-\mathrm{M}_{2}$ sin.

Les dents présentent les caractères typiques - hypsodontie très marquée, muraille externe plate avec plis antérieur et postérieur bien nets au lobe antérieur etc. - pour le Rhinocéros à narines cloisonnées.

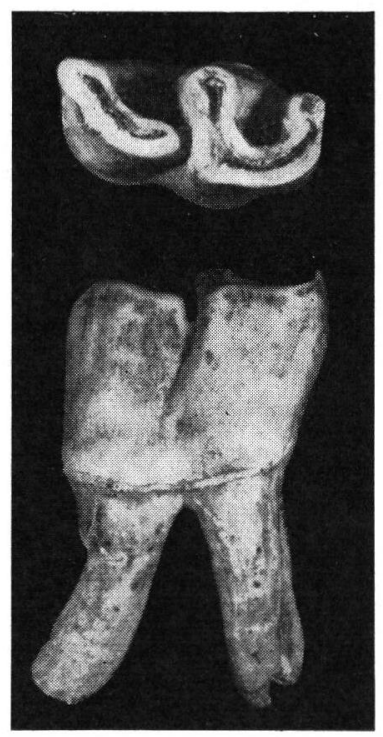

Fig. 16. Coelodonta antiquitatis (Blumb.). Bodoc (Bassin de Sf. Gheorghe). $M_{3}$ dext.: vue occlusale (en haut), vue externe (en bas). ( $1 / 2)$.

Voici quelques mensurations prises sur ces deux pièces:

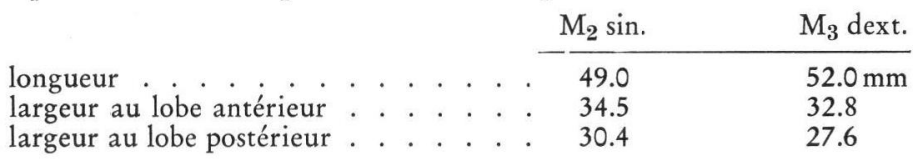

\section{Equus sp.}

Matériel: Bodoc

- P inf. sin. ( $\mathrm{P}_{3}$ ?) (fig. $\left.12 \mathrm{E}\right)$

Sf. Gheorghe-Carrières Sud - Canon post. sin.

Ces deux pièces, comme le montrent leurs dimensions, indiquent la présence d'un grand Cheval, à la fin du Pléistocène moyen, dans le Bassin de Sf. Gheorghe. $\mathrm{P}_{3}$ (?) sin.

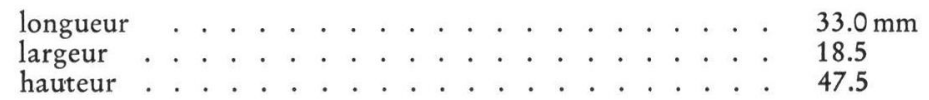

Canon postérieur sin.

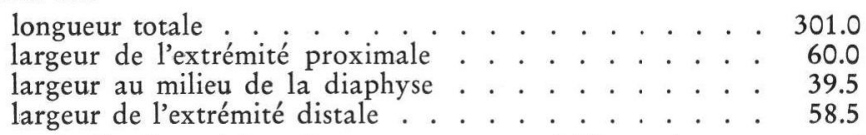

Il n'est pas facile de préciser l'appartenance spécifique de nos exemplaires parce que, d'une part le matériel qui les représente est trop restreint et d'autre part, la systématique 
des Equidés de cette période est encore confuse. En écartant la possibilité qu'ils apartiennent à $E$. germanicus, dont la taille est moindre, il est possible de les rapprocher des grands Chevaux du Riss et de l'Interglaciaire suivant (Steinheim-Taubach).

$$
\begin{gathered}
\text { Ord. Rodentia } \\
\text { Marmota sp. }
\end{gathered}
$$

Matériel: Sf. Gheorghe-Carrières Sud - Radius sin. juvénile

L'os, dépouvu de son épiphyse distale, est suffisamment caractéristique pour démontrer la présence d'une Marmotte dans la région. Seulement la découverte de pièces plus importantes permettra de définir l'espèce à laquelle appartient notre matériel.

3. Faune du Pléis tocène supérie ur

(Horizon IV - partie supérieure)

Ord. Proboscidea

Mammuthus primigenius (Blumenbach)

Matériel: Rotbav-Cariera de sub Brazi $\quad-\mathrm{M}^{3}$ dext.

Ariujd

Ghidfalău
- $\mathrm{M}^{3} \sin$.

- $\mathrm{M}^{3} \sin$.

Les caractéristiques de ces molaires, réunies dans le tableau 9, correspondent très bien au Mammouth, tel que nous le connaissons des autres dépôts du Pléistocène supérieur de notre pays.

Tablea u 9

Dimensions des dents de Mammuthus primigenius (BLumB.)

\begin{tabular}{|c|c|c|c|}
\hline & $\begin{array}{c}\text { Rotbav- } \\
\text { Cariera de sub } \\
\text { Brazi } \\
\text { M3 dext. }\end{array}$ & $\begin{array}{l}\text { A riu jd } \\
\mathrm{M}_{3} \sin .\end{array}$ & $\begin{array}{l}\text { Ghidfalău } \\
\text { M3 dext. }\end{array}$ \\
\hline formule laminaire . . . . . & $\begin{array}{l}\text { x } 22 \text { x (int.) } \\
\text { x } 221 / 2 \times \text { (ext.) }\end{array}$ & $\begin{array}{l}\text { x } 251 / 2 \times \text { (int.) } \\
\text { x } 25 \quad \text { x (ext.) }\end{array}$ & $-21 x$ \\
\hline longueur de la couronne.. & 257.0 & 323.0 & 212.0 \\
\hline largeur maxima . . . . . & $95.0(\mathrm{VI})$ & 108.0 (XII-XIV) & $80.0($ IV-VIII $)$ \\
\hline hauteur maxima . . . . & 158.0 (XII-XIII) & $\sim 162.0(\mathrm{XV})$ & $120.0(\mathrm{XIII})$ \\
\hline longueur de la table d'usure & $159.0(x-X V)$ & $173.0(x-X I V)$ & $155.0($ I-XIII) \\
\hline lames fusionnées . . . . & $\mathrm{x}+\mathrm{I}$ (médian) & - & - \\
\hline épaisseur de l'émail. . . . . & 1.5 & $2-2.5$ & $1.5-2$ \\
\hline indice longueur/largeur . . & 2.70 & 2.96 & - \\
\hline fréquence laminaire. . . . & 9.74 & 8.28 & 10.14 \\
\hline quotient laminaire . . . . & 11.17 & 12.00 & 9.86 \\
\hline
\end{tabular}
des Bassins de Baraolt et de Sf. Gheorghe

Matériel: Crizbav - Arc mandibulaire fragmentaire: symphyse avec incisives, branches horizontales sin. avec $\mathrm{P}_{2}-\mathrm{M}_{3}$ et dext. avec $\mathrm{P}_{3}-\mathrm{M}_{1}$.

Les pièces sont recouvertes d'une croûte calcaire adhérente. La morphologie des dents indique un Cheval évolué de type germanicus. D’après le manque des canines on peut 
attribuer ces restes à un exemplaire femelle qui était âgé de plus de 20 ans. Les mensurations, prises à la surface d'usure, sont les suivantes:

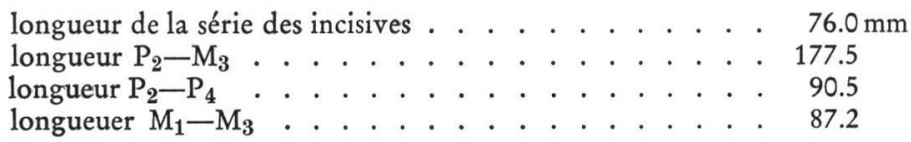

\section{Ord. Artiodactyla}

\section{Megacerosgiganteus (BLUMENBACH)}

Matériel: Ghidfalău - Bois de mue dext., fragment basilaire

La pièce, de conservation médiocre, est roulée, ce qui a produit un effacement partiel de la meule et des cannelures du merrain; la première ramification est brisée.

En ce qui concerne la morphologie et les dimensions, la pièce de Ghidfalău ne diffère pas des bois des Mégacéros würmiens de notre pays.

Les mensurations du fragment sont les suivantes:

circonférence de la meule . . . . . . . . . . . $270.0 \mathrm{~mm}$

grand diamètre de la meule . . . . . . . . . . . . 96.5

petit diamètre de la meule . . . . . . . . . . 65.0

$$
\text { Bison priscus (Bojanus) }
$$

Matériel: Sf. Gheorghe - Crâne fragmentaire (fig. 17)

La tête osseuse est brisée au niveau des orbites; de la base du crâne ne se sont conservés que le basioccipital et une partie du sphénoïde.

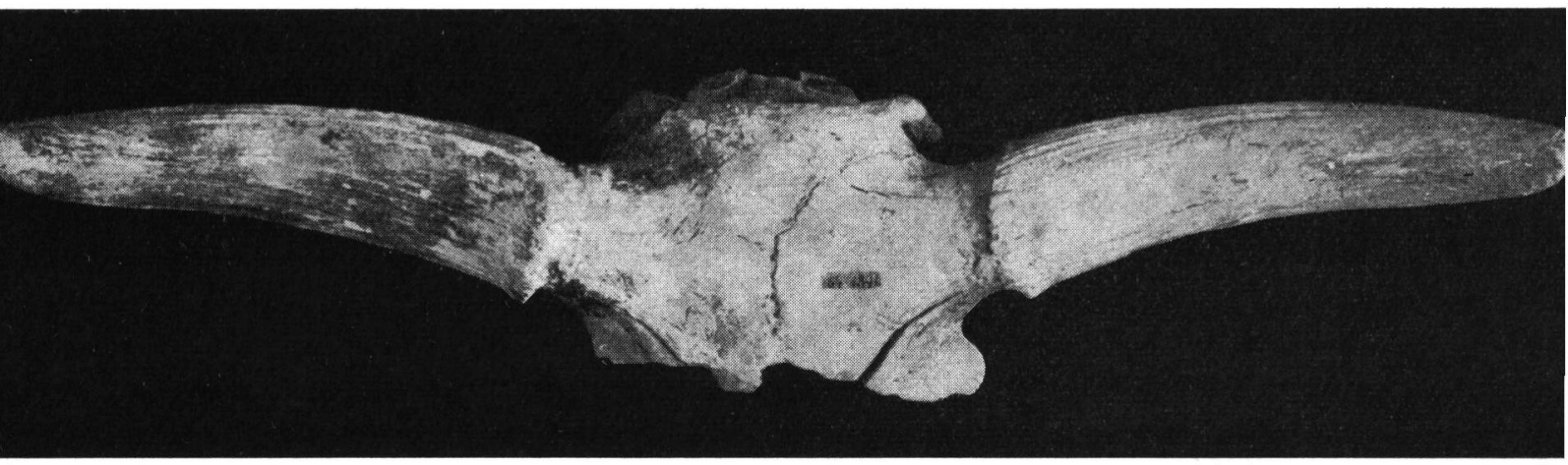

Fig. 17. Bison priscus (BoJ.). Sf. Gheorghe (Bassin de Sf. Gheorghe). Crâne, région fronto-pariétale. $(1 / 6)$.

Nous donnons, plus loin, quelques mensurations:

largeur du frontal aux bords postérieurs des obites . . . . $362.0 \mathrm{~mm}$

largeur du frontal à la constriction post-orbitaire . . . . . 303.0

largeur minima du frontal entre les bases des cornes . . . 325.0

largeur maxima du frontal entre les bases des cornes . . . 420.0

largeur maxima de l'occiput . . . . . . . . . . . . . . 275.0

largeur minima de l'occiput . . . . . . . . . . . . . 199.0

hauteur maxima de l'occiput . . . . . . . . . . . . . . . 148.0

hauteur minima de l'occiput . . . . . . . . . . 108.0

circonférence de la corne à la base . . . . . . . . . 400.0

distance entre les pointes des cornes . . . . . . . . . 1000.0 


\section{Conclusions}

En essayant de retracer, d'une manière générale et aussi brièvement que possible, l'histoire bien longue et pleine de vicissitudes des faunes dont nous venons de finir l'exposé des détails, il convient de faire quelques remarques sur leur position dans la série des faunes équivalentes de notre pays et d'Europe, afin de mieux fixer l'âge géologique des sédiments de la Dépression de Braşov. Il nous a été possible, au cours des pages précédentes, de réunir les Mammifères fossiles de cette région en plusieurs complexes. Nous allons mettre en évidence les particularités qui nous ont fourni les bases pour leur séparation.

Le premier complexe comporte deux phases dont les espèces ont été déjà énumérées. Dans l'ensemble, ce complexe faunique se caractérise par l'apparition du Cheval et du Boeuf - ces termes étant pris évidemment en un sens très large - phénomène qui marque un renouvellement essentiel dans la faune pliocène et implique nécessairement une coupure chronologique de premier ordre. Nous le considérons, en utilisant le principe toujours pertinent de E. HAUG, comme pléistocène; plus précisément, par l'absence du genre Elephas, nous l'attribuons au Villaf ranchien inférieur (P. SAmson \& C. RADULESCO 1963).

La phase la plus ancienne du premier complexe (Horizon I) comprend encore Propotamochoerus, un petit Ursidé, Ursus ruscinensis, et un Rhinocéros très grand proche de Dicerorbinus megarbinus, qui rappellent la faune pliocène supérieure du Roussillon, mais l'existence du Cheval et du Boeuf exclut cependant toute possibilité que cette faune appartienne à l'Astien.

Une association semblable de Mammifères est connue de Măluşteni et Bereşti, en Moldavie méridionale, et du Sud-Ouest de l'Union Soviétique où elle fut signalée sous le nom de "complexe moldave" (L. I. Alexeeva 1961). Ainsi, il semble qu'on soit en présence, dans cette partie de l'Europe, d'une faune plus récente par rapport à celle du Roussillon et probablement un peu plus ancienne comparativement à la faune de PerrierEtouaires. Par conséquent, $\mathrm{la}$ li m i t e p li o-plé i s t o c̀̀ n e doit être située à la base des dépôts qui ont livré cette association faunique.

La phase ultérieure du même complexe (partie inférieure de l'horizon II) se caractérise par l'apparition d'une espèce largement répandue dans tout le Villafranchien: Ursus etruscus; le Rhinocéros, bien qu'apparenté à $D$. cf. megarbinus de la phase précédente, en diffère par une taille moins robuste jointe à certains traits morphologiques plus évolués. Ce niveau semble homologue à celui classique de Perrier-Etouaires (S. Schaub 1944).

Pour le moment, les Ursidés et les Rhinocérotidés sont les seules formes qui nous donnent un argument majeur et suffisant pour la distinction des deux phases successives dans le complexe faunique du Villafranchien inférieur.

Bien que nous soyons, à présent, assez peu informés sur les Cervidés, un groupe primitif, à traces du pli palaeomoeryx s'est maintenu pendant tout le Villafranchien inférieur; nous le trouvons autant à Căpeni, avec U.ruscinensis, qu'à Ilieni, avec U.etruscus. Enfin, les Proboscidiens ne nous offrent rien de particullier; ils sont représentés par les deux Mastodontes, $Z$. borsoni et $A$. arvernensis, la dernière espèce étant la plus fréquente.

La faune de Iarăş-Cariera Veche, rattachée provisoirement à la phase II, représenterait un Villafranchien moyen, si le grand Cerf de cette sablière était un Euctenoceros. Cela vrai, l'absence de l'Eléphant y deviendrait plutôt accidentelle. Notons en plus l'apparition de D. etruscus "typique" 8 ).

Avant d'examiner le complexe du Pléistocène moyen, il est nécessaire de rappeler l'absence de toute association faunique du Villafranchien supérieur. On peut trouver une

8) La succession des Rhinocéros villafranchiens dans le sens que nous venons de suggérer, semble se confirmer aussi par les recherches que Mr. M. FERU entreprend avec deux d'entre nous (C. R. et P. S.) en Olténie. 
explication dans la part de hasard propre à toute découverte et il suffit d'ajouter que, malgré un siècle de recherches, la connaissance de la faune pléistocène moyenne de la Dépression de Braşov est de date bien récente. Il mérite, à ce propos, de prendre en considération les puissants phénomènes volcaniques, qui pourraient éventuellement nous renseigner sur cette lacune dans la faune. Il ne serait pas inimaginable de supposer que pendant le Villafranchien supérieur, lorsque l'activité des volcans devenait de plus en plus intense, les Mammifères ont évité cette zone dangereuse.

Dans le deuxième complexe de Mammifères, nous avons pu séparer trois phases successives, dont les associations fauniques ont été indiquées à leur place.

Les éléments les plus significatifs de la première phase (partie inférieure de l'horizon III) sont un Cerf mégacéroïde très primitif et un Cheval aisément reconnaissable à sa faible taille. Parmi les survivants du Pléistocène inférieur, on rencontre encore l'Eléphant méridional et un Cerf d'aspect "rusoïde". L'association des nouveaux venus et des retardataires donne, à cette phase, un caractère transitionnel.

En essayant de préciser la place chronologique du point fossilifère de Rotbav-Silvestru, il nous semble possible de le situer au début du Pléistocène moyen. Plus ancien que l'optimum climatique du Cromérien, dont les dépôts de Betfia (Püspökfürdö), aussi en Transylvanie, nous offrent une comparaison immédiate, plus jeune que le gisement villafranchien supérieur de Fîntîna lui Mitilan en Olténie (C. Radulesco \& P. SAmson 1962 b), il correspond, paraît-il, au commencement de l'Interglaciaire Günz$\mathrm{M}$ in de l, sinon même au $\mathrm{G}$ ü $\mathrm{n} \mathrm{z}$ i e $\mathrm{n}$.

Bien qu'une synchronisation rigoureuse ne soit pas encore possible, nous sommes tentés de voir un équivalent approximatif de la faune de Rotbav-Silvestru dans celle de SaintPrest (A. LAUgel 1862) - cette dernière peut-être plus récente - et dans le complexe de Taman (N. K. Verestchaguine 1957). Entre ces points extrêmes se placent encore quelques localités de l'Europe Centrale plus ou moins contemporaines (Aalen, Jockgrim, Mosbach-niveau inférieur).

Comme nous l'avons déjà dit à une autre occasion (P. SAmson \& C. Radulesco 1965), l'association faunique de Rotbav-Silvestru marque le début du Pléistocène moyen dans

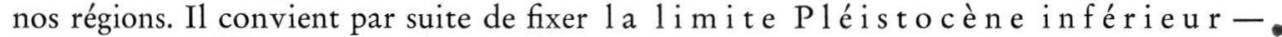
m o y e n immédiatement au-dessous de ce gisement.

La seconde phase du complexe faunique du Pléistocène moyen (partie supérieure de l'horizon III), généralement définie par l'association de Parelephas trogontherii avec Dicerorhinus kirchbergensis, le développement des Cerfs mégacérö̈des (Dolichodoryceros savini), l'apparition d'un Elan très massif (Praealces latifrons), du Chevreuil et des premiers Elaphes, peut couvrir un intervalle correspondant à la fin du C romérien et au $\mathrm{Minde} 1$.

La faune, par suite, semble s'intégrer dans cette vague qui s'étend depuis le Forest Bed d'Angleterre (A. Azzaroli 1953, F. E. Zeuner 1959), à travers l'Europe Centrale avec les localités bien connues de Mosbach, Süssenborn etc. (K. D. Adam 1961, H. D. KahlKe 1961), jusqu'à Tiraspol (M. PAvlov 1906).

Après une lacune, pendant tout l'Interglaciaire Mindel-Riß, nous avons de nouveau des informations concernant une dernière faune de Mammifères du Pléistocène moyen. Dans cette phase (partie inférieure de l'horizon IV) on trouve un Parelephas trogontherii évolué auquel s'ajoutent Coelodonta antiquitatis, un Cheval de grande taille rapproché, par ses métapodes, des formes de Steinheim et une Marmotte. Bien que ces espèces, qui nous servent pour établir l'âge des sédiments, ne soient pas nombreuses, elles semblent caractériser le $R$ is s i e $n$.

Une faune analogue fut signalée dans les "trogontherii-primigenius Schotter" de Steinheim (K. D. Adam 1954, 1961) et dans le loess ancien d'Achenheim (P. Wernert 1957). 
Le troisième complexe de Mammifères (partie supérieure de l'horizon IV) est typique pour le Würmi en.

Après avoir vu la chronologie des complexes fauniques et implicitement des dépôts qui les contenaient, il convient maintenant de faire quelques remarques générales sur l'évolution de la Dépression de Braşov.

$1^{\circ}$. Le stade initial de la formation des sédiments (Horizon I) de cette zone dépressionnaire, qui s'est déroulé pendant la première phase du Villafranchien inférieur, est caractérisé par un faciès de forêt marécageuse au Nord du Bassin de Baraolt, par un faciès d'eau plus profonde au Sud du même bassin et peut être aussi dans le Bassin de Sf. Gheorghe.

$2^{\circ}$. Le stade d'extension maxima correspond à la deuxième phase du Villafranchien inférieur et au Villafranchien moyen, lorsque, par suite de l'enfoncement progressif, le bassin lacustre est devenu assez profond pour permettre la sédimentation de marnes dans la zone axiale, de dépôts variés comme faciès dans la zone littorale (Horizon II). Durant ce deuxième épisode, semblent s'être formés aussi les petits bassins adjacents au Bassin de Sf. Gheorghe. Dans le Villafranchien supérieur se place vraisemblablement le paroxysme des manifestations volcaniques, prouvé par les épanchements de basalte et les agglomérats andésitiques qui recouvrent au Nord du Bassin de Baraolt les sédiments lacustres de l'horizon II.

$3^{\circ}$. Pendant le Pléistcène moyen (dès le Günz jusqu'au Mindel), le lac fut amené à l'assèchement dans la région septentrionale de la Dépression de Braşov, persistant seulement dans la zone Sud où le processus d'enfoncement se continuait. Dans ce stade, caractérisé par un abaissement général du niveau du lac, se sont déposés, en contrebas des sédiments littoraux du deuxième horizon, les dépôts de l'horizon III.

$4^{\circ}$. Dans ce dernier stade, qui correspond à la fin du Pléistocène moyen (Riss) et au Pléistocène supérieur, s'est produit le morcellement du lac et son comblement définitif; au début de cet intervalle, l'Olt a percé le barrage magmatique de 'Tuşnad et a déposé son énorme cône de déjection, tandis que vers la partie finale, se sont formés divers dépôts de pente, torrentiels et fluviatiles (Horizon IV).

\section{Références bibliographiques}

Adam, K. D.: Die mittelpleistozänen Faunen von Steinheim an der Murr (Württemberg). - Quaternaria 1, Roma 1954. - - Die Bedeutung der pleistozänen Säugetier-Faunen Mitteleuropas für die Geschichte des Eiszeitalters. - Stuttgarter Beitr. z. Naturk. 78, Stuttgart 1961.

Alexeeva, L. I.: Oldest mammalian fauna of the Anthropogen in the European South of the URSS (en russe, rés. anglais). - "Voprosy geologii Antropogena" VI Kongress INQUA 1961, Moskva 1961.

Arambourg, C.: Les gros Mammifères des couches tayaciennes, in: La Grotte de Fontéchevade, part. 3. - Arch. Inst. Pal. Hum. 29, Paris 1958.

Atranasiu, S.: Beiträge zur Kenntnis der tertiären Säugetierfauna Rumäniens, I-II. - An. Inst. Geol. Rom., 1, 1, et 2, 3, Bucureşti 1907, 1908.

Azzaroli, A.: I Cervi fossili della Toscana con particolare riguardo alle specie villafranchiane. Pal. Ital. 43, Pisa 1947. - - L'Alce di Senèze. - Ibid. 47, Pisa 1952. - - The deer of the Weybourn Crag and Forest Bed of Norfolk. - Bull. Brit. Mus. (Nat.-Hist.) Geol. 2, 1, London 1953. - - Il nanismo nei Cervi insulari. - Pal. Ital. 56, Pisa 1961. - - Rinoceronti pliocenici del Valdarno inferiore. - Ibid. 57, Pisa 1963.

Beninde, J.: Ưber die Edelhirschformen von Mosbach, Mauer und Steinheim a. d. Murr. - Pal. Z. 19, Berlin 1937.

Czyzewska, T.: Nouvelle espèce de Cervidés du genre Cervocerus Khomenko de la brèche pliocène de Węze près de Dzialoszyn. (en polonais, rés. français). Acta Pal. Pol. 5, 3, Warszawa 1960.

Dawkins, W. B.: The British Pleistocene Mammalia 6: British Pleistocene Cervidae. - Pal. Soc., London 1887.

Del Campana, D.: I Tapiri del Terziario italiano. - Pal. Ital. 16, Pisa 1910. 
Dietrich, W. O.: Nashornreste aus dem Quartär Deutsch-Ostafrikas. - Palaeontogr. 96, Stuttgart 1945.

Erdbrink, D. P.: A review of fossil and recent bears of the Old World 1-2. - Deventer 1953.

Falconer, H.: Palaeontological Memoirs and Notes 2. - London 1868.

FeJfar, O.: Review of quaternary Vertebrata in Czechoslovakia. - Inst. Geol. 34, INQUA Warszawa 1961, Warszawa 1961.

Fuchs, Th.: Beiträge zur Kenntnis der pliozänen Säugetierfauna Ungarns. - Verh. d. k. k. geol. R. A. 12, Wien 1879 .

Gervais, P.: Zoologie et Paléontologie françaises. - Paris 1859.

Halavats, G.: Die ungarländischen fossilen Biberreste. - Termész. Füz. 14, Budapest 1891.

Herbich, Fr. \& Neumayr, M.: Die Süßwasserablagerungen im Südöstlichen Siebenbürgen. - Jb. d. k. k. geol. R. A. 25, Wien 1875

Hoorjer, D. A.: Trogontherium cuvieri Fischer from the Neede Clay (Mindel-Riss Interglacial) of the Netherlands. - Zool. Med. 36, 18, Leiden 1959.

Janovskaia, N. M.: Novyi olen iz sredniego pliocena Moldavii. - Tr. Pal. Inst. 47, 2, Moskva 1954.

Jekelıus, E.: Zăcămintele de lignit din Bazinul pliocenic din Valea superioară a Oltulưi (Transilvania). - Inst. geol. Rom., Stud. tehn.şi econ. 3, Bucureşti 1923 a. - - Puţul artezian de la fabrica de zahăr din Bod (Braşov). - Dări de seamă, Inst. geol. Rom. 9, București 1923 b. - - Die Molluskenfauna der Dazischen Stufe des Beckens von Braşov. - Mem. Inst. geol. Rom. 2, Bucureşti 1932.

KahlKE, H. D.: Die Cervidenreste der altpleistozänen Ilmkiesen von Süssenborn bei Weimar 1-3, Berlin 1956-1959. - - Die Cervidenreste aus den altpleistoznen Tonen von Voigtstedt bei Sangerhausen. - Abh. deutsch. Akad. Wiss. Berlin Jg. 1956, 9, Berlin 1958. - - Die Cervidenreste aus den altpleistozänen Sanden von Mosbach (Biebrich-Wiesbaden). - Ibid. Jg. 195,9, 7, Berlin 1960. - - Revision der Säugetierfaunen der klassischen deutschen Pleistozän-Fundstellen von Süssenborn, Mosbach und Taubach. - Geologie 10, 4/5, Berlin 1961.

Kову, F. E.: Le dimorphisme sexuel des canines d'Ursus arctos et d'U. spelaeus. - Rev. suisse Zool. 56, 36, 1949.

Косн, A: Siebenbürgens Ursäugethierüberreste und auf den Urmenschen bezügliche Funde. - Az. erdélyi muz.-egylet Ev. 1, 5, Cluj 1876. - - Masodik pétlek Erdély ösemlösei és az ösemberre vonatkozó leleteinek kimutatasahoz. - Orv. term. tud. Ert. 1, Cluj 1879. - - Fossile Reh (Cervus capreolus L. foss.) aus dem Lignit von Köpecz. - Ibid. 2, Cluj 1880 a. - Beckenzahn des Mastodon arvernensis Crorz. von Bardócz. Ibid. 2, Cluj 1880 b. - - Die Tertiärbildungen des siebenbürgischen Beckens 2, Neogene Abt. - Budapest 1900.

Kormos, Th.: Die pliozänen Schichten von Ajnacskö und ihre Fauna. - Jb. kgl. ung. geol. R. A. 1915, Budapest 1917. - - Die Wölfe des ungarischen Oberpliozäns. - Folia Zool. et Hydrobiol. 5, 1, Riga 1933. - - Beiträge zur Kenntnis der Gattung Parailurus. - Mitt. Jb. kgl. ung. geol. Anst. 30, 2, Budapest 1935. - - Neue Beiträge zur Kenntnis der Gattung Prospalax. - Allatt. Közlem. 34, 3-4, Budapest 1937.

Kretzor, M.: Die Raubtiere von Gombaszög nebst einer Übersicht der Gesamtfauna (Ein Beitrag zur Stratigraphie des Altquartärs). - Ann. Mus. Nat. Hung. 31, Budapest 1938. - - Quaternary Geology and the Vertebrate Fauna. - Acta Geol. Acad. Sc. Hung. 2, 1-2, Budapest 1953. - - Bericht über die calabrische (Villafranchische) Fauna von Kislang, Kom. Fejér.-Jber. ung. geol. Anst. 1953 1, Budapest 1954. - - Insectivoren, Nagetiere und Lagomorphen der jüngstpliozänen Fauna von Csarnota im Villanyer Gebirge (Südungarn). Vert. Hung. 1, 2, Budapest 1959. - - Stratigraphie und Chrono'ogie in: A. RónaI, M. Kretzoi u. M. PÉCsI: Stand der ungarischen Quartärforschung. - Prace Geol. P.A.N. 21, Warszawa 1961. - - Fauna und Faunenhorizont von Csarnóta. - Jber. ung. geol. Anst. f. 1959, Budapest 1962.

Laugel, A.: La faune de Saint-Prest près Chartre (Eure et Loire). - Bull. Soc. géol. France 19, Paris 1862.

Lehmann, U.: Die Fauna des „Vogelherds“ bei Stetten ob Lontal (Württemberg). - N. Jb. Geol. u. Pal. 99, Stuttgart 1954. - - Weitere Fossilfunde aus dem ältesten Pleistozän der Erpfinger Höhle (Schwäbische Alb). - Mitt. Geol. Staatsinst. Hamburg 26, Hamburg 1957.

Leonardi, P.: Resti fossili inediti di Rinoceronti conservati nelle collezioni dell'Istituto Geologico dell’Università di Padova. - Mem. Ist. Geol. Univ. Padova 15, Padova 1948.

Liteanu, E., MihăIlă, N., \& Bandrabur, T.: Contribuţii la studiul stratigrafiei Cuaternarului din Bazinul mijlociu al Oltului. (Bazinul Baraolt), - Stud. şi Cercet. Geol. 7, 3-4, Bucureşti 1962.

LöRENTHEY, I.: Über die geologischen Verhältnisse der Lignitbildung des Széklerlandes. - Orv. term. tud. Ert. 20, Cluj 1895. - - Neuere Beiträge zur Geologie des Széklerlandes. - Math. u. Naturw. Ber. Ung. 26, Leipzig 1910.

MerLa, G.: I Leptobos Rürim. italiani. - Pal. Ital. 46, Pisa 1949. 
Meyer, H. v.: Über fossile Reste von Ochsen, deren Arten und das Vorkommen derselben. - Nov. Acta Acad. Caes. Leop.-Carol. 17, 1, Breslau u. Bonn 1835. - - Die diluvialen Rhinoceros-Arten. - Palaeontogr. 11, Cassel 1864. - - Die fossilen Reste des Genus Tapirus. Ibid. 15, Cassel 1867.

Motтl, M.: Die mittelpliozäne Säugetierfauna von Gödöllö bei Budapest. - Mitt. Jb. kgl. ung. geol. Anst. 32, 3, Budapest 1939.

Osborn, H. F.: Proboscidea 1-2. New York 1936-1942.

Pavlov, M.: Sélénodontes posttertiaires de la Russie. - Mém. Acad. Sc. St.-Pétersb. 20, St.-Pétersbourg 1906.

Phleps, O.: Über das Skelett eines weiblichen Bison priscus, BoJ. sowie andere Bison- und Bosreste aus dem Diluvium Siebenbürgens. - Verh. u. Mitt. Siebenburg. Ver. f. Naturw. Hermannstadt 56 1906, Hermannstadt 1907.

Popovici, V.: Explorări geologice în Bazinul Baraolt-Vărghiş-Căpeni-Buduş-Aita Seacă. - Comit. Geol., Stud. tehn. econ. A 5, Bucureşti 1959.

Portis, A.: Über die Osteologie von Rhinoceros Merckii JäG. und über die diluviale Säugetierfauna von Taubach bei Weimar. - Palaeontogr. 25, Cassel 1879. - - Elenco delle specie die Cervicorni fossili in Roma e attorno a Roma. - Bull. Soc. Geol. Ital. 39, Roma 1920.

Radulesco, C. \& Samson, P.: Remarques sur quelques Equidés quaternaires de Roumanie. - Zool. Anz. 168, Leipzig 1962(a) - - Sur la présence de Megalovis latifrons dans le Villafranchien d'Olténie (Roumanie). - Vert. Palasiatica 6, 3, Peking 1962(b).

Reichenau, W. v.: Beiträge zur näheren Kenntnis fossiler Pferde aus deutschem Pleistozän, etc. Abh. hess. Geol. L.-Anst. 7, 1, Darmstadt 1915.

Ristori, G.: L'orso pliocenico di Valdarno e d'Olivola in Val di Magra. - Pal. Ital. 3, Pisa 1898.

Samson, P. \& Radulesco, C.: Les faunes mammalogiques du Pléistocène inférieur et moyen de Roumanie. - C. R. Acad. Sc. Paris 257, Paris 1963. - - Die Säugetier-Faunen und die Grenzen Plio-Pleistozän und Unter-Mittelpleistozän in Rumänien. - Ber. Geol. Ges. DDR 10, 1 - Berlin 1965. - - Sur la présence de Praealces gallicus (Azz.) dans le Villafranchien d'Oltenie (Roumanie). - (sous presse).

Schaub, S.: Die kleine Hirschart aus dem Oberpliocaen von Senèze (Haute-Loire). - Eclogae geol. Helv. 34, Basel 1941. - - Die oberpliocaene Säugetierfauna von Senèze (Haute-Loire) und ihre verbreitungsgeschichtliche Stellung. - Ibid. 36, Basel 1944.

Schlesinger, G.: Die Mastodonten der Budapester Sammlungen. - Geol. Hung. 2, 1, Budapest 1922.

Schlosser, M.: Parailurus anglicus und Ursus Böckbi aus den Ligniten von Baróth-Köpecz. - Mitt. Jb. kgl. ung. Geol. Anst. 13, 2, Budapest 1899.

Schreuder, A.: Conodontes (Trogontherium) and Castor from the Teglian Clay compared with the Castoridae from other localities. - Arch. Mus. Teyler 6, 3, Haarlem 1929. - - Trogontherium cuvieri Fischer von Püspökfürdö, nebst einer Bemerkung über die Castoriden von China. - Ann. Mus. Nat. Hung. 29, Budapest. - - The three species of Trogontherium, with a remark on Anchitheriomys. - Arch. Néerland. Zool. 8, 4, Haarlem 1951.

Simionescu, I: Vertebratele pliocene de la Măluşteni (Covurlui). - Acad. Rom., Publ. Fond. V. Adamachi, 9, 49, Bucureşti 1930. - - Les Vertébrés pliocènes de Bereşti. - Bull. Soc. Roum. Géol. 1, Bucureşti 1932.

Stehlin, H. G.: Die Säugetierfauna von Leffe (Prov. Bergamo). - Eclogae geol. Helv. 23, Basel 1930.

Teilhard de Chardin, P. \& Piveteau, J.: Les Mammifères fossiles de Nihovan (Chine). - Ann. Pal. 19, Paris 1930.

Thenius, E.: Die Verknöcherung der Nasenscheidewand bei Rhinocerotiden und ihr systematischer Wert. - Schweiz. Pal. Abh. 71, Basel 195,5.

ToulA, F.: Über Säugetierreste aus der pliocänen Lignitformation von Illyefalva (Szent-Kiraly). Abh. k. k. geol. R. A. 20, 5, Wien 1911.

Vaufrey, R.: Proboscidea in: J. Piveteau: Traité de Paléontologie 6, 2, Paris 1958.

Verestchaguine, N. K.: Ostatki mlekopitaiusčih iz nijne četvertičnyh otlojenii Tamanskogo poluostrova. - Tr. Zool. Inst. Acad. Nauk SSSR 22, Moskva-Leningrad 1957.

Viret, J.: Le loess à bancs durcis de Saint-Vallier (Drome) et sa faune de Mammifères villafranchiens. - Nouv. Arch. Mus. Hist. Nat. Lyon 4, Lyon 1954.

WERnert, P.: Stratigraphie paléontologique et préhistorique des sédiments quaternaires d'Alsace. Mém. Serv. Carte géol. Alsace-Lorraine 14, Strasbourg 195,7.

Woldstedt, P.: Das Eiszeitalter 2. - Stuttgart 1958. - - Über die Gliederung des Quartärs und Pleistozäns. - Eiszeitalter und Gegenwart 13, Ơhringen 1962.

Zeuner, F. E.: The Pleistocene Period. - London 1959.

Manuskript eingeg. 24. 10. 1964.

Anschriften der Verf.: Costin Radulesco et Petre Samson, Institutul de Speologie, Str. Dr. Capşa 8, Bucureşti 15, România; N. Mihăilă, Institutul Geologic, Bucureşti; Al. Kovàcs, Muzeul Regional Sf. Gheorghe, Sfîntu - Gheorghe. 